\title{
PERCEPTIONS OF RETIREMENT ADEQUACY IN LESOTHO: BEHAVIOURAL AND SOCIO-ECONOMIC INFLUENCES
}

\author{
Full dissertation by \\ TOKISO NTHEBE
}

Submitted in fulfilment of the requirements for the degree

\section{Magister Commercii in Financial Management Sciences}

in the

Faculty of Economic and Management Sciences

at the

University of Pretoria

Supervisor:

Dr M Reyers

17 August 2017 


\section{DECLARATION}

1. I understand what plagiarism entails and am aware of the University's policy in this regard.

2. I declare that this assignment is my own, original work. That all sources used/quoted have been indicated and acknowledged by means of a complete reference system.

3. I did not copy and paste any information directly from an electronic source (such as a web page, electronic journal article or CD ROM) into this document.

4. I did not make use of another student's previous work and submitted it as my own.

5. This dissertation was not previously submitted for a degree at another university.

T Nthebe

Signature
17 August 2017

Date 


\section{ACKNOWLEDGEMENTS}

This journey has not been an easy one and would not have been possible without the help and guidance of many people. I would love to thank God the Almighty for all the blessings and making this journey possible. I also express my heartfelt gratitude to the following people:

1. Dr Michelle Reyers, my supervisor, for the unwavering support and guidance. Your expert knowledge and patience is highly appreciated. This study would not have been possible without these.

2. Dr Elbie Louw, who also played an important role in the initial steps of my master's degree journey.

3. Standard Lesotho Bank, First National Bank and Vodacom Lesotho for allowing me to collect data from their employees.

4. My family, with a special mention of Tiisetso Nthebe (my sister) for the words of encouragement throughout this journey. The support you've given me has not gone unnoticed.

5. All my friends and colleagues who were pillars of strength during this journey and for always being there when I needed you most. 


\section{ABSTRACT \\ PERCEPTIONS OF RETIREMENT ADEQUACY IN LESOTHO: BEHAVIOURAL AND SOCIO-ECONOMIC INFLUENCES}

Saving for retirement has become more complicated for employees due to the complexity of the financial decisions involved. Financial decision making is believed to be associated with a number of behavioural and socio-economic factors, and these factors may in turn be related to whether employees perceive themselves to be adequately saving for retirement. This study assesses which factors predict whether individuals working in both the financial and non-financial sectors in Lesotho perceive themselves to be adequately preparing for retirement. The main focus is on financial literacy, financial risk tolerance and future time perspective. As a secondary focus, the study looks at potential differences between two sectors of employees that may be attributed to differing levels of financial literacy. Data was collected using an online survey from 107 banking and 93 non-banking employees in Lesotho and analysed using bivariate and multivariate techniques, with a linear regression model used in terms of the multivariate analysis. This study finds that financial literacy, financial risk tolerance, and future time perspective are all positively related to perceived retirement adequacy in the bivariate analysis. In the multivariate analysis, for those working outside the financial sector, objective financial literacy, subjective financial literacy and future perspective were positively related to perceived retirement adequacy. Whereas for those in the financial sector; higher levels of future time perspective, higher household income and being older were all associated with higher levels of perceived retirement adequacy providing insights to industry role players about the profile of individuals who are confident about retirement savings and how this contrasts with those who are not confident. 


\section{TABLE OF CONTENTS}

\section{CHAPTER 1}

INTRODUCTION

1.1 BACKGROUND 1

1.2 PROBLEM STATEMENT $\quad 8$

1.3 PURPOSE STATEMENT $\quad \mathbf{8}$

1.4 RESEARCH OBJECTIVES 9

1.5 IMPORTANCE AND BENEFITS OF THE PROPOSED STUDY 9

1.6 DELIMITATIONS AND ASSUMPTIONS 9

$\begin{array}{ll}1.7 \text { DEFINITION OF TERMS } & 10\end{array}$

1.8 THE STRUCTURE OF THE STUDY

\section{CHAPTER 2}

2.2 LIFE CYCLE THEORY AND SAVINGS

2.3 FACTORS AFFECTING RETIREMENT DECISION MAKING 15

2.3.1 INTRODUCTION 15

2.3.2 DEMOGRAPHIC FACTORS RELATED TO PERCEIVED RETIREMENT SAVING

2.3.3 BEHAVIOURAL/PSYCHOLOGICAL FACTORS RELATED TO RETIREMENT SAVINGS DECISIONS

2.4.3.1 BOUNDED WILLPOWER AND THE RELATIONSHIP BETWEEN FUTURE TIME PERSPECTIVE AND FINANCIAL DECISION MAKING

2.4.3.2 BOUNDED RATIONALITY AND THE ASSOCIATION BETWEEN FINANCIAL LITERACY AND FINANCIAL DECISION MAKING

2.4.3.3 FINANCIAL LITERACY/EDUCATION

2.4.3.4 FINANCIAL RISK TOLERANCE 


\section{$\underline{\text { CHAPTER } 3}$}

3.1 INTRODUCTION

3.2 DESCRIPTION OF INQUIRY STRATEGY AND BROAD RESEARCH DESIGN

3.3 SURVEY INSTRUMENT

3.3.1 RESEARCH INSTRUMENT

3.3.2 RELIABILITY AND VALIDITY

3.4. DATA COLLECTION

3.5 DATA ANALYSIS

3.5.1 DESCRIPTION OF STUDY VARIABLES

3.5.1 StaTISTICAL TESTS

3.5.2 BIVARIATE ANALYSIS

3.5.2.1 PEARSON'S CORRELATIONS

3.5.2.2 INDEPENDENT SAMPLES T-TEST

3.5.3 MULTIVARIATE ANALYSIS

3.6 LIMITATIONS AND ASSUMPTIONS 52

3.7 RESEARCH ETHICS

\section{CHAPTER 4}

\section{DATA ANALYSIS}

4.1 INTRODUCTION

4.2 RESEARCH OBJECTIVES

4.3 DESCRIPTIVE STATISTICS OF SAMPLE 
4.3.2.3 FINANCIAL RISK TOLERANCE

4.3.2.4 DEMOGRAPHIC VARIABLES 62

4.4.1 FINANCIAL LITERACY AND RETIREMENT ADEQUACY SCORE 67

4.4.2 FutURE TIME PERSPECTIVE

4.4.3 FINANCIAL RISK TOLERANCE

4.5.1 Gender AND RETIREMENT ADEQUACY $\quad 72$

4.5.2 The RELATIONSHIP betWeEn Age and RetiRement AdeQuacy 73

4.4.3 The ReLATIOnShip betWeen Marital Status and Retirement AdeQuacy 74

4.4.4 RELATIONSHIP BETWEEN EdUCATION AND RETIREMENT ADEQUACY 75

4.4.5 RELATIONSHIP BETWEEN INCOME AND RETIREMENT ADEQUACY 77

4.5 MULTIVARIATE ANALYSIS

4.6 SUMMARY AND CONCLUSION 84

\section{$\underline{\text { CHAPTER } 5}$}

5.1 INTRODUCTION

5.2 PERCEIVED RETIREMENT ADEQUACY 85

5.3 Relationship between Financial Literacy and Perceived Retirement ADEQUACY 86

5.4 The relationship between Future Time Perspective and Perceived RETIREMENT ADEQUACY $\quad 89$

5.5 The ReLationship betWeEn Financial Risk ToleranCe and RetiRement ADEQUACY 90

5.6 Demographic Variables And Perceived Retirement Adequacy 90

5.7 SUMMARY AND CONCLUSION 94

CHAPTER 6

6.1 SUMMARY OF FINDINGS 95

$\begin{array}{ll}6.2 \text { CONCLUSIONS } & 97\end{array}$ 
6.3 SUMMARY OF CONTRIBUTIONS 99

6.4 SUGGESTIONS FOR FURTHER RESEARCH 99

LIST OF REFERENCES 100

$\begin{array}{ll}\text { APPENDIX A: QUESTIONNAIRE } & 108\end{array}$

\section{LIST OF FIGURES}

Figure 1-1 Conceptual models of the factors that underlie investor behaviour.... 19

\section{LIST OF TABLES}

Table 1: Perceived retirement adequacy scores

Table 2: T-test: Perceived retirement mean squares of banking and non-banking employees. 55

Table 3: Financial literacy scores .56

Table 4: T-test: Mean scores of financial literacy .57

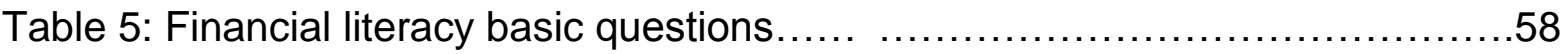

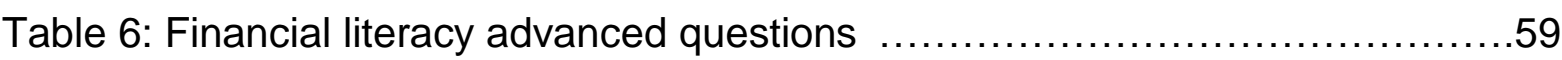

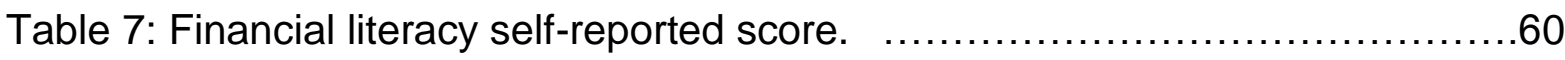

Table 8: T-test: Financial literacy self-reported mean scores $\ldots \ldots \ldots \ldots \ldots \ldots \ldots \ldots \ldots$

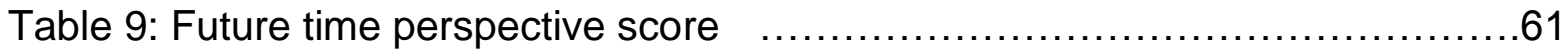

Table 10: T-test: Future time perspective mean scores..........................61

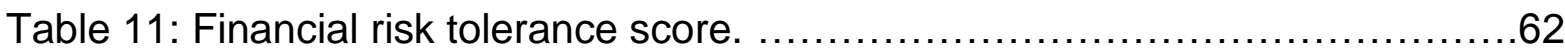

Table 12: T-test: Mean scores for financial risk tolerance..... $\ldots \ldots \ldots \ldots \ldots \ldots \ldots \ldots \ldots \ldots \ldots \ldots \ldots \ldots \ldots \ldots$

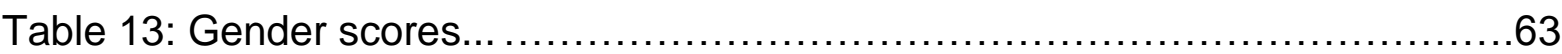

Table 14: Age scores...... .............................................. 63

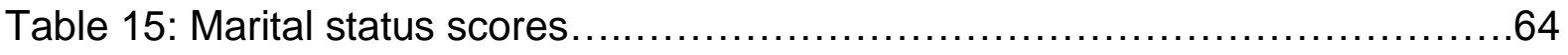

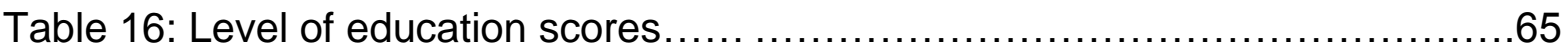

Table 17: Household income scores.............................................66 
Table 18: Race scores.

Table 19: Pearson's correlation: Subjectively assessed financial knowledge and retirement adequacy

Table 20: Pearson's correlation: Objectively assessed financial knowledge and retirement adequacy

Table 21: Pearson's correlation: Future time perspective and retirement adequacy .70

Table 22: Pearson's correlation: Financial risk tolerance and retirement adequacy .71

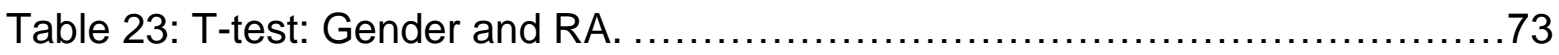

Table 24: Pearson's correlation: Age and retirement adequacy......................73

Table 25: T-test: Marital status and RA............................................. 75

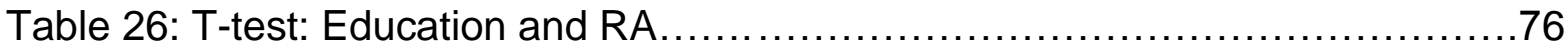

Table 27: T-test: Household income and RA...................................77

Table 28: Descriptive statistics of variables included in regression models...........79

Table 29: Linear model of predictors for full sample... .......................... 80

Table 30: Linear model of predictors for subsample banking employees............81

Table 31: Linear model for predictors - non-banking employees...................82

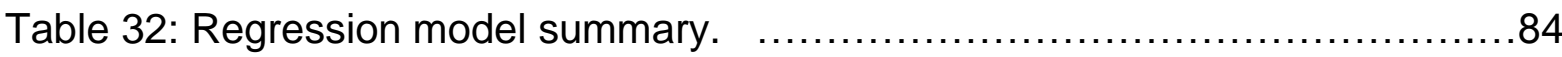




\section{LIST OF ABBREVIATIONS}

\begin{tabular}{|l|l|}
\hline Abbreviation & Meaning \\
\hline ALP & American Life Panel \\
\hline BPOPF & The Botswana Public Officers Pension Fund \\
\hline CBL & Central Bank of Lesotho \\
\hline DB & defined benefit \\
\hline DC & defined contribution \\
\hline FNB & First National Bank \\
\hline FL & financial literacy \\
\hline FRT & financial risk tolerance \\
\hline FTP & future time perspective \\
\hline LPB & Lesotho Postbank \\
\hline LRA & Lesotho Revenue Assurance \\
\hline M & Maloti (Lesotho's currency) \\
\hline NRRI & national retirement risk index \\
\hline PODCPF & Public Officers' Defined Contribution Pension Fund \\
\hline RA & retirement adequacy \\
\hline SLB & Standard Lesotho Bank \\
\hline SME & small medium enterprise \\
\hline VIF & variance inflation factor \\
\hline VCL & Vodacom Lesotho \\
\hline
\end{tabular}




\section{CHAPTER 1}

\section{INTRODUCTION}

\subsection{BACKGROUND}

The decision to save for retirement continues to be a struggle for many households because of the limited financial resources available to pay monthly expenses such as school fees, groceries and fuel. Furthermore, households do not commit to saving for retirement because of the uncertainty of living long enough to enjoy the rewards. According to Selnow (2004) and Poterba, Rauh, Venti and Wise (2007), saving for retirement is also becoming more complicated for individuals, since the shift from defined benefit (DB) to defined contribution (DC) retirement plans which puts the responsibility to make correct financial decisions on the employee as opposed to the employer. Bodie (1989) is of the view that there are two basic types of pension funds where the primary economic function is to provide retirement income security to participants that are part of that pension fund plan. Stewart and Yermo (2009), Andrew (2004), and Bodie, Marcus, and Merton (1988) state that pension schemes can either be a pure DB plan, a pure DC plan, or a hybrid of the two.

Many countries worldwide witnessed the transition from DB plans to DC plans in the last 25 years. The majority of pension funds in the late 1970s were DB plans that were managed by employer-appointed boards (Clark \& d'Ambrosio, 2002). According to Bodie et al. (1988), a DB plan determines an employee's pension benefit entitlement using a formula, where the pension pay-out depends on three factors, namely: the number of years worked, prior earnings and the scheme accrual rate and the employer bears the investment risk.. Poterba et al. (2007) also state that DB plans accrue benefits that do not depend on the financial market returns.

In contrast, DC plans are defined as plans that allow an employee to make the decision on how much they want to save, allocate and where to invest their savings (CBL, 2008). Bodie et al. (1988) and Yu et al. (2012) further explain that DC plans allow both the employer and employee to make contributions towards the employee's individual account. Bodie et al. (1988) are further of the view that there are significant differences between DB and DC plans in terms of flexibility, risks, 
sensitivity of benefits and inflation. Lusardi and Mitchell (2011) mention the flexibility of DC plans, which encourage labour mobility, unlike DB plans. Poterba et al. (2007) highlights that benefits in DC plan are a function of financial market returns presenting a potential risk to people planning for retirement. This idea is supported by Yu et al. (2012) who emphasise that there is uncertainty whether the DC plan will be able to provide a good pension benefit. Lusardi and Mitchell (2011) highlight the risk associated with DC plans where employees face the risk of under-saving, failing to invest wisely or possibly running out of money during retirement as a result of longevity risk. Longevity risk is defined as the risk of people not knowing exactly how long they will live, and therefore potentially outliving their retirement savings (Mitchell \& Utkus, 2004). Mitchell and Utkus (2004) also emphasise that DC plans have become the preferred scheme in many countries across the world, such as Latin American, Germany, Sweden and Russia.

According to Stewart and Yermo (2009), the popularity of DC plans is also on the increase in Africa, where countries such as Nigeria, Kenya, Ghana and Botswana have introduced individual DC accounts. The Botswana Public Officers Pension Fund (BPOPF), for example, was reformed in 2001 when the pension fund was converted from a DB to a DC plan. The conversion to a DC plan resulted in strong growth for the plan as many public servants joined the fund. The move towards DC plans has placed a lot of responsibility on the employee; increasing the spotlight on his/her ability to make correct saving decisions. Lesotho, like other African countries, has also moved towards the DC plan (CBL, 2008).

Lesotho is an independent constitutional monarchy situated in the highlands of Southern Africa, where the economy is driven by the following sectors; agriculture, textile, manufacturing, construction, and diamond mining (Wade, 2015). The financial sector in Lesotho comprises of four banks; Standard Lesotho Bank (SLB), Nedbank Lesotho Limited, First National Bank (FNB), and Lesotho Postbank (LPB) which are governed and regulated by the Central Bank of Lesotho (CBL) (Wade, 2015). According to Coppock et al. (2009), the banking industry in Lesotho is small and shallow, where access to banking services for households and small and medium enterprises (SME) remains limited. The banking industry is highly regulated, 
supervised and adheres to international standards and about 435000 people are using the banking system. This industry is perceived to be secure and reliable with highly competent and financially literate employees. In contrast, the retirement industry in Lesotho is not as regulated as the banking industry and lacks legislation. The lack of legislation in Lesotho's pension fund industry has had severe consequences that will be discussed in the section that follows. The discussion begins with highlighting current legislation in Lesotho and anticipated new developments.

\subsubsection{Public Pension Legislation in Lesotho}

Legislation has for many years focused on the social security of public servants, as can be seen from the following acts: the Income Tax Regulations of 1994, Public Officers' Defined Contribution Pension Fund (PODCPF) Act (No. 8 of 2008), Public Service Act (No. 13 of 1995) and the Teachers' Pension Act (No. 9 of 1994). The Public Service Act, for example, states that a public officer who holds a permanent and pensionable job shall retire from the public service at the age of 55 . Similarly, the Teachers' Pension Act was established to provide for the payment of pensions, gratuities and other allowances that were DB in nature. The Act only applies to teachers appointed on a permanent and pensionable basis under DB plans and who were allowed to retire at the age of 65 .

The private sector remained without specific legislation for many years, while public service legislation evolved. Mhango (2013) explains that Lesotho's pay-as-you-go DB pension system was previously funded from the national budget. The government realised that the pension liability was too high to be financed from thecurrent budget and decided to shift from the DB plan to a DC plan. Another legislative development was the PODCPF Act. Thahane (2008) emphasises that the most significant reform for the government of Lesotho was in the pension for public servants. The government proposed the establishment of a pension fund that would be administered by an independent board of trustees. This reform proposed a change from an unfunded pension scheme to a pre-funded scheme where both the government employee and the government would make annual contributions. The 
PODCPF Act came into operation on 1 April 2008. The fund is categorised as a DC pension fund.

The PODCPF is mandated to provide pension benefits to public officers when they leave the employment of government either through termination, resignation, retrenchment, retirement or disability. The fund has a DC structure and monthly contributions are paid into an employee's individual account. The fund is exposed to inflation, market and interest rate risks - all of which have an impact on the member's retirement income. The private sector, on the other hand, lacks legislation that governs retirement funds in Lesotho and this is discussed in the next section.

\subsubsection{Private sector pension scheme}

There is currently no formal legislation governing pension and retirement funds in the private sector in Lesotho, which presents a challenge for the industry (Metropolitan, 2015). The lack of a private and voluntary retirement legal framework contributed to a social security distortion. The by-product of Lesotho not having retirement fund legislation is the lack of knowledge and education amongst the Basotho nation in terms of retirement savings. As a result of the lack of legislation regarding retirement, retirement fund administrators such as Metropolitan Lesotho often have to rely on the Income Tax Act (No. 11 of 2012) and the Insurance Act (No.18 of 1976) for guidance (Metropolitan, 2015). The purpose of the Insurance Act was to provide regulation and supervision of insurance business in Lesotho while the Income Tax Act (referred to as the Amendment Act) introduced the income tax terminal benefits received from employment. The Amendment Act thus changed the tax treatment of the following types of lump sum employment payments: contract gratuities, gratuities from permanent and pensionable positions, and severance payments.

The Amendment Act allows tax concessions by exempting a certain portion of the lump sum and allows the same tax treatment for the taxation of lump sum employment benefits. Before this amendment came into effect, contract gratuities, gratuities from permanent and pensionable positions and severance pay were taxed differently, thus creating inequity in the tax system. The Amendment Act explicitly states that terminal benefits shall be exempt from income tax, provided they do not 
exceed 25 per cent of basic salary earned during the period of employment. The Act states that when employees retire or leave their employment and consequently the pension schemes, the individual shares in the pension funds are normally split into lump sum gratuity and purchasing periodic payments e.g. monthly pension.

Despite the lack of focused legislation governing retirement funds in Lesotho, the private sector has for many years provided pension plans to their employees that are either DB or DC plans (Metropolitan, 2015). The pension fund industry in Lesotho comprises private pension funds and the government's PODCPF, and the majority of the funds and schemes are managed in South Africa (Wade, 2015). Superannuation funds that are DB funds in nature came into effect pursuant to section 212 of the Income Tax Order of 1993 (Baholo, 1994). These regulations are cited as the Income Tax (Superannuation and Life Assurance) Regulations of 1994. Service providers such as Metropolitan Lesotho provide both DB and DC plans where organisations such as Standard Lesotho Bank, First National Bank and Vodacom Lesotho are on DC plans. Other organisations such as Nedbank Lesotho offer their employees a DB plan. Metropolitan Lesotho provides corporate solutions to organisations such as Standard Lesotho Bank, First National Bank and Nedbank Lesotho that include employee benefit products such as retirement funds, group life assurance and disability cover (Metropolitan, 2015). Recent developments in Lesotho have also seen the Central Bank of Lesotho introduce new legislation that is aimed at improving governance for the retirement industry. This is discussed in the next section of the literature review.

\subsubsection{New developments in Lesotho}

The Central Bank of Lesotho $(\mathrm{CBL})$ is currently working on a draft bill called the Private Pensions Bill 2014 aimed at regulating pension and retirement fund administration in Lesotho. The Act will be cited as the Private Pension Funds Act 2015, which will start operating as soon as it has been published in the Gazette, which has not yet happened. The Central Bank of Lesotho, as the regulator, will be responsible for the administration of the Act. The draft Act stipulates that every private pension fund will be administered by an administrator who shall be appointed by its governing body, a long-term insurer or a person appointed by the regulator. 
The Act emphasises that the investment policy for pension funds whereby members make investment choices must ensure that an appropriate array of investment options, including default options, are available for members and these plans will be DC in nature. Therefore, the investment policy must categorise the investment options according to the investment risk the member shall be exposed to. A custodian should be appointed by the registered pension fund administrator who will be responsible for the safekeeping of the pension's assets. Members will be responsible for their decisions and therefore need to have access to the right information to help them make investment decisions when saving for retirement. This responsibility has been found to put individuals under pressure to make correct financial decisions and incorrect decisions may result in inadequate savings (Choi, Laibson, Madrian, \& Metrick, 2002). The consequence of inadequate savings is that many employees face retirement with insufficient funds to support themselves. Previous studies, such as the one by Jacobs-Lawson and Hershey (2005) in America with a sample size of 270 working adults, indicate that households are not saving sufficiently for retirement and are only saving at a rate of one third of what will be needed during retirement. Other studies such as that by Lusardi and Mitchell (2005) argue that only a few American households are confident about their savings for retirement where they devised and fielded purpose-built module on planning and financial literacy for the 2004 Health and Retirement Study (HRS) which included 1,269 participants. . They found that only one third of their sample of 50 -year olds confirmed to be planning and saving adequately for retirement. While generally the population of Lesotho may lack knowledge and education in financial matters related to retirement, there is a financial sector where employees would be expected to have higher levels of financial knowledge. Studies have generally found that those who have a financial background/education save more (Lusardi \& Mitchell, 2007). As financial knowledge has been identified as a key factor in retirement savings, these employees might therefore differ from those who work in other sectors in terms of their attitudes and confidence related to retirement. Other studies looking at individuals aged 25 to 71 years found that 50 per cent of the sample confirmed that they would not have saved enough for a comfortable retirement (Jacobs-Lawson \& Hershey, 2005). 
Financial decision making is believed to be associated with a number of behavioural and socio-economic factors, and these factors may in turn be related to whether employees perceive themselves to be adequately saving for retirement. One may therefore ask which variables influence the decisions individuals make with regard to retirement saving. Researchers like Lusardi and Mitchell (2005), Kim, Kwon, and Anderson (2005) and Van Rooij, Lusardi, and Alessie (2012) have actively tried to understand different variables that influence how individuals make decisions about saving and how they come to these decisions. Lusardi and Mitchell (2005) have attributed this to a variety of reasons, such as financial literacy (FL) or availability of information about financial products that are believed to play an important role when people make retirement saving decisions. Financial illiteracy has been identified as a variable that contributes to inadequate savings for retirement (Lusardi \& Mitchell, 2007).

Jacobs-Lawson and Hershey (2005) also make reference to psychological variables such as future time perspective (FTP) and financial risk tolerance (FRT) that have a bearing on retirees when financial decisions are made. Selnow (2004) alludes to self-control as another factor affecting savings and people postponing the decision to save for retirement. People convince themselves that there is still time and findings indicate that people in emerging markets put off saving for retirement due to limited financial resources (Selnow, 2004). Many studies in this field have focused on developed economies and little research has been done in developing economies such as in Africa, and in particular Lesotho. This study therefore looks at a developing economy where little research has been done. 


\subsection{PROBLEM STATEMENT}

Many researchers, for example Lusardi and Mitchell (2009), have argued that many households face retirement with inadequate savings. The common discussion amongst ${ }^{1}$ many of the studies in this field is that there are a number of psychological and socio-economic factors that play a significant role with regard to the adequacy of retirement saving. The focus of these studies has been on developed economies, with few studies looking at developing economies.

The complexity of making a financial decision is attributed to a variety of factors that influence an individual. The biggest challenge for individuals is to make the correct financial decisions to help them achieve what they perceive to be adequate savings, which is often not easy. The problem statement that is addressed by this study is to determine if there is a relationship between certain psychological variables, such as FRT, FTP and FL, and an individual's perception that he/she is adequately prepared for retirement. In addition, the study will consider whether there are differences in terms of perceived retirement confidence between those employees working in financial institutions and those working in non-financial institutions.

\subsection{PURPOSE STATEMENT}

This study sets out to explore the link between FL, FRT, FTP and perceived retirement adequacy (RA). The key research aim is to examine which factors determine whether employees in Lesotho perceive themselves to be adequately prepared for retirement. As a secondary focus, the study will look at potential differences in terms of perceived retirement confidence between those working in the financial services sector and those working outside this sector.

\footnotetext{
${ }^{1}$ Hershey, D. A. (2004). Psychological influences on the retirement investor. CSA: Certified Senior Advisor, 22, 31-39.

Hershey, D. A., Jacobs-Lawson, J. M., McArdle, J. J., \& Hamagami, F. (2007). Psychological foundations of financial planning for retirement. Journal of Adult Development, 14, 26-36.

Hershey, D. A., \& Mowen, J. C. (2000). Psychological determinants of financial preparedness for retirement. The Gerontological Society of America, 40(6), 687-697.

Jacobs-Lawson, J. M., \& Hershey, D. A. (2005). Influence of future time perspective, financial knowledge, and financial risk tolerance on retirement saving behaviors. Financial Services Review 14, 331-344.
} 


\subsection{RESEARCH OBJECTIVES}

This study has the following research objectives:

- to determine whether employees in Lesotho perceive themselves to be adequately prepared for retirement;

- to determine the relationship between FL, FRT, FTP, and perceived RA; and

- to determine whether there are differences in the predictors of RA when comparing those employed in financial institutions to those in non-financial institutions.

\subsection{IMPORTANCE AND BENEFITS OF THE PROPOSED STUDY}

The bulk of research done in this field focused on continents such as America, Australia and Europe. This study focuses on Lesotho to get a clearer understanding of how confident individuals are about their retirement preparation because of the Lesotho's very limited retirement system. This study is also important to better understand what factors are associated with whether individuals perceive themselves to be adequately prepared for retirement, as this may differ from countries where retirement systems are more advanced and where public pension plans are in place to provide an additional safety net during retirement.

This research will provide insights to financial planners, educators and policy makers about the profile of individuals who are confident about retirement savings, and how this contrasts with those who are not confident so that they are perhaps able to tailor advice and policies to particular sub groups of the population. Furthermore, this research will lay the foundation for future research in the field of retirement saving in Lesotho and other African countries.

\subsection{DELIMITATIONS AND ASSUMPTIONS}

While the literature review considers international studies, empirical research for this study is limited to employees who are members of DC plans in Lesotho. For purposes of this study, post-retirement decisions are not discussed in the literature review. The primary data collected excluded the public sector; however, the literature 
review makes references to legislation governing public sector pension schemes. A convenience sample is used for this study and the empirical data was collected from selected financial and non-financial institutions in Lesotho that offer DCs to their employees. This study is therefore exploratory and results are not generalised to the broader population of Lesotho.

\subsection{DEFINITION OF TERMS}

Definitions of key terms used in the dissertation are provided below.

1. Financial literacy (FL): Shambare and Rugimbana (2012) describe FL as the ability of consumers to make financial decisions in the monetary economy in which they operate, and to understand the implications of their decisions on financial well-being.

2. Retirement adequacy (RA): the adequacy of retirement savings refers to whether resources (from personal savings, private pensions and social security) are adequate for spending during retirement (Montalto, 2000).

3. Defined benefit (DB) plan: a plan where the amount payable at retirement depends on the number of years worked prior earnings and the scheme accrual rate and the investment risk lies with the employer (Central Bank of Lesotho, 2008).

4. Defined contribution (DC) plan: a plan that affords employees the decision of how much to save, where to invest and how to allocate their savings (Clark \& d'Ambrosio, 2002). The investment risk and benefits lies with the member of the DC plan.

5. Financial risk tolerance (FRT): the total amount of uncertainty that a person is prepared to accept when making a financial decision (Grable, 2000).

6. Future time perspective (FTP): a psychological variable that refers to an individual's outlook towards the future instead of the present or the past (JacobsLawson \& Hershey, 2005). 


\subsection{THE STRUCTURE OF THE STUDY}

The structure of the study is discussed in the next few paragraphs.

Chapter 1 provides the introduction and highlights the three research objectives this study aims to achieve. The problem statement and the importance of this research are also covered in Chapter 1.

Chapter 2 provides the literature review. It provides a critical analysis of relevant theoretical work in this field. The focus of the discussion is on the Life Cycle Theory, behavioural factors and RA principles. A summary to the literature review is also provided.

Chapter 3 of the study presents the research design and methods used to achieve the research objectives discussed in Chapter 1 . Chapter 3 begins with the discussion of the research design and the details of the sample. The discussion on the research instrument used in the study follows, which also elaborates on how the data was collected. The last section of the chapter focuses on the data analysis, describing the statistical tests used.

Chapter 4 presents the data analysis and findings. This chapter introduces the findings from the data collected in order to address the research objectives of this study. The premise of the discussion is based on the literature review covered in Chapter 2 and on the statistical tests discussed in the method section in Chapter 3.

Chapter 5 of the study presents the discussion and interpretation of Chapter 4's findings. This chapter discusses the bivariate and multivariate relationships of each of the variables and compares the findings to prior studies. The discussion also compares the full sample and each of the subsamples, i.e. banking and non-banking samples, and provides a summary of the chapter.

Chapter 6 is the final chapter of this study and provides a summary of the key findings and the final conclusions that relate back to the original research objectives 
of the study. The chapter also provides a summary of the contributions of the study as well as recommendations for future research. 


\section{CHAPTER 2}

\section{LITERATURE REVIEW}

\subsection{INTRODUCTION}

The literature review will start by discussing the Life Cycle Theory and then discuss three important factors, namely FL, FTP and FRT that form the basis of the literature review. The discussion will elaborate on FL and education and how they influence decision making. The literature review will also focus on behavioural/psychological factors that contribute to how decisions are made. A summary of all elements discussed in the literature review can be found in the conclusion.

\subsection{LIFE CYCLE THEORY AND SAVINGS}

Neoclassical economic theory suggests that the level of savings is influenced by people's trade-off between spending today and putting money away for the future, thus emphasizing the rationality of employees (Mitchell \& Utkus, 2004). According to Becker (1962) and Browning and Crossley (2001), traditional theory assumes that households choose the best collection of commodities consistent with the limited resources available to them. It can further be mentioned that the Life Cycle model of saving hypothesises that individuals are rational when it comes to their consumption and saving needs over their lifetimes (Mitchell \& Utkus, 2004; Malroutu \& Xiao, 1995; Skinner, 2007).

One view, expressed by MacFarland, Marconi, and Utkus (2003), is that in an ideal world, rational participants should follow a process to ensure that they are adequately prepared for retirement. Employees would then be expected to identify a retirement goal and calculate how much they need to save to achieve it by creating an optimal investment portfolio. According to Mitchell and Utkus (2004), employees are described as net dissavers during their younger years where they acquire debt to boost current consumption. Employees only become net savers during their middle age where they buy and acquire assets but later decumulate when income earned during employment reduces. 
Banks, Blundell, Disney, and Emmerson (2002) also support this notion by referring to the 'consumption smoothing' that suggests that people should borrow money during their younger years when income is low, and increase savings during their middle age in order to prepare and build up savings for the future. Butler and van Zyl (2012) suggest that some households experience consumption increases in retirement due to rising healthcare expenditure while other households do not experience a change in consumption at retirement. This challenges the appropriateness of RA goals that assume a reduction in consumption at retirement. Browning and Crossley (2001) argue that in the life cycle framework, smoothing does not mean keeping consumption or expenditure constant, but instead, smoothing means that agents try to keep the marginal utility of money constant over time.

Browning and Crossley (2001) allude to the challenges that the life cycle framework has that do not agree with the smoothing of consumption at different frequencies. They state that the life cycle framework intends to integrate many aspects of behaviour in a coherent and disciplined way; however, building a model that includes the different facets of behaviour is a discouraging task. Mitchell and Utkus (2004) argue that the Life Cycle Theory failed to demonstrate the skill or competency expected from households to estimate their needs. Empirical research found that people were not as rational or as competent at planning and saving for retirement. Surveys found that fewer than 40 per cent of US workers had calculated how much they would need to retire on, 30 per cent had not saved anything for retirement and only 20 per cent felt confident about having enough money to live comfortably in retirement (Mitchell \& Utkus, 2004).

Researchers such as Shambare and Rugimbana (2012), Scheresberg (2013), and Lusardi and Mitchell (2011) are of the view that there are a number of factors that affect the saving decisions of employees, especially when it comes to saving for retirement. The following section elaborates on factors such as FL and psychological factors that influence decision making. 


\subsection{FACTORS AFFECTING RETIREMENT DECISION MAKING}

\subsubsection{INTRODUCTION}

Saving for retirement is a difficult undertaking for many households that struggle with putting money away for future consumption. According to Lusardi and Mitchell (2007), ordinary consumers are faced with the challenge of making tough financial decisions and it becomes increasingly harder when they lack FL. The level of responsibility required from households to make financial decisions regarding their retirement savings has increased since the shift towards DC plans (Clark \& d'Ambrosio, 2002). Households are now required to be active participants and make decisions on how much to save towards their retirement, making it very important for them to understand how retirement savings decisions are made (Duflo \& Saez, 2003).

Duflo and Saez (2003) explain that deciding how much to save for retirement is a difficult decision to make and requires that households process a lot of information to make the correct decision. They also state that the consequences of getting this decision wrong often leads to inadequate savings. It is therefore important to establish what factors play a role in financial decision making. Research has found that socio-economic factors such as income level, education, and gender influence decision making, but have also found additional factors that are important to consider. In this regard there have been studies that have focused on personality, the influence of peer decisions and psychological characteristics. The following sections discuss the socio-economic and demographic factors that are related to retirement savings decisions and thereafter the focus shifts to understanding the psychological factors.

\subsubsection{DEMOGRAPHIC FACTORS RELATED TO PERCEIVED RETIREMENT SAVING}

Researchers such as Hershey, Jacobs-Lawson, McAdle, and Hamagami (2007) and Munnell, Webb and Golub-Sass (2007) are of the view that socio-economic and demographic factors, i.e. gender, age, marital status, income and level of education, influence the level of retirement savings. According to Hershey et al. 
(2007), the focus of many studies has been on understanding of demographic factors such as gender, age and income levels when trying to understand saving behaviour. Ntalianis and Wise (2011) also emphasise the need to include these factors to determine how they influence savings for retirement. This section of the literature review will focus on how socio-economic and demographic factors influence retirement savings decisions.

\subsubsection{Gender, marital status and age}

Calasanti (1996) argues that traditional retirement research has focused on men's experiences and the male model has been highlighted in the study. The male model suggests that health, financial satisfaction, education and marital status contribute to life satisfaction during retirement. Noone, Alpass, and Stephens (2010) support that research with regard to retirement saving has focused on the role of men, ignoring the fact that the presence of women in the work place has increased since the Second World War.

Phua and McNally (2008) found that older males are more likely to actively plan and save for retirement than younger males. Jacobs-Lawson, Hershey, and Neukam (2008) found that women spent less time planning for and thinking about retirement than men. Fisher (2010) introduced a different study where the focus was on the differences of saving behaviour between males and females who are not married and live alone. Results showed gender differences with regards to saving behaviour where women were less likely to save than their male counterparts in the short term. Montalto (2000) provides a different view where they found that married couples were more likely to hold retirement assets than unmarried individuals.

Studies such as that by Van Rooij et al. (2012) argue that age as a demographic variable has an influence on retirement saving. They found that there was a strong correlation between age and retirement saving. Similarly, Jacobs-Lawson et al. (2008) are of the opinion that age has an effect on retirement savings, especially among men who are worried about achieving their retirement goals. Results indicate that age was positively and significantly related to the amount of time invested in planning (Jacobs-Lawson et al., 2008). Furthermore, results also found that the 
effect of age depended on how worried men were about achieving their retirement goals in comparison to women (Jacobs-Lawson et al., 2008). Income is also considered an important factor that needs to be considered, and this is discussed below.

\subsubsection{Income}

According to Jacobs-Lawson et al. (2008), income is considered an important variable with regard to financial decision making. However, Bender (2011) argues that only looking at economic factors may omit socio-demographic factors such as gender, marital status, race and age. By using a large group of respondents from the 2000 Health and Retirement Study in the USA, Bender (2011) looked at the sociodemographic, economic and non-economic factors that influence financial well-being during retirement. Findings reveal that although economic factors such as income and wealth have a significant bearing on well-being during retirement; understanding the socio-demographic factors is critical too. Research findings indicate that low levels of well-being negatively affect some retirees to a point that some need to move to smaller homes or go back to work in order to survive retirement. A similar study was done by Barretta and Kecmanovic (2013), who looked at how successfully households managed the transition to retirement - taking into account the adequacy of their savings. Their research found that subjective well-being either improves or remains unchanged for the large majority of individuals as they retire from formal employment (Barretta \& Kecmanovic, 2013).

Montalto (2000) also emphasises that income is the variable with the biggest influence on adequacy of retirement saving for American households. Data was analysed from the public use tape of the 1998 Survey of Consumer Finances released by the Federal Reservce Board in 2000, where 4309 households were interviewed. Montalto's (2000) findings indicate that 27 per cent of American households that earn less than $\$ 10000$ annually and 23 per cent that earn between $\$ 10000$ and $\$ 25000$ will not have adequate retirement savings. In contrast, 54 per cent of those with incomes between $\$ 50000$ and $\$ 100000$, and 69 per cent of those with incomes over $\$ 100000$, will be able to retire with adequate savings. 
The studies reviewed above indicate that the level of savings is influenced by socioeconomic and demographic factors such as gender, age and income. Other studies argue that psychological factors also influence how financial decisions are made by participants. The next section will discuss how psychological factors relate to retirement saving decisions.

\subsubsection{Behavioural/psychological factors related to retirement savings decisions}

Jacobs-Lawson and Hershey (2005) and Hershey, Jacobs-Lawson, McArdle, and Hamagami (2007) are of the view that psychological factors play a role when trying to understand factors that influence the decision to save for retirement. JacobsLawson and Hershey (2005) introduced these psychological factors that influence retirement savings in their study. They argue that to promote retirement savings, interventions should target people on the basis of three psychological factors, namely: knowledge of retirement planning, FTP and FRT. In addition to FTP and FRT, Hershey et al. (2007), highlight that psychological factors are important considerations when discussing retirement saving decisions. They refer to the model of retirement planning that was advanced by Hershey (2004) to explain the factors that influence how participants make decisions. The model suggests that there are four pillars that influence participants. These are illustrated in Figure 1-1 and discussed in more detail below. 
Figure 1-1 Conceptual model of the factors that underlie investor behaviour

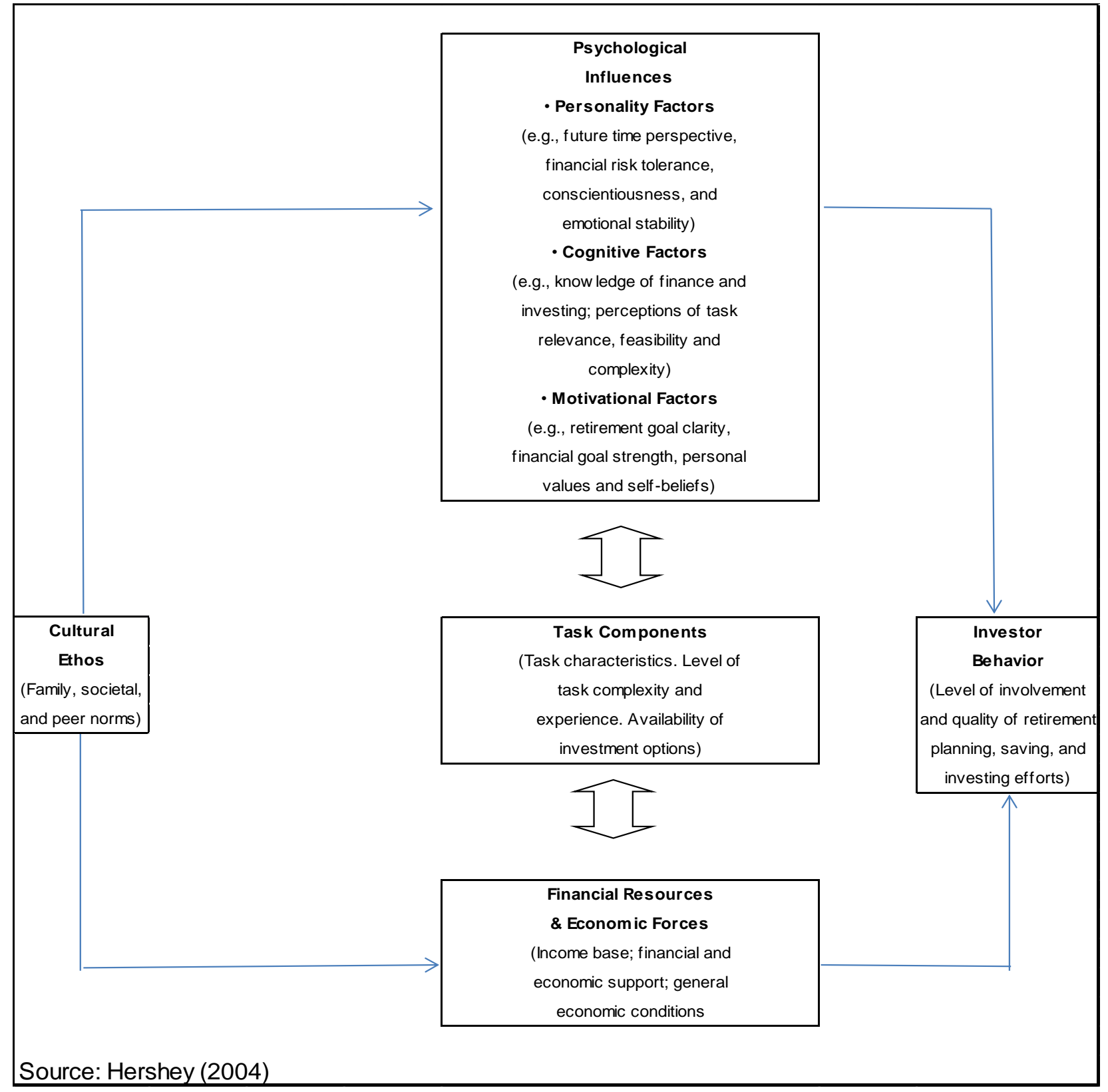

Hershey et al. (2007) explain that the conceptual framework consists of four major qualitative pillars that influence the behaviour of an investor. The first pillar, psychological influences, discusses factors such as personality linked to FTP and risk tolerance. Researchers are of the view that a person's personality is an important behavioural indicator towards saving and suggests that there are two types of people: savers and non-savers. 
Hershey and Mowen (2000), for example, agree that the personality of respondents is an important consideration when trying to understand how decisions are made. They found that the unique personality traits of respondents had an influence on their financial readiness. Under the first pillar, the framework also discusses motivational forces such as the retirement goal clarity, personal values and self-beliefs of the individual that also influence saving decisions. The third element under the first pillar observes the cognitive factors that look at how knowledgeable individuals are with regard to finance and investment.

The second pillar of the framework looks at task components, for example, the complexity of tasks, characteristics of the different tasks, prior experience and which investment options are available. The third pillar of the framework looks at the cultural ethos: how society influences an investor's thinking, attitudes and perceptions. Duflo and Saez (2003) are of the view that peers or family influence other people's decision making. They suggest that, when looking at the participation trend of a specific department or group, similar behavioural trends are found amongst peer groups. Benartzi and Thaler (2007) also support the idea that peer effects play an important role when people make savings decisions because they seek advice from their friends, partners or colleagues. This also helps to understand why the decisions people make are not necessarily their own, but are influenced and shaped by other people.

Lastly, the framework also focuses on financial resources and economic forces such as household income. Hershey et al. (2007) state that when these factors are taken together their interaction with each other not only influences individuals' planning, but also the quality of their planning efforts.

There is an implicit assumption in traditional financial decision-making theory that employees are well-informed economic agents who act rationally to maximise selfinterest (Mitchell \& Utkus, 2004). Furthermore, it is assumed that employees can interpret and weigh information about options from government or employers, assess the information, and balance these choices to make an informed decision. However, 
there is growing consensus that the traditional model is flawed and that there are limitations to individual decision-making ability.

The Hershey (2004) model discussed above is a clear indication that there are other psychological factors that play a role in saving decisions. Research, such as that by Jacobs-Lawson and Hershey (2005), has been carried out to understand the relationship between these factors and savings decisions.

The focus of the current study is on understanding how pillar one of the Hershey (2004) model, which relates to psychological factors, linked to FRT and FTP, in combination with cognitive factors, linked to $\mathrm{FL}$, relate to individual perceptions of RA. These aspects will be discussed in the sections that follow.

\subsubsection{Bounded willpower and the relationship between future time perspective and financial decision making}

Jacobs-Lawson and Hershey (2005) describe FTP as a psychological variable that refers to an individual's outlook towards the future instead of the past or present. It is further explained that FTP has a direct influence on saving behaviour because people often have to make a trade-off between present consumption and spending in the future. Hershey and Mowen (2000) share the view that individuals who are future orientated and are financially knowledgeable, are likely to plan for retirement. They also found that people who had not planned for retirement were worried about the future. The challenge remains that some people lack the willpower to plan and execute their savings desires, with the concept often referred to as bounded willpower, or a lack of self-control.

Mitchell and Utkus (2004) state that employees are faced with a situation where they have the right intentions or beliefs to save for retirement, but lack the willpower to implement the behavioural changes necessary to achieve the desired action. The lack of willpower is also described as bounded self-control, which highlights people's limitation to execute their intentions (Mitchell \& Utkus, 2004). The lack of willpower is described as one of the reasons people lack adequate preparation for retirement and this argument is supported by Mitchell and Utkus (2004), DiCenzo (2007) and 
Reyers, van Schalkwyk, and Gouws (2014). DiCenzo (2007) agrees that people procrastinate and never take action because of self-control problems.

Mitchell and Utkus (2004) explain further that while employees understand the advantages of taking the required action to save for retirement, they actually struggle to implement their desires to save or do so ineffectively. This impacts retirement savings negatively, because the more people delay the saving process, the later they can start benefiting from the concept of time value of money. According to Repetto and Tobacman (1998), researchers have found that people's near-term discount rates are much higher than their long-term discount rates.

Mitchell and Utkus (2004) and DiCenzo (2007) describe hyperbolic discounters as individuals that place higher discount rates on the short term and lower discount rates on the long term. They thus place a higher value on the present benefits and a lower value on the future. The concept of hyperbolic discounting when applied to retirement saving explains that employees prefer to overspend today and under save for the future. This is due to the problem of self-control and, to minimise this, one solution is to automatically enrol employees in retirement plans.

Benartzi and Thaler (2007) refer to automatic enrolment as a strategy where employees are advised that they will be enrolled into a retirement plan unless they choose to opt out. Automatic enrolment has increased participation in the DC plans and saw the number of new employees joining the plan reach 90 per cent in the first year, increasing to 98 per cent after three years; suggesting that automatic enrolment encouraged early participation. Madrian and Shea (2000) also found that participation was higher under automatic enrolment, which dramatically changed the savings behaviour of employees.

In contrast, DiCenzo (2007) highlights that many participants exhibit behaviour referred to as default behaviours. This is a tendency to remain invested in a plan at the default contribution rate. Findings indicate that participation increased due to automatic enrolment; however, about 70 per cent of the participants did not change their default contribution rate. This highlights the impact of inertia on decision 
making. According to Mitchell and Utkus (2004), a lot of participants in DC plans remain enrolled in default savings and conservative investment options. They state that participants display default saving behaviours where they are not active in making contribution rate changes. The question many researchers attempted to answer is: "What can be done to combat the problem of self-control?"

Benartzi and Thaler (2007) make reference to the ${ }^{2}$ Save More Tomorrow (SMT), a US program where participants are given an option to indicate that they would like to increase their pension contribution rates at scheduled times. The Save More Tomorrow program according to Benartzi and Thaler (2007) invites participants to make a commitment to save whenever they get a salary raise. By synchronizing salary increases with savings increases, the participants does not see a decreased in the net salary and therefore do not see their increased retirement contributions as a loss. The goal of this program is to address behaviours such as procrastination that participants struggled with. The program takes into account that participants struggle with self-control and provides an opportunity to commit to a contribution increase in advance. The program also takes advantage of participants' behaviours of inertia by exploiting opportunities when people sign up for retirement plans. This program has been instrumental in addressing the problem of inadequate retirement savings amongst a sample of faculty and staff at the University of Southern California (Benartzi \& Thaler, 2007). The next problem participants are faced with is bounded rationality, which is discussed below.

\subsubsection{Bounded rationality and the association between financial literacy and financial decision making}

According to Mitchell and Utkus (2004), many people's decisions are subject to bounded rationality; a situation where some decisions are too complex for an

\footnotetext{
${ }^{2}$ Save More Tomorrow was constructed with certain psychological principles in mind where it is easier for people to accept self-control restrictions that take place in the future. Second, potential losses have roughly twice the effect on people's decision-making as gains (Kahneman and Tversky, 1979; Tversky and Kahneman, 1992). Third, losses are evaluated in nominal terms (Kahneman,Knetsch, and Thaler, 1986; Shafir, Diamond, and Tversky, 1997). Fourth, inertia plays a powerful role in participants' behavior.
} 
employee to make on their own. Due to limited computational ability, some use rules of thumb (heuristics) that in many cases lead to sub-optimal decision making. Binswanger and Carman (2012) are of the view that people use rules of thumb to make saving decisions. Findings suggest that using rules of thumb may be an important instrument to improve savings for people who struggle to work out a savings plan.

Heuristics are important when trying to understand human behaviour in terms of how they make saving decisions. Benartzi and Thaler (2007) found that 58 per cent of the staff at the University of Southern California spent less than 60 minutes calculating how much they contribute and used heuristics such as the "multiple of five heuristic" when deciding on a contribution rate.

The market continually increases the number of retirement plans with many benefits and features, making it difficult for people to choose. Benartzi and Thaler (2007) suggest that it is easier for people to divide investment choices equally amongst available plans. This heuristic is referred to as the $1 / n$ rule or naïve diversification strategy. Benartzi and Thaler (2007) conducted an online survey where two groups of participants had to indicate how they would allocate their retirement savings. The results of the survey found that only 10 per cent of the first group, who could see a list of only four plans and a link to four other plans, selected more than four retirement funds. In the second group, who could view all eight plans at once; 40 per cent selected more than four plans, indicating that the $1 / n$ diversification strategy becomes impractical when the number of investment funds increases. The direct consequence of the impracticality was inadequate savings that many participants encountered, especially for their retirement.

Another aspect considered by researchers is the impact that $\mathrm{FL}$ can have on financial decision making. The key issue in this regard is that those with higher levels of FL would be able to overcome the computational complexity of the decisionmaking situation. Therefore much research has focused on the concept of FL as it relates to financial decision making and preparation for retirement. 


\subsubsection{Financial literacy/education}

FL is an important factor when discussing financial decision making, according to Hershey et al. (2007). Lusardi and Mitchell (2007) state that FL and financial education are important factors that directly influence the level of savings for retirement; more so when the responsibility for retirement savings under DC plans has shifted to the employee. Shambare and Rugimbana (2012) describe FL as the ability of consumers to make financial decisions in the monetary economy in which they operate and to understand the implications of their decisions on financial wellbeing. Employees are therefore under pressure to ensure that they make correct financial decisions for savings or suffer the consequences of their ignorance.

Lusardi and Mitchell (2007) are of the opinion that the level of retirement savings is determined by the degree of FL. Financial illiteracy has been identified as a factor that contributes to inadequate savings for retirement (Lusardi \& Mitchell, 2007). Agarwal, Amromin, Ben-David, and Chomsisengphet (2015) emphasize that people who lack $F L$ are unable to make informed decisions. The lack of $F L$ negatively affects people, many of whom only start saving later in their lives, resulting in inadequate savings (Clark \& d'Ambrosio, 2002). Lusardi and Mitchell (2009) found that respondents struggled with FL and could not do basic financial calculations. Respondents also did not have the financial knowledge to understand concepts such as risk diversification, asset pricing or the functioning of a stock market, which negatively affected their financial decision making (Lusardi \& Mitchell, 2009).

Lusardi and Mitchell $(2007,2009)$ used the Rand American Life Panel (ALP) dataset through an Internet survey aimed at addressing the levels of FL. Respondents were asked questions on basic numeracy, compound interest, inflation, time value of money and money illusion to determine their level of FL. The study found that only 47 per cent of respondents answered all five questions correctly, indicating that $\mathrm{FL}$ remains a problem. Agarwal et al. (2015) conducted a similar study where three questions on numeracy, inflation and diversification were asked of 1694 respondents in India, United Arab Emirates, Iraq and Singapore. Findings based on correctly answering the three questions suggest that respondents were generally more financially literate in developed countries. 
Bucher-Koenen and Lusardi (2011) argue that there is a positive correlation between financial saving and FL. They found that about 70 per cent of households in Germany who saved for retirement, answered the three questions on numeracy, inflation and risk correctly, compared to 54 per cent of households who did not save for retirement. Some studies argue that being exposed to financial education programs has an influence on financial decision making.

According to Collins and O'Rourke (2010), financial education and counselling programmes are premised on the assumption that consumers lack financial information to make sound financial choices. Lusardi (2005) thinks that financial education influences savings. Findings suggest that financial education enhances the quality of saving decisions, especially in low-income households. A similar view is shared by Hershey and Mowen (2000). They emphasise that people who are exposed to financial education are better prepared for retirement. Lusardi and Mitchell (2007) also allude to the fact that many employers have embarked on providing education on retirement saving in the workplace to improve FL. They found that employees who were exposed to financial education in the workplace were likely to show higher levels of FL. Furthermore, being financially knowledgeable improves the understanding of other benefits, such as pension and social security. In their study, Robb and Woodyard (2011) found that financial knowledge (objective) and financial confidence (subjective) displayed a low level of correlation and both had a significant impact on behaviour.

Gustman and Steinmeier (2005) discovered that 50 per cent of respondents could not give feedback on how much their expected social security and pension benefits were. They maintain that being knowledgeable about social security and pension is systematically related to the information that is provided at work aimed at improving financial knowledge. This view supports Lusardi and Mitchell's (2007) suggestion regarding the role employers are to play in terms of improving financial education.

Bernheim and Garrett (2003)'s stance is that financial education programs that are employer driven, stimulates savings and planning for retirement. Shambare and 
Rugimbana (2012) suggest that making financial education formal as early as primary and high school, would assist young consumers to appreciate the concept of money and finances as they move into adulthood. In contrast Fernandes, Lynch, and Netemeyer (2014) found that financial education interventions only explained about 0.1 per cent of the variance in financial behaviour. They also found that average effects of interventions directed at the low-income population were weaker than for general population samples.

Fernandes et al. (2014) refer to two types of studies in their paper: "manipulated FL" and "measured FL". Manipulated studies include experimental and quasiexperimental studies on the effects of FL interventions and the measured studies include correlational and econometric studies that measured FL by the percentage of financial questions correctly answered. Fernandes et al. (2014) found much larger effects on financial behaviour when FL was measured rather than manipulated. Measured literacy reflects the cumulative effects of all information over an individual's lifetime that affects financial knowledge, where manipulated FL studies test the effect of a small subset of that information.

Despite evidence of the limited role that FL may play in financial behaviour, many researchers have found associations between $\mathrm{FL}$ and socio-economic and demographic factors. Van Rooij et al. (2012) found that there was a positive correlation between FL and wealth accumulation. The study also took the stance that FL was associated with retirement saving behaviour, where empirical studies indicated that people who demonstrated confidence in their knowledge of finance had the propensity to plan and save. Other researchers such as that of Hershey et al. (2007) are of the view that there is a relationship between FL and demographic factors such as gender, income, age and level of education that influences financial decision making.

Agarwal et al. (2015) agree that demographic factors such as gender, age and education are important when trying to understand FL. They found that male respondents displayed better FL than female respondents. De Clercq and Venter (2009) also found that gender was amongst the factors that had an influence on FL. 
They found that men were more financially literate than women. A similar view is shared by Scheresberg (2013), who found that FL was low among women and minorities. Even when taking socio-demographic factors into consideration, findings indicate that the difference in FL between men and women remains significant. Lusardi and Mitchell (2011) also emphasise that FL is particularly low amongst young women.

Lusardi and Mitchell (2007) argue that age is another demographic factor that is important when discussing FL and decision making. Their study found that respondents 50 years and older proved to be more financially literate than younger respondents. De Clercq and Venter (2009) also found that age was an important factor because it was related to the level of FL. The age of respondents ranged from 17 to 56 years and respondents were divided into four age groups: 17-22 years, 2329 years, 30-39 years, and 40 years and older. In their study, results indicated that accounting students aged 30-39 years displayed higher levels of FL in comparison to younger students who lacked experience in personal finance, as many had just completed high school.

Other researchers such as Scheresberg (2013) are of the opinion that the level of education influences FL. Findings indicated that only 49 per cent of young respondents who had a college education and 60 per cent of young postgraduates could correctly answer the three basic financial education questions aimed at assessing FL.

In addition to the relationships between bounded willpower and bounded rationality and financial decision making, studies have also found evidence of a relationship between the level of financial risk people are willing to take and financial decision making. The next section will discuss what FRT is, its relationship to various factors and how it potentially influences decisions.

\subsubsection{Financial Risk Tolerance}

According to Yao, Hanna, and Lindamood (2004), FRT plays an important role in the decisions households make about building their portfolios and growing their wealth. 
FRT is described as the total amount of uncertainty a person is prepared to accept when making a financial decision (Grable, 2000). Van de Venter, Michayluk, and Davey (2012) are of the view that FRT is a personality trait that distinguishes individuals from each other. The debate amongst academics, however, circles around whether FRT is an enduring psychological attribute or whether it changes over time (Van de Venter et al., 2012).

Many studies have tried to determine which factors influence respondents' FRT. It is argued that the level of risk tolerance is influenced by current news regarding the stock market return and general economic conditions. Grable, Lytton, and O'Neill (2004) highlight a theory in their study that advocates that investors tend to sell stocks when market prices trend downward, when the decision may not always be rational. Yao et al. (2004) and Grable et al. (2004) found that an individual's FRT was elastic and that current market events had an influence on risk tolerance. Their research confirms that stock market prices influence risk attitudes. However, the debate is on-going as to whether FRT is a stable characteristic or not.

To understand people's willingness to take financial risks, factors such as socioeconomic, demographic, psychological factors and attitude need to be considered. Grable (2000) states that factors such as gender, age, marital status and income have an influence on the level of risk a person takes daily. Similarly, Van de Venter et al. (2012) agree that there is a relationship between FRT and factors such as gender, age, income and education. Research found that married women had the lowest risk tolerance and unmarried people were more likely to take risks than married people (Grable, 2000). Furthermore, findings indicate that males tend to take more risks than their female counterparts.

In terms of the relationship between FRT and financial decision making with respect to retirement, Grable (2000) found that people with higher risk tolerance invested in equity, saved and achieved their retirement goal, whereas those with lower risk tolerance, did not. Yao et al. (2004) highlight that households may obtain higher or lower returns depending on their risk tolerance level. A household with low risk tolerance will most probably not invest in stocks and may therefore end up with 
inadequate retirement savings. The question that remains to be answered is whether all these variables, psychological and behavioural, are associated with adequate retirement savings or not. The next section focuses on RA and how it has been measured in different studies.

\subsection{RETIREMENT ADEQUACY}

Many households are worried about not accumulating sufficient savings for retirement. According to Li, Montalto, and Geistfeld (1996), the adequacy of financial resources for retirement has significant implications for employees, their behaviour and timing of retirement. Adequacy of financial resources also has an important bearing on their quality of life and financial security during their retirement years. It is therefore important that employees make the right financial decisions to achieve their retirement goals and to avoid inadequate savings during retirement. Butler and Van Zyl (2012) and Montalto (2000) define RA goals as financial assets that need to be accumulated to meet retirement needs adequately.

A view by studies such as that of Butler and Van Zyl (2012) and Montalto (2000) is that households calculate their retirement goals to establish how much will be needed for a comfortable retirement. According to Butler and Van Zyl (2012) households therefore perceive themselves to be adequately prepared for retirement by putting money away to achieve retirement goals, but research has found that many members of households who were employed go into retirement without having saved enough. Lusardi (2005) found, using information from the United States Health and Retirement Study, that a significant number of people reach retirement without enough money. Having observed a sample of 972 respondents, $\mathrm{Li}$ et al. (1996) found that only 46 per cent had accumulated sufficient financial resources to maintain their preretirement consumption level, resulting in many not achieving retirement goals. Jacobs-Lawson and Hershey (2005) also state that baby boomers are only saving at a rate of one third of what will be required during retirement and the younger baby boomers are saving at lower levels. They allude to the fact that 50 per cent of people aged between 25 and 71 years will not have enough savings to maintain their standard of living during retirement or achieve their retirement goals. 
Binswanger and Schunk (2012) challenge the perspective of people maintaining their standard of living during retirement. Their view of an adequate standard of living relates to the trade-off between spending during their working life and spending during old age. Findings suggest that the goal of many participants is to have a spending profile where their old-age spending is in excess of 80 per cent of workinglife spending. Skinner (2007) is also of the opinion that consuming less during retirement might not endanger retirement security because retirees may move from high-cost living spaces to where the cost of living is lower; but the struggle many households face is not achieving sufficient savings. The question that households need to address is how they can maintain their standard of living during their retirement years.

Kim et al. (2005) argue that those who calculate their retirement goals will save more than those who do not. Their research findings indicate that while households are not adequately prepared for retirement, those who calculated how much they would need for retirement saved more and thus had higher confidence towards retirement. Montalto (2000) also found that only 44 per cent of households who were employed at the time, accumulated retirement savings that would be sufficient to maintain the pre-retirement standard of living throughout the retirement years; this reiterates the fact that many households are not achieving retirement goals, resulting in inadequate retirement savings.

While the section above indicates that households indeed need to calculate their retirement goals, many households still struggle to determine how much money or what percentage is required to have adequate savings for retirement. Researchers make reference to contribution and replacement rates that address how much must be saved in order to be adequately prepared. The idea that is brought forward is that there must be a relationship between what the households contribute towards retirement and the replacement rate they achieve (Antolin, 2009).

Antolin (2009) suggests that there is a linear relationship between replacement rate and contribution rates that influences RA. Antolin (2009) explains that an increase in contribution rates leads to an increase in the retirement income. Contribution rates 
that are recommended by the World Bank are between 10 per cent and 13 per cent of the annual salary (National Treasury of Republic of South Africa, 2004). Antolin (2009) states that the key relationship that measures the adequacy of retirement income is the number of years spent saving for retirement versus the number of years in retirement. The emphasis is that the higher this ratio, the higher the contribution rate required achieving the replacement rate.

Other researchers are of the opinion that there are many ways to measure adequacy of retirement income. Brady (2010) and Antolin (2009) think the most commonly used measure to determine adequacy of retirement income is the replacement rate. Brady (2010) states that to maintain a standard of living, a replacement rate measure must be determined to ensure adequate retirement income. Reno and Lavery (2007) argue that the recommended replacement rate is 70 to 80 per cent of earnings since work-related expenses, payroll taxes and retirement savings will fall away. Brady (2010) agrees that the minimum pre-retirement income that needs to be saved for a comfortable retirement should be from a minimum of between 75 and 80 per cent of earnings and more. In their study, Binswanger and Schunk (2012) calculated the minimum income replacement rate for respondents in the US to range between 95 and 45 per cent and in the Netherlands between 75 and 60 per cent.

Haveman, Holden, Romanov, and Wolfe (2007) compare the adequacy of retirement income from the beginning of retirement and 10 years into retirement to establish if there is stability in the adequacy. Findings suggest that one fifth of retirees who had been above the replacement rate of 70 per cent at the start of retirement had shifted below the standard, however, one third moved above the standard. Knoef et al. (2015) focused on the Dutch pension system in their study to determine adequacy of retirement savings where a median gross replacement rate of 83 per cent was found. In contrast, Skinner (2007) suggests that a target rate should be determined and compared to a retirement rate that will allow a household to measure its preretirement standard of living. Findings indicate that about 43 per cent of households that were sampled would not maintain their standard of living during retirement (Munnell et al., 2007). In the section above, the argument is that calculating a retirement rate influences households to prepare and save towards retirement; other 
studies, on the other hand, focus on understanding what factors predict whether households are adequately preparing for retirement.

\subsection{PREDICTORS OF RETIREMENT ADEQUACY}

Studies that consider what predicts RA generally use self-reported or subjective assessments of whether individuals believe they are adequately preparing for retirement. Malroutu and Xiao (1995), for example, refer to RA as a dependent variable, where subjective tests were used to measure adequacy. Malroutu and Xiao (1995) used a subjective question in their study to determine the RA, where respondents had to indicate whether or not they perceived themselves adequately prepared for retirement. Many studies, for example that of Van Dalen, Henkens, and Hershey (2010), take the view that individuals' perceived saving adequacy is influenced by a number of psychological and socio-economic predictors of RA, such as retirement goal clarity, FTP, the level of financial knowledge, trust in pension institutions and governments, and demographic predictors, which are discussed below.

Segel-Karpas and Werner (2014) state that there are psychological factors such as retirement goal clarity that affect retirement savings. Retirement goal clarity is defined as having realistic financial goals for retirement that are associated with retirement saving behaviour and perceived savings adequacy (Chou et al., 2015). Findings indicate that goal clarity has a direct effect on how individuals plan for retirement (Chou et al., 2015). In support of the argument of retirement goal clarity, Lusardi and Mitchell (2005) used subjective questions to determine if respondents were calculating how much they needed to save for retirement, for example, "Have you ever tried to figure out how much your household would need to save for retirement?" Findings suggest that only 31 per cent indicated that they attempted to do a retirement saving calculation. A similar question, "Have you calculated your retirement benefits?" was posed to respondents by Lusardi (2005) where findings indicated that attending retirement seminars helped increase the level of savings for retirement. Scheresberg (2013) also posed a subjective question, "Have you ever tried to figure out how much you need to save for retirement?" and found that only 35 per cent actually calculated how much they needed. Malroutu and Xiao (1995) also 
found that more than 60 per cent of respondents felt they were not adequately prepared after posing a subjective question.

The second psychological predictor of RA many researchers refer to is an individual's outlook towards the future and their attitude towards retirement. Studies such as Chou et al. (2015) state that FTP is a psychological predictor of RA. FTP is defined as the extent to which individuals perceive the future as important compared to the present - the assumption is that a positive relationship exists between retirement saving and saving adequacy (Chou et al., 2015). Van Dalen et al. (2010) similarly found that FTP had a significant effect on RA among American workers in comparison to Dutch workers. Chou et al. (2015) found that three psychological factors (future time orientation, goal clarity and financial knowledge) have a significant direct or indirect impact on retirement saving. Another example of researchers who used subjective questions relating to FTP is Jacobs-Lawson and Hershey (2008). Five questions were posed to respondents using a Likert-type scale, for example, "How difficult will it be for you to have enough money in retirement"? Though phrased differently from "Do you perceive yourself to be adequately prepared for retirement?" this question contributes significantly to the proposed study as it seeks to subjectively determine peoples' perceptions regarding RA. This study revealed statistically significant differences for gender, income and education level where larger scores to the question: "How difficult will it be for you to have enough money in retirement?" were associated with greater perceived levels of future financial difficulties. Findings indicate that women spent less time thinking about retirement than men and gender was differentially related to the factors predictive of this activity (Jacobs-Lawson \& Hershey, 2008).

The third psychological predictor is financial knowledge - an important factor associated with retirement savings. Segel-Karpas and Werner (2014) set out to determine factors that might be associated with an individual's perception of their financial preparedness for future retirement. They considered the following psychological factors: perceived financial knowledge, financial involvement and attitude towards retirement. The assumption was that individuals with a high level of financial knowledge would be more likely to plan, save, and have a higher level of 
perceived adequacy (Chou et al., 2015). Segel-Karpas and Werner (2014) found that financial knowledge was significantly related to perceived financial preparedness for retirement. They argued that the most significant predictors of RA were to understand financial matters and actively participate in financial activities.

In line with the views above, Mullock and Turcotte (2012) asked respondents subjective questions to measure and predict an individual's retirement saving behaviour, phrased as follows: "Are you financially preparing for your retirement either on your own or through an employer pension plan?" Results indicated that 80 per cent of the respondents were saving for their retirement, however, of the 80 per cent who were saving, only half knew how much they had to save to maintain their standard of living in retirement. Individuals, who scored higher on the FL quiz, saved more for retirement and knew how much they needed to save to achieve their retirement goals. Furthermore, the impact of FL on retirement saving behaviour was stronger among lower- and middle-income groups (Mullock \& Turcotte, 2012). Other researchers, such as Power, Hobbs, and Ober (2011) used "yes" or "no" questions in their study to determine whether respondents perceived themselves to be adequately prepared for retirement. Findings indicated that 15.8 per cent of nonbusiness students felt adequately prepared to make a retirement decision compared to 42.3 per cent of business students.

Kim et al. (2005) are of the view that people who are better prepared for their retirement generally have a more positive attitude to retirement. Their study set out to examine the factors that contribute to an individual's retirement confidence including anticipation and preparation for retirement. Findings indicated that those who calculated their retirement fund and saved more for retirement had higher levels of perceived RA (Kim et al., 2005).

Segel-Karpas and Werner (2014) found that some people might feel optimistic about their retirement even though they had inadequate retirement savings. Their study explored factors that lead to retirement confidence. As a part of retirement preparation, workplace financial education and advice were found to be significant predictors of retirement confidence. Additionally, these findings support those studies 
that found attending a retirement workshop seminar influenced attitude toward retirement (Segel-Karpas \& Werner, 2014). Furthermore, researchers argued that individuals' trust in pension fund institutions and government was a predictor of RA. The assumption was that higher levels of trust in the prevailing pension fund institutions will be associated with higher levels of perceived savings adequacy (Van Dalen et al., 2010). Findings indicated that the confidence individuals expressed in pension fund institutions was related to perceived saving adequacy, whilst trust in government as a provider of adequate public pension was not significant to perceived RA (Dalen et al., 2010)

Research also found socio-economic factors to be predictors of RA. In their study, Malroutu and Xiao (1995) found that perceived RA was influenced by socioeconomic factors such as income, age, gender, and employment status. This study found that younger respondents perceived themselves to be inadequately prepared for retirement. Responses ranged from low-pay jobs to lack of knowledge. Similarly, females were less likely to perceive themselves as adequately prepared, which was influenced by the inability of females to secure permanent employment. In their study, Jacobs-Lawson and Hershey (2008) found that better educated women expected less difficulty in funding their retirement than women with lower education. This was attributed to the fact that highly educated women were more likely to work in better positions offering better benefits than those less educated.

Similarly, Jacobs-Lawson et al. (2008) found that demographic factors were related to the perception respondents had about retirement and its importance. They found that the amount of time women spent planning for retirement was largely determined by age, income, FTP and their level of worry. Among men, the effect of age, income and FTP depended on how worried they were about achieving their retirement goals (Jacobs-Lawson et al., 2008). In another study, a significant and positive relationship was found between race, household income and retirement confidence (Kim et al., 2005). Their study found that those with savings and investments of $\$ 25000$ to $\$ 99$ 999, and those with between $\$ 100000$ to $\$ 250000$ or more, were more confident about their ability to have a comfortable retirement; therefore suggesting that savings had a positive impact on retirement confidence. Similarly, race was found to be a 
significant predictor of retirement confidence - findings from this study suggest that African-Americans, Hispanics and Asians might have higher retirement confidence than their white counterparts (Kim et al., 2005).

Kim et al. (2005), however, found that proximity to retirement; gender, education, marital status; financially dependent children and employer contribution to a retirement plan were not significant predictors of retirement confidence, which was inconsistent with previous studies. Segel-Karpas and Werner (2014) did not find any significant relationships between gender, ethnicity and educational level and financial preparedness. Researchers such as Joo and Pauwels (2002) also think that factors such as FRT influence retirement confidence. Results from their study found that FRT was not a statistically significant factor of retirement confidence amongst men. In contrast, Joo and Pauwels (2002) found FRT to be a statistically significant factor for retirement confidence in women. Women who had lower levels of risk aversion were found to be more confident than other women.

Other studies also found that predictors of retirement confidence such as education, future time orientation and perceived financial knowledge were significantly greater for younger workers than older workers (Chou et al., 2015). Age was found to be a significant predictor of RA - results showed that 37 per cent of an older age group (53 years old and older) reported making retirement calculations and 31 per cent reported managing to meet their saving goals (Segel-Karpas \& Werner, 2014). Other demographic variables such as marital status were also a predictor of RA. SegelKarpas and Werner (2014) found that being married was negatively associated with perceived financial preparedness for retirement. Using subjective assessments to measure RA and how respondents perceive themselves in relation to retirement saving, the studies mentioned above provide a strong theoretical background for the proposed study and the measurement instruments put forward.

\subsection{SUMMARY AND CONCLUSION}

The literature review started with the life cycle theory that explains the rationality of individuals with regard to their consumption. Factors that affect retirement saving decisions, such as socio-economic and demographic variables, were discussed next. 
The literature review then expanded to discuss the psychological factors and referred to a conceptual model of the factors that underlie investor behaviour. This was followed by a discussion on FTP, FL and FRT that were related to retirement savings decisions and were key discussion aspects of the literature review. This section highlighted bounded rationality where various heuristics were covered, such as the $1 / n$ diversification strategy used by people when making financial decisions, and computational limitations that affect decision making. The last section of the review focused on the adequacy of retirement savings and predictors of RA where the emphasis was on the contribution rates individuals need to maintain their standard of living and various measurements of RA. Many of the studies discussed focus on America, Europe, Australia and Asia with a limited number focusing on Africa. Due to the very limited retirement system in Lesotho and limited literature published to address what factors are associated with whether employees perceived themselves to be adequately preparing for retirement. This study proposes to obtain clearer understanding of how confident individuals are about their retirement and what factors are associated with perceived retirement adequacy as this may differ from countries where retirement systems are more advanced and where public pension plans are in place to provide an additional safety net during retirement. 


\section{CHAPTER 3}

\section{RESEARCH DESIGN AND METHODS}

\subsection{INTRODUCTION}

Chapter 3 focuses on the discussion of the research design and methods adopted in this study. This study set out to determine if there was a relationship between certain psychological variables such as FL, FTP and FRT on the one hand and an individual's perception of RA on the other hand. In addition, the study considered whether there were differences between those employees working in financial institutions and those from non-financial institutions.

Chapter 3 begins with a discussion of the research design and the details of the sample. A discussion of the research instrument, which also elaborates on how the data was collected, follows. The last section of the chapter focuses on the data analysis, describing the statistical tests used.

\subsection{DESCRIPTION OF INQUIRY STRATEGY AND BROAD RESEARCH DESIGN}

This study used a quantitative research approach to determine and analyse if there were relationships between the dependent and independent variables. Leedy and Ormrod (2013) state that quantitative research has a purpose of explaining, predicting, confirming or validating; where the focus is on variables that are known. The quality of research designs are defined on the basis of four characteristics: internal, external, construct validity and statistical conclusion validity (Bhattacherjee, 2012).

The specific research design followed in this study was an analytical survey where a closed-ended questionnaire was designed to test the relationship between specific predictor variables identified in prior literature and the outcome variable, which was perceived RA. A survey is described as a system for collecting information from people to describe, explain or compare (Sekaran \& Bougie, 2013). An analytical 
survey goes beyond just describing the data as it allows the testing of hypotheses (Caldwell, 2010).

A cross-sectional approach was adopted as the data was collected at a certain time from respondents at various companies in Lesotho. To collect data, a selfadministered questionnaire was distributed electronically; further detail regarding the data collection process is contained in section 3.4.

Studies by Sulaiman (2012), Hershey et al. (2007), Jacobs-Lawson and Hershey (2005), and Binswanger and Carman (2012) used survey-based research similar to this study. Jacobs-Lawson and Hershey (2005) used data from a larger national study on the psychological determinants of retirement saving. Their questions were based on FTP, knowledge of financial planning for retirement and FRT. Grable (2000) also used a questionnaire to assess FRT which was determined by calculating a risk tolerance index. Studies by Stoller and Stoller (2003), Malroutu and Xiao (1995), and Power et al. (2011) also used surveys to collect information on perceived RA. The next section discusses the advantages and disadvantages of using survey designs.

Survey designs have a number of general strengths and weaknesses that are discussed below. According to Bhattacherjee (2012), external validity is strength of surveys as they are able to collect, capture and control for a large number of variables. Leedy and Ormrod (2013) explain that external validity refers to the extent to which conclusions drawn can be generalised to other contexts. Survey research where data is collected from various individuals tends to have generalisability (Bhattacherjee, 2012). However, in the case of this study, as a convenience sample was used (see further detail in section 3.4), the findings are not generalisable. Furthermore, surveys have the ability to study a problem using many theories and are economical in terms of time, effort and cost.

Leedy and Ormrod (2013) refer to weaknesses of survey research designs. According to Leedy and Ormrod (2013) and Bhattacherjee (2012), survey designs may be subject to respondents' biases, where participants misrepresent the facts in 
an attempt to impress the researcher. Bhattacherjee (2012) also states that because of surveys' non-temporal nature, internal validity is difficult to infer due to the respondents' biases. Other biases include non-response bias, sampling bias and social desirability bias (Bhattacherjee, 2012). The ways in which these biases introduced limitations to this study, or were mitigated, are discussed in more detail in section 3.3.2, which considers aspects of reliability and validity, and section 3.4, which contains information about the data collection process.

\subsection{SURVEY INSTRUMENT}

An empirical study is a technique that allows the researcher to capture and control for a large number of variables and examine a problem from many different angles (Sekaran \& Bougie, 2013). This empirical study collected primary data through a self-administered survey questionnaire that was distributed electronically. A questionnaire is a research instrument that comprises a set of questions with the intention of capturing responses in a standardised manner (Bhattacherjee, 2012). Electronic surveys are administered over the internet where respondents receive an electronic mail request to participate in a survey (Bhattacherjee, 2012). The questionnaire in this study allowed the respondents to remain anonymous and participants were able to respond with the assurance that their responses were confidential (Leedy \& Ormrod, 2013).

\subsubsection{Research Instrument}

A self-administered questionnaire that was structured with closed-ended questions was distributed and participants were provided with multiple choice questions that were mandatory. The survey was configured and designed to prevent a respondent from submitting multiple responses that could compromise the study. A respondent was allowed to only select and submit one answer.

The dependent variable for this study was perceived RA. To measure perceived RA, the survey instrument used five self-assessment questions from a study by JacobsLawson and Hershey (2005). Questions such as, "Relative to my peers, I made meaningful contributions to a voluntary retirement savings plan", "I have saved a great deal for retirement" and "Based on how I plan to live my life in retirement, I 
have saved accordingly" were asked. These questions were previously developed and tested where researchers such as Segel-Karpas and Werner (2014), Malroutu and Xiao (1995), and Jacobs-Lawson and Hershey (2008) adopted similar questions in their studies.

FL or knowledge was measured using a combination of basic and advanced FL multiple-choice questions from Lusardi and Mitchell (2009) to determine a FL score. Lusardi and Mitchell (2009) worked on developing FL over a number of years, and extended their questionnaire from three basic questions to five questions, and then added a further eight questions that tested more advanced or sophisticated aspects of FL. The five basic FL questions have been used in numerous studies such as those by Van Rooij et al. (2012), Agarwal et al. (2015), and Lusardi and Mitchell (2011) where respondents were asked five questions on basic numeracy, compound interest, inflation, time value of money and money illusion, to determine the level of FL amongst participants. The eight sophisticated FL questions measure advanced financial knowledge such as the relationship between risk and return, the relationship between bond prices and interest rates, and concepts such as risk diversification. The advanced questions have been used in a number of studies both internationally (Van Rooij et al 2011) and in a South African context (Reyers, Van Schalkwyk \& Gouws, 2015). Therefore, to measure basic and advanced or sophisticated FL, this study adopted the five basic and the eight advanced questions from a study by NBER working paper.

Both the basic and advanced questions were formulated with the same wording as in the studies; however, minor changes were made to the currency. This study used Loti (plural Maloti), which is the currency used in Lesotho. In addition to the objective test of financial knowledge, and in line with previous studies, a subjective measure of financial knowledge from Lusardi and Mitchell (2009) was also captured as participants were asked to rate their level of financial knowledge using a seven-item scale.

Jacobs-Lawson and Hershey (2005) describe FTP as a variable that refers to an individual's outlook towards the future instead of the past or present. Using the 
questions developed by Jacobs-Lawson and Hershey (2005), FTP was measured using six questions that required participants to select the best option from the seven-item scale, for example, "I follow the advice to save for a rainy day" and "The distant future is too uncertain to plan for."

FRT is described as the total amount of uncertainty that a person is prepared to accept when making a financial decision (Grable, 2000). To measure FRT, this study adopted questions from Jacobs-Lawson and Hershey (2005), for example, "I prefer investments that have higher returns even though they are riskier" and "I am willing to risk financial losses." Five questions were asked to determine the participants' risk appetite.

The questionnaire also included demographic questions to collect information about participants' gender, age, marital status, level of education and income. Malroutu and Xiao (1995), Agarwal et al. (2015), Grable (2000), and Van de Venter et al. (2012) used socio-economic factors such as income, age, gender and employment status that are believed to be related to perceived RA. The complete questionnaire is included in Appendix A.

\subsubsection{Reliability and validity}

Bhattacherjee (2012) states that the measurement scale used must indeed measure what it was intended to measure consistently and precisely. Reliability and validity, also known as psychometric properties, are defined as measures against which the adequacy and accuracy of measurement procedures are evaluated in scientific research (Bhattacherjee, 2012). Reliability is defined as the degree to which the measure of a construct is consistent or dependable (Bhattacherjee, 2012). Similarly, validity, also called construct validity, refers to the extent to which a measure adequately represents the underlying construct that it is supposed to measure (Bhattacherjee, 2012).

As detailed above, this study used questions developed by other researchers that have been found to be valid and reliable and where variables such as FL, FTP and FRT were measured. 


\subsection{DATA COLLECTION}

Sampling is defined as the statistical process of selecting a subset (called a "sample") of a population of interest for purposes of making observations and statistical inferences about that population (Bhattacherjee, 2012). In terms of the sampling approach followed in this study, non-probability sampling was used where a single member did not have a predetermined chance of being selected due to the practical difficulties from a time and cost perspective. The focus was on employees working in the banking sector and the telecommunications sector as this allowed the study to compare differences between those working in the financial and nonfinancial sectors in Lesotho.

A convenience sample was used for this study where an e-mail with an electronic link to the survey was sent to employees at Standard Lesotho Bank, FNB in Lesotho, and Vodacom Lesotho. Sekaran and Bougie (2013) define convenience sampling as collecting information from members of the population who are available to provide it. The data was collected from employees at selected institutions that offer DC plans to their employees as these employees are required to be actively involved in decisions regarding their retirement contributions and asset allocation, and bear the investment risks associated with these decisions. Furthermore, in order to compare whether there were differences in the predictors of RA, data was collected from employees in financial institutions and from non-financial institutions. The convenience sampling approach to data collection introduced limitations, and therefore, due to the sampling technique, findings are exploratory and are neither generalisable to employees in these sectors throughout Lesotho, nor the general working population in Lesotho.

Data collection took place from 1 July 2016 until 30 September 2016. In total, 650 emails were distributed where the e-mail provided a cover letter explaining what the research aimed to achieve and that participation was voluntary. Participants could complete the survey on a computer or on a mobile device, provided Internet access was available. The survey was designed to prevent multiple submissions from a single respondent and forced respondents to complete each question before moving on to the next. The questionnaire was configured to request valid e-mail addresses 
from respondents where the multiple submissions from the same e-mail was not allowed. As an incentive for participants to complete the survey, five shopping vouchers were offered to randomly selected participants who completed the survey by a set date. E-mail reminders were sent to participants at different intervals to remind them that the questionnaire had not yet been completed.

Of the 650 e-mails sent out, data was collected from 200 participants; 107 participants were employees in the banking industry and 93 from a non-banking company, Vodacom Lesotho. According to Sekaran and Bougie (2013), one of the main disadvantages of electronic questionnaires is low response rates. In the present study, low response rates were a challenge and the final response rate was $30 \%$. While the resulting sample was large enough to carry out the proposed statistical tests, the potential for non-response error was an issue. According to Keller and Warrack (2003) non-response error refers to a bias introduced when responses are not obtained from the full sample. A non-response error was therefore a potential limiting factor for this study.

Another potential disadvantage of surveys is the potential subjectivity and biases of respondents who do not always provide a true response, but rather what they believe the researcher needs (Leedy \& Ormrod, 2013). However, as the responses were anonymous and the survey conducted electronically, this disadvantage was mitigated in the present study.

\subsection{DATA ANALYSIS}

The data analysis provides a discussion of the various statistical techniques used in the study. The analysis was conducted using Statistical Package for Social Sciences (SPSS) version 23

\subsubsection{Description of study variables}

The dependent variable for this study was perceived RA. Using a Likert-type scale, respondents were asked to rate their perceived RA using a seven- item scale where 1 represented "strongly disagree" and 7 represented "strongly agree". Five questions from Jacobs-Lawson and Hershey (2005) were used to measure perceived RA. An 
average score for the five questions was calculated for each respondent, resulting in a continuous variable that was used in the statistical analysis.

FL was measured using a combination of the five basic and eight advanced questions from Lusardi and Mitchell (2009) to determine an FL percentage score, based on the number of questions that each respondent correctly answered. The percentage score was then treated as a continuous variable used in the statistical analysis. Another measure of FL was to determine the self-reported FL scores by asking the following subjective question "How would you rate your level of financial knowledge?" Participants were asked to rate their level of financial knowledge using a seven-item scale. The self-reported score for each respondent was used as a continuous variable in the statistical analysis.

Using the questions developed by Jacobs-Lawson and Hershey (2005), FTP was measured using a seven-item scale where 1 meant "strongly disagree" and 7 meant "strongly agree". Participants were required to select a level of agreement in respect to the six statements that described their FTP. An average score for the six questions was calculated for each respondent resulting in a continuous variable that was used for statistical analysis.

Similarly, to measure FRT, this study adopted questions from Jacobs-Lawson and Hershey (2005) where five questions were asked to determine their risk appetite. A seven-item scale was used where 1 represented "strongly disagree" and 7 represented "strongly agree". An average score for the five questions was calculated for each respondent resulting in a continuous variable that was used for statistical analysis.

The study also included demographic variables where the actual age was captured as a continuous variable. Gender and marital status were measured using the nominal scale, where marital status had four options: single, married, divorced or separated, to choose from. Other variables, such as level of education and income, were measured using ordinal scales. The next section discusses the statistical tests used in the study. The complete questionnaire is included in Appendix A. 


\subsubsection{Statistical Tests}

The data was analysed using different techniques to determine the relationship between FL, FTP and FRT (independent variables) and perceived RA (dependent variable). In the first instance tests were conducted to establish bivariate relationships between each independent variable and the dependent variable, and secondly all independent variables were combined into a multivariate model. Table 1 provides a list of the independent variables indicating the category type of each variable and the resultant tests performed in the bivariate analysis.

\section{Table 1: Statistical Techniques}

\begin{tabular}{|l|l|}
\hline Independent variable \& category type & $\begin{array}{l}\text { Perceived retirement adequacy: } \\
\text { interval variable }\end{array}$ \\
\hline Financial literacy (ratio scale) & Pearson's Correlation \\
\hline Future time perspective (interval) & Pearson's Correlation \\
\hline Financial risk tolerance (interval) & Pearson's Correlation \\
\hline Gender (nominal 2 categories) & t-Test \\
\hline Age (ratio scale) & Pearson Correlation \\
\hline Marital status (nominal 2 categories) & t-Test \\
\hline Education (ordinal 2 categories) & t-Test \\
\hline Income (ordinal 2 categories) & t-Test \\
\hline
\end{tabular}

"Categories were combined for the purposes of the statistical analysis as a result of the low frequency of responses in some of the original categories.

In addition to the bivariate tests, a multivariate analysis was also conducted using multiple regressions to determine the relationship between a combined model that included all the independent variables and perceived RA. The sections that follow discuss each test in detail.

\subsubsection{Bivariate Analysis}

According to Keller and Warrack (2003), bivariate analysis is used to determine the relationship between two variables. This section discusses the various techniques used in this study to determine bivariate relationships. 


\subsubsection{Pearson's Correlations}

Field (2009) explains that a simple way to determine whether two variables are related is to establish if they co-vary. If two variables are related, then changes in one variable should be met with similar changes in the other variable (Field, 2009). This implies that when one variable deviates from its mean, a similar deviation is expected in the other variable.

Keller and Warrack (2003) explain that the Pearson product-moment correlation coefficient or Pearson's correlation coefficient is used to measure the direction and strength of association between two variables. To minimise the biases of linearity and normality, the outcome variable was measured on an interval level.

Covariance is known as the averaged sum of combined deviations, which is used to determine deviations of variables from each other. The standardised covariance is known as the correlation coefficient that is a measure of an observed effect and is used to measure the size of an effect and defined as follows (Field, 2009):

$$
r=\underline{\operatorname{cov} x_{i}} \underline{y}_{i}
$$

$$
s_{x} s_{y}
$$

$r=$ Pearson's correlation coefficient

$\mathrm{S}_{\mathrm{x}}=$ the standard deviation of the first variable

$S_{y}=$ the standard deviation of the second variable

$\mathrm{X}=$ mean of the sample

$X_{i}=$ data point in question

$N_{\mathrm{i}}=$ number of observations

When the covariance is standardised, this results in a value that lies between -1 and 1. A correlation of +1 indicates that the two variables are perfectly positively correlated. A correlation coefficient of -1 indicates a perfect negative relationship (Keller \& Warrack, 2003). Where the coefficient is zero, no linear relationship exists 
between the variables. The p-value was used to determine the significance of the correlation using the following equation with the t-statistic defined as follows;

$\operatorname{tr}=\frac{r \sqrt{N}-2}{r \sqrt{N}-R^{2}}$

\subsubsection{Independent samples t-Test}

The independent samples t-test was used to compare the difference between sample means. The independent means t-test requires that there be two experimental conditions and different participants assigned to each condition (Field, 2009).

The t-statistic determines whether the value differs from 0 relative to the variation across samples. Confidence is gained in the hypothesis when the value differs significantly from 0 and the predictor variable contributes significantly to our ability to estimate values of the outcome (Field, 2009). The t-statistic was used to test the null hypothesis and was calculated as follows to compare the model or effect against the error:

$t=\frac{(X 1-X 2)-(\mu-\mu 2)}{\text { estimate of the standard error }}$

The standard error was used to determine the level of fluctuation that is also known as the error in the estimate of the mean. The standard deviation of the sampling distribution tells how variable differences between the sample means are by chance alone. As a rule, if the observed significance is less than .05 then there is a statistically significant difference between the means of the two groups that are being compared.

The assumption with any linear model is that the variance of the outcome is stable as the predictor changes. Homogeneity of variance is assumed, according to Field (2009), to ensure that the estimates of the parameters that define a model and significance test are accurate. This assumption is tested using Levene's test, which tests the null hypothesis that the variances of the groups are the same (Field, 2009). 
If Levene's test is significant $(p<.05)$, the variance is said to be significantly different. In this case, the assumption of homogeneity of variances is violated, and therefore the t-test values that are used to determine whether there is a significant difference in the mean scores of the groups is determined under the condition that equal variances are not assumed.

\subsubsection{Multivariate Analysis}

\subsubsection{Multiple Regression Analysis}

Multiple regression was used to determine the relationship between multiple predictors, and multiple regressions were applied using the following equation:

$Y_{1}=\left(b_{0}+b_{1} X_{1 i}+b_{2} X_{2} i+\ldots b_{n} X_{n i}\right)+$ error $_{1}$

$Y_{1}=$ the outcome variable

$b_{1}=$ the coefficient of the first predictor $\left(X_{1}\right)$

$b_{2}=$ the coefficient of the second predictor $\left(X_{2}\right)$

$b_{n}=$ the coefficient of the $n^{\text {th }}$ predictor

There are three methods by which variables can be entered into a regression model. The hierarchical regression selects predictors on the basis of past research where the researcher decides on the order in which the predictors will be entered (Field, 2009). The general rule is that known predictors should be entered in order of importance. The second approach is the forced entry, which forces all predictors into the model at the same time. Forced entry is dependent on good theoretical reasons for including the chosen predictors. The last approach is the stepwise method. Field (2009) explains that in stepwise regressions, the order in which predictors are entered into the model is based on a purely mathematical criterion. This study employs the forced entry model, which is also a method followed by past studies and literature to identify theoretically important variables.

In terms of the resultant model, the linear regression output provides details regarding which of the predictor variables are statistically significant predictors of the 
outcome variable in a multivariate context, where all other variables are held constant. In addition, the key statistics that are relevant in terms of the resultant linear regression model are $\mathrm{R}^{2}$ and the F-ratio.

$R^{2}$ was used to measure how much of the variability in the outcome was accounted for by the predictors (Field, 2009). The $R^{2}$ was calculated by dividing the sum of squares for the model by the total sum of squares as per the equation below (Field, 2009);

$R^{2}=\frac{S S m}{S S t}$

The F-ratio represents the ratio of the improvement in prediction that results from fitting the model, relative to the inaccuracy that still exists in the model. As a general rule, a good model should have an F-ratio that is greater than 1 (Field, 2009).

To assess the assumptions of the linear model related to independent errors, the Durbin-Watson score was used. The Durbin-Watson test allows researchers to determine whether there is evidence of first-order autocorrelation (Keller \& Warrack, 2003). The Durbin-Watson score determines whether adjacent residuals are correlated, where the test statistic varies between 0 and 4, with a value of 2 meaning that the residuals are uncorrelated. A value greater than 2 indicates a negative correlation and a value below 2 indicates a positive correlation (Field, 2009).

Another assumption of linear regression is that there should be no perfect multicollinearity between variables. Multicollinearity exists when there is a strong correlation between two or more predictors (Keller \& Warrack, 2003). To assess multicollinearity, collinearity diagnostics, like the variance inflation factor (VIF), were used. VIF indicates if a predictor has a strong linear relationship with the other predictor. As a general rule, a VIF greater than 10 indicates a cause for concern. Similarly, if the average VIF is greater than 1 , this may indicate a regression that is biased as a result of multicollinearity. A tolerance statistic relates to the VIF, which is the reciprocal (1/VIF), and the general rule is that values less than 0.1 are a cause 
for concern. The next section discusses the limitations and assumptions of this study, followed by a discussion of the research ethics.

\subsection{LIMITATIONS AND ASSUMPTIONS}

A convenience sample was used for this study and the empirical data collected from selected financial and non-financial institutions in Lesotho that offer DC plans to their employees. Therefore, this study was exploratory and results will not be generalised to the broader population of Lesotho. A non-response error was a limiting factor due to the low response rate (Sekaran \& Bougie, 2013). According to Keller and Warrack (2003), non-response error refers to a bias introduced when responses are not obtained from the complete sample. The key concern is that those who responded to the survey differ from those who did not and this introduces limitations regarding the generalisability of the findings of the study. Another potential limitation of the study is that it measures individuals' subjective assessments of their RA which may not be the same as their objectively measured level of RA. However, what might mitigate this limitation is that prior studies from the USA and Europe have found that individuals generally seem to have a good understanding of what constitutes an adequate income in retirement (Binswanger \& Schunk, 2012).

\subsection{RESEARCH ETHICS}

This study obtained approval from the University of Pretoria's Faculty of Economic and Management Sciences' Research Ethics Committee before the collection of data. Furthermore, consent to distribute questionnaires to staff was obtained from Standard Lesotho Bank, First National Bank in Lesotho and Vodacom Lesotho. Lastly, participants in the study gave consent before completing the questionnaire. All responses were confidential and the anonymity of respondents was therefore maintained. 


\section{CHAPTER 4}

\section{DATA ANALYSIS}

\subsection{INTRODUCTION}

The focus of this chapter will be to discuss the results of the data collected from the sample in order to address the research objectives of this study. The premise of the discussion is based on the literature review covered in Chapter 2 and the statistical tests discussed in the method section in Chapter 3 . This chapter begins with a review of the research objectives this study aims to address and provides an overview of the descriptive statistics of the sample. The analysis and interpretation of the findings will follow thereafter.

\subsection{RESEARCH OBJECTIVES}

The three research objectives that this study aims to address are as follows; the first objective is to determine whether employees in Lesotho perceive themselves to be adequately prepared for retirement. The second objective is to determine the relationship between FL, FRT, FTP and RA. The third objective is to determine whether there are differences in the predictors of RA when comparing those employed in financial institutions to those in non-financial institutions.

\subsection{DESCRIPTIVE STATISTICS OF SAMPLE}

A total of 200 respondents participated in the study, with the sample comprising employees from Standard Lesotho Bank (SLB), First National Bank (FNB) and Vodacom Lesotho (VCL). Section 4.3.1 covers the descriptive statistics of the sample in more detail.

\subsubsection{Dependent Variable}

The dependent variable for this study was perceived RA. To measure the dependent variable, subjective questions similar to Jacobs-Lawson and Hershey (2005) were used. Five questions were presented to respondents using a Likert-type scale. The respondents were asked to rate their perceived RA using a seven-item scale where 
1 (represented "strongly disagree") to 7 (represented "strongly agree"), as shown below.

\begin{tabular}{|c|c|c|c|c|c|c|}
\hline $\begin{array}{c}\text { Strongly } \\
\text { disagree }\end{array}$ & Disagree & $\begin{array}{c}\text { Disagree } \\
\text { to some } \\
\text { extent }\end{array}$ & Neutral & $\begin{array}{c}\text { Agree } \\
\text { to } \\
\text { some } \\
\text { extent }\end{array}$ & Agree & $\begin{array}{c}\text { Strongly } \\
\text { agree }\end{array}$ \\
\hline 1 & 2 & 3 & 4 & 5 & 6 & 7 \\
\hline
\end{tabular}

Using the Likert scale discussed above, a histogram was used to show the results. The histogram showed a mean of 3.74 which represents the average score for the five questions. On average, participants' rating of their perceived RA was between "Disagree to some extent" and "Neutral" and the standard deviation for the sample $n$ $=200$ was 1.475 .

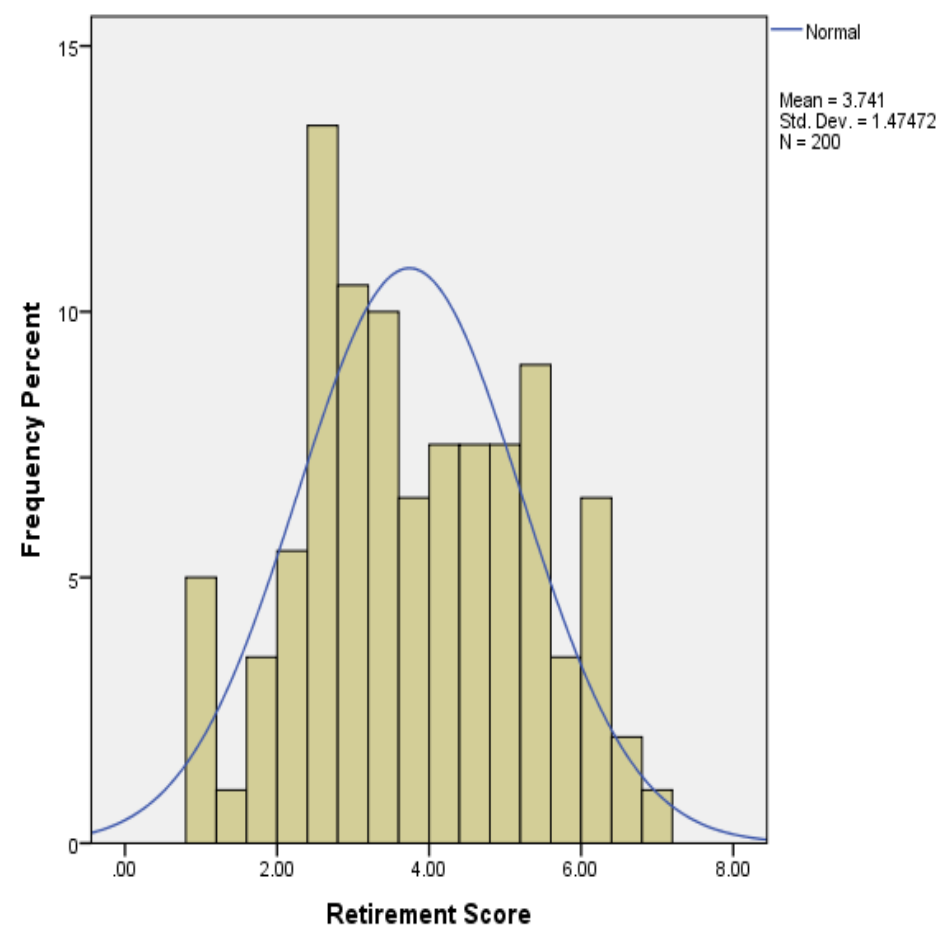

Source: SPSS

While the RA scores were not normally distributed, as the sample size was sufficiently large, the central limit theorem applies and the assumption could be made that the sampling distribution was normal and therefore parametric tests were appropriate for analysing the data (Field, 2009). 
This study found that $53.5 \%$ of the sample worked in the banking industry and $46.5 \%$ in the non-banking industry. Table 1 shows the means, medians and standard deviations for the perceived RA scores of the subsamples.

Table 1: Perceived retirement adequacy scores

\begin{tabular}{|c|c|c|c|}
\hline & $\begin{array}{c}\text { Full sample } \\
(\boldsymbol{n}=\mathbf{2 0 0})\end{array}$ & $\begin{array}{c}\text { Banking } \\
\text { employees } \\
(\boldsymbol{n}=\mathbf{1 0 7})\end{array}$ & $\begin{array}{c}\text { Non-banking } \\
\text { employees } \\
(\boldsymbol{n}=\mathbf{9 3})\end{array}$ \\
\hline Mean & 3.7410 & 3.8000 & 3.6732 \\
\hline Median & 3.6000 & 3.6000 & 3.400 \\
\hline $\begin{array}{l}\text { Standard } \\
\text { deviation }\end{array}$ & 1.47472 & 1.39270 & 1.568 \\
\hline
\end{tabular}

Source: SPSS

Banking employees reported higher perceived retirement adequacy scores $(M=$ 3.800, $S D=1.39270)$ than non-banking employees $(M=3.6732, S D=1.568)$. However, this difference was not significant $t(185.623)=-.601,(p=.549), p>.05$ as shown in the t-test results in Table 2 below.

Table 2 T-test: Perceived retirement adequacy mean scores of banking and non-banking samples

\begin{tabular}{|l|c|c|c|}
\hline & T & Df & Significance \\
& & & $(p)$ \\
\hline $\begin{array}{l}\text { Full sample }(\mathrm{n}= \\
200)\end{array}$ & -.601 & 185.623 & .549 \\
\hline
\end{tabular}

Source: SPSS 


\subsubsection{INDEPENDENT VARIABLES}

There are a number of independent variables in the study. Each variable will be discussed separately in relation to the dependent variable. The discussion starts with the descriptive discussion of FL, FTP, FRT and demographic variables.

\subsubsection{Financial literacy}

FL is measured using a combination of basic and advanced questions, where a respondent is rated on the number of correct questions. This study employed the FL questions used by Lusardi and Mitchell (2009). The questions were modified for Lesotho's currency. To determine the level of understanding of financial concepts such as numeracy, inflation, compound interest, time value of money and interest rates, respondents had to answer five basic questions. Similarly, eight advanced questions were asked to determine the level of FL on the stock market and unit trusts.

Table 3 Financial literacy scores

\begin{tabular}{|l|c|c|c|}
\hline & $\begin{array}{c}\text { Full } \\
\text { sample }(\boldsymbol{n} \\
\mathbf{= 2 0 0})\end{array}$ & $\begin{array}{c}\text { Banking } \\
\text { employees } \\
(\boldsymbol{n}=\mathbf{1 0 7})\end{array}$ & $\begin{array}{c}\text { Non-banking } \\
\text { employees } \\
(\boldsymbol{n}=93)\end{array}$ \\
\hline $\begin{array}{l}\text { Mean } \\
\text { (All questions) }\end{array}$ & $62.80 \%$ & $63.12 \%$ & $62.53 \%$ \\
\hline $\begin{array}{l}\text { Standard deviation } \\
\text { (All questions) }\end{array}$ & $20.87 \%$ & $21.53 \%$ & $20.20 \%$ \\
\hline $\begin{array}{l}\text { Mean } \\
\text { (Basic questions) }\end{array}$ & $70.20 \%$ & $71.91 \%$ & $68.17 \%$ \\
\hline $\begin{array}{l}\text { Standard deviations } \\
\text { (Basic questions) }\end{array}$ & $24.55 \%$ & $24.39 \%$ & $24.71 \%$ \\
\hline $\begin{array}{l}\text { Mean } \\
\text { (Advanced questions) }\end{array}$ & $23.31 \%$ & $22.21 \%$ & $24.22 \%$ \\
\hline $\begin{array}{l}\text { Standard deviation } \\
\text { (Advanced questions) }\end{array}$ & & $60.20 \%$ & $56.79 \%$ \\
\hline
\end{tabular}

Source: SPSS 
Table 3 contains details of the mean scores for the FL questions. For the full sample, the basic $\mathrm{FL}$ questions reported higher mean scores ( $M=70.20 \%, S D=24.55 \%)$ than the advanced FL questions ( $M=58.38 \%, S D=23.31 \%)$. This difference was also evident in the two subsamples.

In terms of the comparison of the two subsamples, non-banking employees reported lower FL mean scores $(M=62.53 \%, S D=20.20 \%)$ than banking employees $(M=$ $63.12 \%, S D=21.54 \%)$ for all questions. The difference is not significant $t(196.82)=-$ $198(p=.843), p>.05$, the t-test results are shown in Table 4 below. Similarly, for the basic questions, there was no statistically significant difference between the scores of the subsamples, where $t(193.416)=1.088, p>.05$. Looking at the advanced questions, there is again no statistically significant difference between the scores of the subsamples where $t(197.418)=-1.041, p>.05$.

Table 4: T-test: Mean scores for financial literacy

\begin{tabular}{|l|c|c|c|}
\hline & T & Df & $\begin{array}{c}\text { Significance } \\
(p)\end{array}$ \\
\hline $\begin{array}{l}\text { All questions } \\
(n=200)\end{array}$ & -198 & 196.824 & 0.843 \\
\hline $\begin{array}{l}\text { Basic questions }(n= \\
200)\end{array}$ & 1.088 & 193.416 & 0.273 \\
\hline $\begin{array}{l}\text { Advanced questions } \\
(n=200)\end{array}$ & -1.041 & 197.418 & 0.299 \\
\hline
\end{tabular}

Source: SPSS

Table 5 shows the results of the replies to the basic financial questions for the full sample, banking employees and non-banking employees. 
Table 5: Financial literacy basic questions

\begin{tabular}{|c|c|c|c|}
\hline & $\begin{array}{l}\text { Full sample } \\
\qquad(n=200)\end{array}$ & $\begin{array}{c}\text { Banking } \\
\text { employees ( } n \\
=107)\end{array}$ & $\begin{array}{c}\text { Non-banking } \\
\text { employees } \\
(n=93)\end{array}$ \\
\hline $\begin{array}{l}\text { 1.Numeracy } \\
\text { question }\end{array}$ & $90 \%$ & $92 \%$ & $87 \%$ \\
\hline $\begin{array}{l}\text { 2.Compound } \\
\text { interest }\end{array}$ & $68 \%$ & $72 \%$ & $67 \%$ \\
\hline $\begin{array}{l}\text { 3.Inflation } \\
\text { question }\end{array}$ & $71 \%$ & $73 \%$ & $72 \%$ \\
\hline $\begin{array}{l}\text { 4. Time value of } \\
\text { money }\end{array}$ & $53 \%$ & $56 \%$ & $51 \%$ \\
\hline 5. Money illusion & $59 \%$ & $64 \%$ & $56 \%$ \\
\hline
\end{tabular}

Source: SPSS

The results shown in Table 5 highlight that banking employees scored better than the non-banking employees in all five questions, with the highest score being the numeracy question. The next section looks at the responses to the advanced questions. Table 6 shows the results for the full sample, banking employees and non-banking employees. 
Table 6 Financial Literacy Advanced Questions

\begin{tabular}{|l|c|c|c|}
\hline & $\begin{array}{c}\text { Full sample } \\
(\boldsymbol{n}=\mathbf{2 0 0})\end{array}$ & $\begin{array}{c}\text { Banking } \\
\text { employees } \\
(\boldsymbol{n}=\mathbf{1 0 7})\end{array}$ & $\begin{array}{c}\text { Non-banking } \\
\text { employees } \\
(\boldsymbol{n}=93)\end{array}$ \\
\hline $\begin{array}{l}\text { 1. Stock Market } \\
\text { Functioning }\end{array}$ & $60 \%$ & $64 \%$ & $54 \%$ \\
\hline $\begin{array}{l}\text { 2. Knowledge of } \\
\text { Mutual Funds }\end{array}$ & $54 \%$ & $56 \%$ & $51 \%$ \\
\hline $\begin{array}{l}\text { 3. Interest Rate and } \\
\text { Bond Price links }\end{array}$ & $45 \%$ & $48 \%$ & $42 \%$ \\
\hline \begin{tabular}{l} 
4. Company Stock \\
\hline 5. Asset Risk
\end{tabular} & $60 \%$ & $38 \%$ & $42 \%$ \\
\hline $\begin{array}{l}\text { 6. Long Term } \\
\text { Returns }\end{array}$ & $60 \%$ & $68 \%$ & $56 \%$ \\
\hline $\begin{array}{l}\text { 7. Asset } \\
\text { Fluctuation/Volatility }\end{array}$ & $44 \%$ & $45 \%$ & $56 \%$ \\
\hline $\begin{array}{l}\text { 8. Risk } \\
\text { Diversification }\end{array}$ & $68 \%$ & $71 \%$ & $64 \%$ \\
\hline Sour SPSS & $62 \%$ & \\
\hline
\end{tabular}

Source: SPSS

As shown in Table 6, non-banking employees scored better in the company stock questions, which refers to the main functioning of a stock market; where $42 \%$ answered the question correctly compared to $38 \%$ of the banking employees. Banking employees scored better than non-banking employees in the other seven questions.

To determine the FL self-reported scores, participants were asked to rate their level of FL using a seven-item scale. Tables 7 and 8 below show the results for the FL self-reported questions. Banking employees reported higher scores $(M=4.925, S D$ 
$=1.12183)$ than non-banking employees $(M=4.4194, S D=1.21872)$. The difference is statistically significant $t(188.617)=3.038, p=.003$ where $p<.05$.

Table 7: Financial literacy self-reported score

\begin{tabular}{|c|c|c|c|}
\hline & $\begin{array}{c}\text { Full sample } \\
(\boldsymbol{n}=\mathbf{2 0 0})\end{array}$ & $\begin{array}{c}\text { Banking } \\
\text { employees }\end{array}$ & $\begin{array}{c}\text { Non-banking } \\
\text { employees } \\
(\boldsymbol{n}=\mathbf{1 0 7})\end{array}$ \\
\hline Mean & 4.6900 & 4.9252 & 4.4194 \\
\hline $\begin{array}{l}\text { Standard } \\
\text { deviation }\end{array}$ & 1.19206 & 1.12183 & 1.21872 \\
\hline
\end{tabular}

Source: SPSS

Table 8 T-test: Financial literacy self-reported mean scores

\begin{tabular}{|l|c|c|c|}
\hline & $\mathbf{T}$ & Df & $\begin{array}{c}\text { Significance } \\
(\boldsymbol{p})\end{array}$ \\
\hline $\begin{array}{l}\text { Full sample }(n= \\
200)\end{array}$ & 3.038 & 188.617 & .003 \\
\hline
\end{tabular}

Source: SPSS

\subsubsection{Future time perspective}

Similar to Jacobs-Lawson and Hershey (2005), FTP was measured using a sevenitem scale where 1 represents strongly disagree and 7 represents strongly agree with six questions. Participants were required to select the option that reflected their level of agreement with a particular statement. Table 9 shows the FTP scores for the entire sample $(n=200)$, for banking employees $(n=107)$ and non-banking employees $(n=93)$. 
Table 9 Future time perspective score

\begin{tabular}{|l|c|c|c|}
\hline & $\begin{array}{c}\text { Full sample } \\
(\boldsymbol{n}=\mathbf{2 0 0})\end{array}$ & $\begin{array}{c}\text { Banking } \\
\text { employees } \\
(\boldsymbol{n}=\mathbf{1 0 7})\end{array}$ & $\begin{array}{c}\text { Non-banking } \\
\text { employees } \\
(\boldsymbol{n}=\mathbf{9 3})\end{array}$ \\
\hline Mean & 4.7419 & 4.7415 & 4.742 \\
\hline $\begin{array}{l}\text { Standard } \\
\text { deviation }\end{array}$ & 0.95175 & 0.96288 & 0.944 \\
\hline
\end{tabular}

Source: SPSS

Banking employees $(n=107)$ reported marginally lower mean scores $(M=4.7415$, $S D=0.96288)$ than non-banking employees $(M=4.742, S D=0.944)$. As shown in the t-test results in Table 10, there is no statistically significant difference between FTP of the two subsamples $t(195.130)=-0.006$ and $p=.995, p>.05$.

Table 10: T-test: Future time perspective mean scores

\begin{tabular}{|l|c|c|c|}
\hline & T & Df & $\begin{array}{c}\text { Significance } \\
(p)\end{array}$ \\
\hline $\begin{array}{l}\text { Full sample }(n= \\
200)\end{array}$ & -.006 & 195.130 & .995 \\
\hline
\end{tabular}

Source: SPSS

\subsubsection{Financial risk tolerance}

To measure FRT, five questions were asked to determine the risk appetite. A sevenitem scale was used where participants had to select the most suitable response. Table 11 shows the standard deviation and mean $(M=3.4535, S D=1.0555)$ for the entire sample $(n=200)$. 
Table 11 Financial Risk tolerance score

\begin{tabular}{|l|c|c|c|}
\hline & $\begin{array}{c}\text { Full sample } \\
(\boldsymbol{n}=\mathbf{2 0 0})\end{array}$ & $\begin{array}{c}\text { Banking } \\
\text { employees } \\
(\boldsymbol{n}=\mathbf{1 0 7})\end{array}$ & $\begin{array}{c}\text { Non-banking } \\
\text { employees } \\
(\boldsymbol{n}=\mathbf{9 3})\end{array}$ \\
\hline Mean & 3.4535 & 3.5636 & 3.3269 \\
\hline $\begin{array}{l}\text { Standard } \\
\text { deviation }\end{array}$ & 1.05544 & 1.06411 & 1.03663 \\
\hline
\end{tabular}

Source: SPSS

Banking employees reported higher mean scores $(M=3.5636, S D=1.06411)$ than non-banking employees $(M=3.3269, S D=1.03663)$. As shown in Table 12 below, there is no statistically significant difference where $t(195.420)=1.591$, $p=.113, p>.05$.

Table 12: T-test mean scores for financial risk tolerance

\begin{tabular}{|l|c|c|c|}
\hline & T & Df & $\begin{array}{c}\text { Significance } \\
(p)\end{array}$ \\
\hline $\begin{array}{l}\text { Full sample }(n= \\
200)\end{array}$ & 1.591 & 195.420 & 0.113 \\
\hline
\end{tabular}

Source: SPSS

\subsubsection{Demographic variables}

Demographic variables are a significant aspect of this study and as discussed in Chapter 2, they have been found to be related to the level of retirement savings. The sections that follow will discuss each variable separately.

\section{a) Gender}

Gender is measured on a nominal scale where participants had to indicate if they were male or female. Table 13 below indicates that 52 per cent of the entire $(n=200)$ 
sample was male and 48 per cent was female. However, in the banking employees subsample $(n=107)$, females were in the majority with $50.5 \%$.

Table 13 Gender Scores

\begin{tabular}{|c|c|c|c|}
\hline & $\begin{array}{c}\text { Full sample } \\
(n=200)\end{array}$ & $\begin{array}{c}\text { Banking } \\
\text { employees } \\
(\boldsymbol{n}=107)\end{array}$ & $\begin{array}{c}\text { Non-banking } \\
\text { employees } \\
(\boldsymbol{n}=93)\end{array}$ \\
\hline Male & $52 \%$ & $49.5 \%$ & $54.8 \%$ \\
\hline Female & $48 \%$ & $50.5 \%$ & $45.2 \%$ \\
\hline
\end{tabular}

Source: SPSS

b) Age

Age is a continuous variable and was measured on an interval scale. To measure age as a variable, the actual age of respondents for the sample $(n=200)$ was captured. The mean age for the entire sample $(n=200)$ was 31.860 years and the standard deviation 5.481, as shown in Table 14. The mean for banking employees ( $n$ $=107)$ was 32.5327 years and for non-banking employees, 31.086 years. The standard deviation for banking employees ( $n=107)$ was $S D=6.024$ and for nonbanking employees $(n=93)$ it was $S D=4.694$.

Table 14: Age Scores

\begin{tabular}{|c|c|c|c|}
\hline & $\begin{array}{c}\text { Full sample } \\
(\boldsymbol{n}=\mathbf{2 0 0})\end{array}$ & $\begin{array}{c}\text { Banking } \\
\text { employees } \\
(\boldsymbol{n}=\mathbf{1 0 7})\end{array}$ & $\begin{array}{c}\text { Non-banking } \\
\text { employees } \\
(\boldsymbol{n}=\mathbf{9 3})\end{array}$ \\
\hline Mean & 31.860 & 32.5327 & 31.0860 \\
\hline $\begin{array}{l}\text { Standard } \\
\text { deviation }\end{array}$ & 5.481 & 6.02404 & 4.694 \\
\hline
\end{tabular}

Source: SPSS

\section{c) Marital status}

The third demographic variable was marital status. The variable, being nominal, had four options that respondents could choose from, namely single, married, divorced/ 
separated or widowed. Table 15 indicates that the highest frequency was $53 \%$ single respondents $(n=200)$ followed by $45 \%$ of married individuals.

Table 15 Marital status scores

\begin{tabular}{|l|c|c|c|}
\hline & $\begin{array}{c}\text { Full sample } \\
(\boldsymbol{n}=\mathbf{2 0 0})\end{array}$ & $\begin{array}{c}\text { Banking } \\
\text { employees } \\
(\boldsymbol{n}=\mathbf{1 0 7})\end{array}$ & $\begin{array}{c}\text { Non-banking } \\
\text { employees } \\
(\boldsymbol{n}=\mathbf{9 3})\end{array}$ \\
\hline Single & $53 \%$ & $49.5 \%$ & $57 \%$ \\
\hline Married & $45 \%$ & $47.7 \%$ & $41.9 \%$ \\
\hline Divorced/Separated & $1.5 \%$ & $1.9 \%$ & $1.1 \%$ \\
\hline Widowed & $0.5 \%$ & $0.9 \%$ & $0 \%$ \\
\hline
\end{tabular}

Source: SPSS

\section{d) Education}

Education is a demographic variable measured on an ordinal scale. To measure the level of education, participants were required to select their highest level of education from seven options: secondary education, Form E/matric, higher diploma, first degree, honours degree, master's degree or doctorate. Using frequency to measure results, Table 16 indicates the level of education for the entire sample ( $n=$ 200) where 58.5 per cent of the respondents held first degrees and 28 per cent were postgraduates. 
Table 16 Level of education scores

\begin{tabular}{|l|c|c|c|}
\hline & $\begin{array}{c}\text { Full sample } \\
(\boldsymbol{n}=\mathbf{2 0 0})\end{array}$ & $\begin{array}{c}\text { Banking } \\
\text { employees } \\
(\boldsymbol{n}=\mathbf{1 0 7})\end{array}$ & $\begin{array}{c}\text { Non-banking } \\
\text { employees } \\
(\boldsymbol{n}=\mathbf{9 3})\end{array}$ \\
\hline $\begin{array}{l}\text { Secondary } \\
\text { Education }\end{array}$ & $0.5 \%$ & $0 \%$ & $1.1 \%$ \\
\hline Form E/Matric & $1.5 \%$ & $0.9 \%$ & $2.2 \%$ \\
\hline $\begin{array}{l}\text { Higher } \\
\text { diploma }\end{array}$ & $11.5 \%$ & $15 \%$ & $7.5 \%$ \\
\hline First degree & $58.5 \%$ & $57 \%$ & $60.2 \%$ \\
\hline $\begin{array}{l}\text { Honours } \\
\text { degree }\end{array}$ & $23.0 \%$ & $22.4 \%$ & $23.7 \%$ \\
\hline $\begin{array}{l}\text { Master's } \\
\text { degree }\end{array}$ & $1.0 \%$ & $2.8 \%$ & $5.4 \%$ \\
\hline Doctorate & $1.9 \%$ & $0 \%$ \\
\hline
\end{tabular}

Source: SPSS

\section{e) Income}

Income is an ordinal variable measured using frequency tables. Table 18 shows the results for household income. The majority of the sample $(n=200)$ earned less than M20 000. Looking at the subsamples, 37.4 per cent and 40.9 per cent of banking $(\mathrm{n}=107)$ and non-banking $(\mathrm{n}=93)$ employees earn less than $\mathrm{M} 10000$ respectively. In the next interval 35.5 per cent of non-banking employees earned between M10 001 and M20 000 more than 32.7 per cent of banking employees. 
Table 17 Household income scores

\begin{tabular}{|l|c|c|c|}
\hline & $\begin{array}{c}\text { Full sample } \\
(\boldsymbol{n}=\mathbf{2 0 0})\end{array}$ & $\begin{array}{c}\text { Banking } \\
\text { employees } \\
(\boldsymbol{n}=\mathbf{1 0 7})\end{array}$ & $\begin{array}{c}\text { Non-banking } \\
\text { employees } \\
(\boldsymbol{n}=\mathbf{9 3})\end{array}$ \\
\hline $\begin{array}{l}\text { Less than } \\
\text { M10 000 }\end{array}$ & $40.0 \%$ & $37.4 \%$ & $40.9 \%$ \\
\hline $\begin{array}{l}\text { M10 001- } \\
\text { M20 000 }\end{array}$ & $40.5 \%$ & $32.7 \%$ & $35.5 \%$ \\
\hline M20 001- & $11.5 \%$ & $22.4 \%$ & $14 \%$ \\
\hline M30 000 & $4.5 \%$ & $2.8 \%$ & $2.2 \%$ \\
\hline M30 001- & $1.0 \%$ & $2.8 \%$ & $1.1 \%$ \\
\hline M40 000 & $1.0 \%$ & $1.9 \%$ & $0.5 . \%$ \\
\hline M50 000 & & & \\
\hline M50 001- & $1.5 \%$ & $0 \%$ & \\
\hline M60 000 & & & \\
\hline $\begin{array}{l}\text { Greater than } \\
\text { M60 001 }\end{array}$ & & & \\
\hline
\end{tabular}

Source: SPSS

\section{a) Race/ethnicity}

Race/ethnicity of the sample was determined. Table 18 shows the results for race where 96.5 per cent of the entire sample $(n=200)$ were black and 2 per cent were white. Looking at the banking employees and non-banking employees, 96.3 per cent and 98.9 per cent respectively were black. 
Table 18 Race scores

\begin{tabular}{|l|c|c|c|}
\hline & $\begin{array}{c}\text { Full sample } \\
(\boldsymbol{n}=\mathbf{2 0 0})\end{array}$ & $\begin{array}{c}\text { Banking } \\
\text { employees } \\
(\boldsymbol{n}=\mathbf{1 0 7})\end{array}$ & $\begin{array}{c}\text { Non-banking } \\
\text { employees } \\
(\boldsymbol{n}=\mathbf{9 3})\end{array}$ \\
\hline Black & $96.5 \%$ & $96.3 \%$ & $98.9 \%$ \\
\hline White & $1.9 \%$ & $1.9 \%$ & $0 \%$ \\
\hline Indian & $0.5 \%$ & $0.9 \%$ & $1.1 \%$ \\
\hline Coloured & $0.9 \%$ & $0.9 \%$ & $0 \%$ \\
\hline Other & $0 \%$ & $0 \%$ & $0 \%$ \\
\hline
\end{tabular}

Source: SPSS

The next section will discuss the relationship between the dependent and independent variables. The discussion begins with the relationship between FL, FTP, FRT and RA (dependent variable). The discussion about the dependent variable and the demographic variables follows.

\subsection{BIVARIATE RELATIONSHIPS BETWEEN INDEPENDENT VARIABLES AND RETIREMENT ADEQUACY}

For the bivariate analysis, hypotheses were constructed for the relationship of each independent variable to the dependent variable. Directional hypotheses were only used where prior literature had confirmed that a specific directional relationship exists between the dependent and independent variables.

\subsubsection{Financial literacy and retirement adequacy score}

FL was measured in two ways. Firstly respondents were asked to provide a subjective measure of financial knowledge on a seven-point scale, and secondly respondents' FL was assessed objectively in terms of their responses to various FL questions. The first hypothesis therefore related to the relationship between subjective FL and RA. 
Hypothesis:

$\mathrm{H}_{0}$ : There is no relationship between subjectively assessed financial knowledge and RA.

$\mathrm{H}_{\mathrm{a}}$ : There is a positive relationship between subjectively assessed financial knowledge and RA

Table 19 Pearson's correlation: Subjectively assessed financial knowledge and retirement adequacy

\begin{tabular}{|l|c|c|c|}
\hline & $\begin{array}{c}\text { Full sample } \\
(n=200)\end{array}$ & $\begin{array}{c}\text { Banking } \\
\text { employees } \\
(n=107)\end{array}$ & $\begin{array}{c}\text { Non-banking } \\
\text { employees } \\
(n=93)\end{array}$ \\
\hline $\begin{array}{l}\text { Pearson's } \\
\text { correlation }\end{array}$ & 0.383 & 0.291 & 0.469 \\
\hline $\begin{array}{l}\text { Significance (1- } \\
\text { tailed) }\end{array}$ & 0.000 & 0.002 & 0.000 \\
\hline
\end{tabular}

Source: SPSS

Table 19 shows Pearson's correlation for the entire sample was $r=0.383$. This indicated a positive correlation between financial knowledge and RA. The significance value $(p=.000)$ was below the standard criterion $p<.05$. Therefore the null hypothesis was rejected.

The Pearson's correlation for banking employees $(n=107)$ is shown in Table 19 where $r=0.291$, indicating a positive relationship. The significance value $(p=.002)$ was less than the standard criterion $p<.05$, therefore, the null hypothesis was rejected. The Pearson's correlation for non-banking employees $(n=93)$ where $r=$ 0.469 also indicated a positive relationship. The significance value $(p=.00)$ was below the standard criterion $p<.05$ and the null hypothesis was rejected.

For the full sample and each of the subsamples there was a statistically significant positive relationship between subjective financial knowledge and RA. Therefore, those who reported higher levels of subjective financial knowledge had higher levels of perceived RA. 
The second hypothesis related to the relationship between objectively assessed financial knowledge and RA.

Hypothesis:

$\mathrm{H}_{0}$ : There is no relationship between objectively assessed financial knowledge and RA.

$\mathrm{H}_{\mathrm{a}}$ : There is a positive relationship between objectively assessed financial knowledge and RA.

Table 20 Pearson's correlation: objectively assessed financial knowledge and retirement adequacy

\begin{tabular}{|l|c|c|c|}
\hline & $\begin{array}{c}\text { Full sample } \\
(n=200)\end{array}$ & $\begin{array}{c}\text { Banking } \\
\text { employees } \\
(n=107)\end{array}$ & $\begin{array}{c}\text { Non-banking } \\
\text { employees } \\
(n=93)\end{array}$ \\
\hline $\begin{array}{l}\text { Pearson's } \\
\text { correlation }\end{array}$ & 0.368 & 0.323 & 0.423 \\
\hline $\begin{array}{l}\text { Significance (1- } \\
\text { tailed) }\end{array}$ & 0.000 & 0.001 & 0.000 \\
\hline
\end{tabular}

Source: SPSS

As shown in Table 20, the Pearson's correlation for the entire sample $(n=200)$ was $r$ $=0.368$, indicating a positive correlation between the RA score and objectively measured financial knowledge for the full sample. Furthermore, the significance value $(p=.00)$ was less than the standard criterion $p<.05$, indicating that the null hypothesis had to be rejected.

The Pearson correlation for banking employees $(n=107)$ was $r=0.323$, which indicated a positive correlation. The significance value was below the standard criterion $p<.05$. The Pearson's correlation for non-banking $(n=93)$ was also determined where $r=0.423$ indicates a positive correlation. The significance value ( $p$ 
$=.00)$ was less than the standard criterion $p<.05$, and the null hypothesis was rejected.

For the full sample and each of the subsamples there was a statistically significant positive relationship between objectively assessed financial knowledge and RA. Therefore, those who had higher levels of objectively assessed financial knowledge had higher levels of perceived RA.

\subsubsection{Future Time Perspective}

FTP was the second independent variable that was measured. A bivariate correlation was calculated to determine whether a relationship existed between FTP and RA.

$\mathrm{H}_{0}$ : There is no relationship between FTP and RA.

$\mathrm{H}_{\mathrm{a}}$ : There is a positive relationship between FTP and RA.

Table 21 Pearson's correlation: Future Time Perspective and retirement adequacy

\begin{tabular}{|l|c|c|c|}
\hline & $\begin{array}{c}\text { Full sample } \\
(n=200)\end{array}$ & $\begin{array}{c}\text { Banking } \\
\text { employees } \\
(n=107)\end{array}$ & $\begin{array}{c}\text { Non-banking } \\
\text { employees } \\
(n=93)\end{array}$ \\
\hline $\begin{array}{l}\text { Pearson's } \\
\text { correlation }\end{array}$ & 0.366 & 0.401 & 0.332 \\
\hline $\begin{array}{l}\text { Significance (1- } \\
\text { tailed) }\end{array}$ & 0.000 & 0.000 & 0.001 \\
\hline
\end{tabular}

Source: SPSS

As shown in Table 21, the Pearson's correlation for the entire sample $(n=200)$ was $r$ $=0.366$, indicating a positive relationship. The significance value $(p=.00)$ was less than the standard criterion $p<.05$. Therefore the null hypothesis was rejected.

The Pearson's correlation for banking employees $(n=107)$ also showed a positive relationship where $r=0.401$. The significance value $(p=.00)$ was less than the standard criterion $p<.05$. Therefore, the null hypothesis was rejected. 
The Pearson's correlation for non-banking employees $(n=93)$ showed a positive relationship where $r=0.332$. The significance value $(p=.001)$ was less than the standard criterion $p<.05$, indicating that the null hypothesis had to be rejected.

For the full sample and each of the subsamples there were statistically significant positive relationships between FTP and RA. Therefore, those who reported higher levels of FTP had higher levels of perceived RA.

\subsubsection{Financial Risk Tolerance}

To determine whether a relationship exists between FRT and RA, a Pearson's correlation was determined and the results are shown in Table 23 below.

$\mathrm{H}_{0}$ : There is no relationship between FRT and RA.

$\mathrm{H}_{\mathrm{a}}$ : There is a relationship between FRT and RA

Table 22 Pearson's correlation: Financial Risk Tolerance and retirement adequacy

\begin{tabular}{|l|c|c|c|}
\hline & $\begin{array}{c}\text { Full sample } \\
(\boldsymbol{n}=\mathbf{2 0 0})\end{array}$ & $\begin{array}{c}\text { Banking } \\
\text { employees } \\
(\boldsymbol{n}=107)\end{array}$ & $\begin{array}{c}\text { Non-banking } \\
\text { employees } \\
(\boldsymbol{n}=93)\end{array}$ \\
\hline $\begin{array}{l}\text { Pearson's } \\
\text { correlation }\end{array}$ & 0.153 & 0.075 & 0.227 \\
\hline $\begin{array}{l}\text { Significance (2- } \\
\text { tailed) }\end{array}$ & 0.031 & 0.441 & 0.029 \\
\hline
\end{tabular}

Source: SPSS

Pearson's correlation for the entire sample $(n=200)$ was determined where $r=$ 0.153 indicating a small but positive correlation between FRT and RA. The significance value $(p=.031)$ was less than the standard criterion $p<.05$ and the null hypothesis was therefore rejected. 
The Pearson's correlation for banking employees $(n=107)$ is shown in Table 21, where $r=0.075$; indicating a small but positive relationship. However, the significance value $(p=.441)$ was greater than the standard criterion $p>.05$ and therefore, the null hypothesis could not be rejected.

The Pearson's correlation for non-banking employees was also determined where $r$ $=0.227$, indicating a small but positive relationship. The significance value $(p=.029)$ was less than the standard criterion $p<.05$ and the null hypothesis was rejected.

For the full sample and non-banking subsample there was a statistically significant positive relationship between FRT and RA. Therefore, those who reported higher levels of FRT, had higher levels of perceived RA.

The discussions above highlighted the relationship between FL, FTP, FRT and the demographic variables. Section 4.5 discusses the relationship between the demographic variables and the dependent variable.

\subsection{BIVARIATE RELATIONSHIPS BETWEEN DEMOGRAPHIC VARIABLES AND RETIREMENT ADEQUACY}

\subsubsection{Gender and Retirement adequacy}

The relationship between gender and RA was assessed using the independent samples t-test. The following was tested:

$\mathrm{H}_{\mathrm{o}}$ : The mean RA score of males does not differ from that of females.

$\mathrm{H}_{\mathrm{a}}$ : The mean RA score of males is higher than that of females.

On average, females reported higher RA scores $(M=3.825, S D=0.139)$ than males $(M=3.664, S D=0.154)$. Levene's test for the equality of variances indicated that there were significant differences in variances between the groups. The t-test value for unequal variances was used to determine whether there were statistically significant differences in the mean RA scores of males versus females. As illustrated in Table 23, this difference was not significant $t(197.287)=-0.778,(p>.05)$ and the null hypothesis could not be rejected. 
Table 23 T-test: Gender and RA

\begin{tabular}{|l|c|c|c|}
\hline & T & Df & Significance $(\boldsymbol{p})$ \\
\hline $\begin{array}{l}\text { Full sample }(n= \\
\text { 200) }\end{array}$ & -0.778 & 197.287 & 0.438 \\
\hline Banking employees & -0.914 & 101.465 & 0.363 \\
\hline $\begin{array}{l}\text { Non-banking } \\
\text { employees }\end{array}$ & -1.51 & 90.286 & 0.881 \\
\hline
\end{tabular}

Source: SPSS

Looking at banking employees, females reported higher RA scores $(M=3.922, S D=$ 1.272) than males $(M=3.6755, S D=1.5075)$ but the difference was not significant $t(101.465)=-.914, p>.05$.

Similarly for non-banking employees, females reported higher RA scores $(M=3.700$, $S D=1.4824)$ than males $(M=3.6510, S D=1.65062)$. It could be observed that the difference was not significant where $t(90.286)=-1.51, p>.05$ and the null hypothesis could not be rejected. Therefore, there is no statistically significant difference between the perceived RA scores for men and women for the full sample and both subsamples.

\subsubsection{The relationship between Age and Retirement Adequacy}

A Pearson's correlation was used to determine the relationship between age and RA.

$\mathrm{H}_{0}$ : There is no relationship between age and RA.

$\mathrm{H}_{\mathrm{a}}$ : There is a positive relationship between age and RA.

Table 24 Pearson's correlation: age and retirement adequacy

\begin{tabular}{|l|c|c|c|}
\hline & $\begin{array}{c}\text { Full sample } \\
(\boldsymbol{n}=\mathbf{2 0 0})\end{array}$ & $\begin{array}{c}\text { Banking } \\
\text { employees } \\
(\boldsymbol{n}=107)\end{array}$ & $\begin{array}{c}\text { Non-banking } \\
\text { employees } \\
(\mathbf{n}=93)\end{array}$ \\
\hline Pearson's correlation (r) & 0.069 & 0.146 & -0.041 \\
\hline $\begin{array}{l}\text { Significance (1-tailed) } \\
(\mathrm{p})\end{array}$ & 0.328 & 0.132 & 0.698 \\
\hline
\end{tabular}

Source: SPSS 
Table 24 shows the Pearson's correlation for the entire sample $(n=200)$ where $r=$ 0.069 , indicating a positive correlation between age and RA. The significance value $(p=.328)$ is greater than the standard criterion of 0.05 . For this correlation to be significant the $p$-value had to be less than 0.05 , therefore, the null hypothesis could not be rejected.

The Pearson's correlation for banking employees $(n=107)$ was also determined; $r=0.146$ indicated a positive correlation. The significance value $(p=.132)$ was above the criterion of 0.05 . For this correlation to be significant, the $p$-value had to be less than 0.05 . The null hypothesis could not be rejected.

The correlation between non-banking employees and RA was determined where $r=$ -0.041 , indicating a negative correlation. The significance value $(p=.698)$ was greater than the standard criterion of 0.05 and the null hypothesis could not be rejected. Therefore, there was no statistically significant relationship between the perceived RA scores and age for the full sample and both subsamples.

\subsubsection{The relationship between Marital Status and Retirement adequacy}

The T-test was used to test whether a relationship between the dependent variable and marital status existed. Given the low frequency of responses in certain categories, for the purposes of the statistical analysis the individuals were divided into two categories for marital status, namely single (which included divorced/separated and widowed) and married.

$\mathrm{H}_{\mathrm{o}}$ : The mean RA score of married individuals does not differ from that of unmarried individuals.

$\mathrm{H}_{\mathrm{a}}$ : The mean RA score of married individuals is higher than that of unmarried individuals.

Single people for the full sample $(n=200)$ reported lower RA scores $(M=3.7345$, $S D=1.56782)$ than married couples $(M=3.7489, S D=1.36095)$. Levene's test for equality of variances indicated that there were significant differences in variances between the groups; therefore the t-test value for unequal variances was used to determine whether there were statistically significant differences in the mean RA 
scores of marital status. However, as reported in Table 25, $\mathrm{t}(197.286)=-0.069$, where the significance value $p=.945$ was greater than 0.05 , therefore, the null hypothesis could not be rejected.

Table 25 T-test: Marital Status and RA

\begin{tabular}{|l|c|c|c|}
\hline & T & Df & Significance (p) \\
\hline $\begin{array}{l}\text { Full sample }(n= \\
\text { 200) }\end{array}$ & -0.069 & 197.286 & 0.945 \\
\hline Banking employees & 0.084 & 104.783 & 0.934 \\
\hline $\begin{array}{l}\text { Non-banking } \\
\text { employees }\end{array}$ & -0.129 & 87.369 & 0.898 \\
\hline
\end{tabular}

Source: SPSS

Amongst banking employees, single people reported lower RA scores ( $M=$ $3.788223, S D=1.29393)$ than married couples $(M=3.8107, S D=1.48858)$. This difference was not significant $t(104.783)=0.084$ with a significance value $(p=.934)$ which was greater than the standard criterion of $p>.05$, therefore, the null hypothesis could not be rejected.

Looking at non-banking employees, single people reported lower RA scores ( $M=$ 3.6556, $S D=1.65628)$ than married couples $(M=3.6974, S D=1.4595)$. There was no statistically significant difference; $t(87.369)=-0.129$ and $p=.898(p>.05)$, and the null hypothesis could not be rejected. Therefore, there was no statistically significant difference between the perceived RA scores for single people versus married people for the full sample and both subsamples.

\subsubsection{Relationship between Education and Retirement adequacy}

The T-test was used to test the relationship between the level of education and RA. Again, due to low response rates in specific categories, two categories were used to measure level of education, namely first degree and postgraduate degree. The category of first degree comprises respondents with first degrees and lower. The postgraduate category comprises of respondents with honours degrees and higher.

$\mathrm{H}_{0}$ : The mean RA score of those with lower levels of education is not different from those with postgraduate qualifications. 
$\mathrm{H}_{\mathrm{a}}$ : The mean RA score of those with lower levels of education is lower than those with postgraduate qualifications.

The results indicated that the first degree category reported lower RA scores for the full sample $(M=3.5792, S D=.39243)$ than the postgraduate category $(M=4.1571$, $S D=1.60713)$. Levene's test for equality of variances indicated that there were significant differences in variances between the groups, and the t-test value for unequal variances was used to determine whether there were statistically significant differences in the mean RA scores of educational level. The results of the t-test are reported in Table 26, for the full sample $t(88.866)=-2.368(p=.02), p<.05$, therefore the null hypothesis was rejected

\section{Table 26 T-test: Education and RA}

\begin{tabular}{|l|c|c|c|}
\hline & T & Df & Significance $(p)$ \\
\hline Full sample $(n=200)$ & -2.368 & 88.866 & 0.020 \\
\hline $\begin{array}{l}\text { Banking employees } \\
(n=107)\end{array}$ & -2.823 & 49.650 & 0.007 \\
\hline $\begin{array}{l}\text { Non-banking } \\
\text { employees }(n=93)\end{array}$ & -0.771 & 40.260 & 0.445 \\
\hline
\end{tabular}

Source: SPSS

Looking at the banking employees subsample, the category with first degrees reported lower retirement scores $(M=3.5744, S D=1.344429)$ than the postgraduate category $(M=4.4069, S D=1.36013)$. For the $\mathrm{t}$-test, banking employees showed a significance value $(p=.0070)$ where $t(49.650)=-0.2823$. The significance value $(p=.007)$ is $p<.05$ indicating that the null hypothesis had to be rejected.

Similarly for non-banking employees, the category with first degrees reported lower retirement scores $(M=3.5848, S D=1.45763)$ than the postgraduate category $(M=$ $3.8889, S D=1.82406)$. The results of the t-test reported a significance value of $p=$ .445 which was greater than 0.05 . The difference was not statistically significant and therefore the null hypothesis could not be rejected. 
There was a statistically significant difference between the perceived RA scores for those with a higher level of education level than those with a lower education level for the full sample and banking employees subsample and no statistically significant difference for the non-banking subsample. For the full sample and the banking employees subsample, those with higher education levels reported higher levels of perceived RA than those with lower education levels.

\subsubsection{Relationship between Income and Retirement adequacy}

For the full sample, those with household income of less than M10 $000(M=3.3205$, $S D=1.52497$ ) reported lower RA scores than those with household income of more than M10 000 ( $M=4.0098, S D=1.38202)$. Table 27 shows the results for household income using a t-test. Levene's test for equality of variances indicated that there were significant differences in variances between the groups. The t-test value for unequal variances was used to determine whether there were statistically significant differences in the mean RA scores for household income. The results of the t-test are reported in Table 27. For the full sample $t(152.362)=-3.233, p<.05$, the null hypothesis was rejected.

Table 27 T-test: Household Income and RA

\begin{tabular}{|l|c|c|c|}
\hline & T & Df & Significance $(\boldsymbol{p})$ \\
\hline $\begin{array}{l}\text { Full sample }(n= \\
\text { 200 })\end{array}$ & -3.233 & 152.362 & .002 \\
\hline Banking employees & -4.120 & 81.838 & .000 \\
\hline $\begin{array}{l}\text { Non-banking } \\
\text { employees }\end{array}$ & -.752 & 70.797 & .455 \\
\hline
\end{tabular}

Source: SPSS

Banking employees with a household income of less than M10 $000(M=3.130, S D=$ 1.30211) reported lower RA scores than those with a household income of higher than $M 10000(M=4.200, S D=1.2956)$. Banking employees showed a significance value $(p=.000)$ where $t(81.838)=-4.120$. As $p<.05$, the null hypothesis was rejected.

Non-banking with a household income of less than M10 $000(M=3.5211, S D=$ 1.72394) reported lower RA scores than those with a household income of higher 
than $\mathrm{M} 10000(M=3.7782, S D=1.45891)$. In terms of the t-test for non-banking employees, a significance value $(p=.455)$ was $p>.05$ where $t(70.797)=-.752$ and the null hypothesis could not be rejected.

There is thus a statistically significant difference between the perceived RA scores of those with higher household income compared to those with lower household income for the full sample and banking employees subsample. In both cases, those with higher household income reported higher levels of perceived RA than those with lower household income.

\subsection{MULTIVARIATE ANALYSIS}

Multiple regressions were used to determine if the independent variables were predictors of the dependent variable (RA) in a combined model for the full sample and then for the subsamples of banking and non-banking employees. The objective was to establish if there were linear combinations of predictors that correlated with the outcome variable. Using a forced-entry method, all the predictors were entered into the regression model at the same time. The equation below illustrates the variables included in the multiple regression analysis:

Perceived $R A=b_{0}+\left(\right.$ Objective FL) $b_{1}+\left(\right.$ Subjective FL) $b_{2}+(F R T) b_{3}+(F T P) b_{4}+$ (Gender) $b_{5}+($ Age $) b_{6}+($ Marital status $) b_{7}+\left(\right.$ Education) $b_{8}+$ (Household Income) $b_{9}+$ error term.

Household income was selected as the independent variable for the multivariate regression instead of individual income, as this would provide a better measure of each individual's financial situation in the context of total income accruing to the household. For the purpose of this analysis the variables for marital status, educational level and household income each comprised two categories (as identified in the bivariate analysis above). The requirement for the independent variables to be either continuous or categorical with only two categories was thus adhered to. 
Table 28 provides descriptive details of the variables for the full sample and the subsamples where the mean and standard deviation scores of each variable were calculated.

Table 28: Descriptive statistics of variables included in regression models

\begin{tabular}{|l|l|c|c|c|}
\hline & Full Sample & $\begin{array}{c}\text { Banking } \\
\text { employees } \\
(\boldsymbol{n}=\mathbf{2 0 0})\end{array}$ & $\begin{array}{c}\text { Non-banking } \\
\text { employees } \\
(\boldsymbol{n}=\mathbf{9 3})\end{array}$ \\
\hline Retirement & Mean & 3.7410 & 3.8000 & 3.6731 \\
Adequacy & Std Deviation & 1.4747 & 1.3927 & 1.5686 \\
\hline Objective & Mean & $62.80 \%$ & $63.12 \%$ & $62.53 \%$ \\
financial literacy & Std Deviation & $20.87 \%$ & $21.53 \%$ & $20.21 \%$ \\
\hline Subjective & Mean & 4.6900 & 4.9252 & 4.4194 \\
Financial literacy & Std Deviation & 1.1920 & 1.1218 & 1.2187 \\
\hline Financial Risk & Mean & 3.4535 & 3.5636 & 3.3269 \\
tolerance & Std Deviation & 1.0554 & 1.06411 & 1.0366 \\
\hline Future time & Mean & 4.7419 & 4.7415 & 4.742 \\
perspective & Std Deviation & .95175 & .9628 & .9440 \\
\hline Gender (Male) & Mean & .5200 & .4953 & .5484 \\
& Std Deviation & .50085 & .5023 & .5003 \\
\hline Age & Mean & 31.860 & 32.5327 & 31.0860 \\
\hline Marital Status & Std Deviation & 5.481 & 6.0240 & 4.6942 \\
(Married) & Mean & .4500 & .4766 & .4194 \\
\hline Education (Post & Mean & .5581 & .5018 & .4961 \\
\hline graduate) & Std Deviation & .2800 & .2710 & .2903 \\
\hline Household & Mean & .4501 & .4465 & .4563 \\
\hline Income (Above & Std Deviation & .6100 & .6262 & .5914 \\
M10 000) & .4889 & .4861 & .4942 \\
\hline
\end{tabular}

Table 28 shows the parameters for the full sample model where the $b$-values that determine the relationship between the predictor and outcome were calculated. The standard error for each predictor was also calculated indicating the extent to which these values would vary across samples (Field, 2009).

As observed in Table 31, three predictors out of nine were statistically significant predictors of RA in the model $(p<.05)$, namely objective FL, subjective FL, and FTP. All beta values were positive, indicating that higher levels of objective and subjective 
$\mathrm{FL}$, as well as a higher level of FTP, were all associated with higher levels of perceived RA.

Table 29: Linear model of predictors for Full Sample

\begin{tabular}{|c|c|c|c|c|c|c|}
\hline \multirow[b]{2}{*}{ Variables } & \multirow[t]{2}{*}{ Beta } & \multirow[t]{2}{*}{ S.E } & \multirow[t]{2}{*}{ Sig $(p)$} & \multirow[t]{2}{*}{$\begin{array}{l}\text { Std } \\
\text { Beta }\end{array}$} & \multicolumn{2}{|c|}{$\begin{array}{c}\text { 95\% Confidence } \\
\text { Level }\end{array}$} \\
\hline & & & & & Lower & Upper \\
\hline Constant & -1.115 & .872 & .187 & & -2.874 & -.564 \\
\hline Financial Literacy (Objective) & 1.140 & .541 & .036 & .161 & .073 & 2.206 \\
\hline Financial Literacy (Subjective) & .245 & .096 & .012 & .198 & .055 & .435 \\
\hline Financial Risk tolerance & .102 & .097 & .292 & .073 & -.089 & .293 \\
\hline Future Time Perspective (FTP) & .365 & .105 & .001 & .235. & .158 & .571 \\
\hline Male & -.196 & .190 & .304 & -.066. & -.570 & .179 \\
\hline Age & .024 & .019 & .296 & .089 & -.014 & .062 \\
\hline Postgraduate Education & .077 & .217 & .723 & .024 & -.350 & .504 \\
\hline Married & .102 & .220 & .645 & .034 & -.333 & .536 \\
\hline Household Income> M10 000 & .362 & .209 & .085 & .120 & -.050 & .775 \\
\hline
\end{tabular}

Source: SPSS

To assess multicollinearity in the model above, the variance inflation factor (VIF) was used to determine if a predictor had a strong linear relationship with other predictors (Field, 2009). Looking at the full sample, VIF values were all below 10 and tolerance statistics above 0.2 , indicating that there was no multicollinearity within the data. The average VIF was calculated as 1.317 , which is close to 1 , indicating that there were no multicollinearity issues.

The next section looks at the banking employee model. Observed in Table 29, three predictors of nine are statistically significant predictors of RA in the model $(p<.05)$ : FTP, household income and age. All beta values were positive indicating that a higher level of FTP, a higher household income and being older were all associated with higher levels of perceived RA.

Table 30: Linear model of predictors for the subsample of banking employees 


\begin{tabular}{|l|c|c|c|c|c|c|}
\hline & Beta & S.E & Sig $(\boldsymbol{p})$ & $\begin{array}{c}\text { Std } \\
\text { Beta }\end{array}$ & \multicolumn{2}{|c|}{$\begin{array}{c}\text { Confidence } \\
\text { Level }\end{array}$} \\
\hline Variables & & & & & Lower & Upper \\
\hline Constant & -1.040 & 1.101 & .0347 & & -3.226 & 1.145 \\
\hline Financial Literacy (Objective) & .781 & .719 & .280 & .121 & -.645 & 2.208 \\
\hline Financial Literacy (Subjective) & .080 & .142 & .575 & .064 & -.202 & .361 \\
\hline Financial Risk tolerance & .096 & .130 & .462 & .073 & -.162 & .355 \\
\hline Future Time Perspective (FTP) & .349 & .138 & .013 & .241 & .074 & .624 \\
\hline Male & .187 & .245 & .446 & .068 & -.674 & .299 \\
\hline Age & .048 & .024 & .045 & .209 & -.001 & .095 \\
\hline Postgraduate Education & .406 & .283 & .154 & .130 & -.155 & .968 \\
\hline Married & .0146 & .296 & .623 & -.053 & -.732 & .441 \\
\hline Household Income $>$ M10,000 & .708 & .275 & .011 & .247 & .163 & 1.252 \\
\hline
\end{tabular}

Source: SPSS

To assess multicollinearity in the model, the variance inflation factor (VIF) was used to determine if a predictor had a strong linear relationship with other predictors (Field, 2009). Looking at the banking sample, VIF values were all below 10 and tolerance statistics above 0.2 , indicating that there were no multicollinearity issues within the data. The average VIF was calculated as 1.460 , which was close to 1 , indicating that there were no multicollinearity issues.

The last model looked at the non-banking employee model. Observed in Table 30, three predictors of nine were statistically significant predictors of RA in the model ( $p$ $<.05$ ): objective FL, subjective FL, and FTP. All beta values were positive indicating that higher levels of objective and subjective FL, as well as a higher level of FTP, were all associated with higher levels of perceived RA.

To assess multicollinearity in the model above, the variance inflation factor (VIF) was used to determine if a predictor had a strong linear relationship with other predictors (Field, 2009). Looking at the full sample, VIF values were all below 10 and tolerance statistics above 0.2 , indicating that there was no multicollinearity within the data. The 
average VIF was calculated as 1.315 , which was close to 1 , indicating that there were no issues with multicollinearity.

Table 31: Linear model for predictors - Non-Banking employees

\begin{tabular}{|l|c|c|c|c|c|c|}
\hline & Beta & S.E & Sig $(\boldsymbol{p})$ & $\begin{array}{c}\text { Std } \\
\text { Beta }\end{array}$ & \multicolumn{2}{|c|}{$\begin{array}{c}\text { 95\% Confidence } \\
\text { Level }\end{array}$} \\
\hline Variables & & & & & Lower & Upper \\
\hline Constant & -.494 & 1.428 & .730 & & -3.334 & 2.347 \\
\hline Financial Literacy (Objective) & 2.164 & .880 & .016 & .279 & .414 & 3.913 \\
\hline Financial Literacy (Subjective) & .395 & .142 & .007 & .307 & .113 & .677 \\
\hline Financial Risk tolerance & .143 & .143 & .320 & .095 & -.142 & .428 \\
\hline Future Time Perspective (FTP) & .327 & .160 & .045 & .197 & -.008 & .645 \\
\hline Male & .001 & .297 & .997 & .000 & -.592 & .590 \\
\hline Age & -.032 & .034 & .359 & -.094 & -.100 & .036 \\
\hline Postgraduate Education & -.205 & .335 & .541 & -.060 & -.872 & .461 \\
\hline Married & .358 & .326 & .275 & .113 & -.290 & 1.005 \\
\hline Household Income $>$ M10,000 & -.134 & .325 & .681 & -.042 & -.782 & .513 \\
\hline
\end{tabular}

Source: SPSS

Table 31 describes the overall regression model where the correlation between the variables is .524 for the full sample $(n=200) . R^{2}$ is .274 which means it explains $27.8 \%$ of the variation.

The Durbin-Watson statistic, which provides an indication of whether the assumption regarding independent errors was met, is also reported in Table 31. In general, values close to 2 indicate that the assumption was met. The Durbin-Watson statistic for the full sample was calculated at 1.919. Non-banking employees had a DurbinWatson score of 1.869 compared to banking employees who had a score of 2.031. This indicated that the assumption had been met for the full sample and the subsamples. 
Table 32: Regression Model Summary

\begin{tabular}{|l|c|c|c|c|c|}
\hline & $\boldsymbol{R}$ & $\boldsymbol{R}^{2}$ & F-statistic & $\begin{array}{c}\text { Sig value } \\
\text { (F-statistic) }\end{array}$ & $\begin{array}{c}\text { Durbin- } \\
\text { Watson }\end{array}$ \\
\hline $\begin{array}{l}\text { Full Sample } \\
\text { (n=200) }\end{array}$ & .524 & .274 & 7.970 & .000 & 1.919 \\
\hline $\begin{array}{l}\text { Banking employees } \\
(\mathrm{n}=107)\end{array}$ & .569 & .324 & 5.167 & .000 & 2.031 \\
\hline $\begin{array}{l}\text { Non-banking } \\
\text { (n=93) }\end{array}$ & .588 & .345 & 4.865 & .000 & 1.869 \\
\hline
\end{tabular}

Source: SPSS

Table 32 also includes ANOVA results that predict whether the model is significantly better in determining the outcomes than using the mean as a best guess. Looking at the full sample, the F-statistic is greater than 1 where $(p=.000)$ which is $p<.005$. Similarly for banking employees, the F-statistic is greater than 1 where $(p=.000)$ which is $p<.05$. Non-banking employees reported an F-statistic of 4.865 , which is greater than $1,(p=.000)$ where $p<.05$. In all cases this indicates that the models significantly improved the ability to predict the outcome variable.

The multiple regression analysis above looked at the descriptive statistics of the model. Using forced entry the predictors were entered into the model as follows; RA $=\mathrm{b}_{0}+\left(\right.$ Objective FL) $\mathrm{b}_{1}+\left(\right.$ Subjective FL) $\mathrm{b}_{2}+(\mathrm{FRT}) \mathrm{b}_{3}+(\mathrm{FTP}) \mathrm{b}_{4}+($ Gender $) \mathrm{b}_{5}+$ (Age) $b_{6}+\left(\right.$ Marital status) $b_{7}+($ Education $) b_{8}+($ Household Income $) b_{9}+$ error term.

The linear model for predictors for the full sample and the two subsamples are also discussed above. The analysis assessed multicollinearity in the model, to determine if a predictor had a strong linear relationship with other predictors. The last section of the analysis provides the regression model summary. 


\subsection{SUMMARY AND CONCLUSION}

This chapter started with a discussion of the research objectives of this study, followed by a discussion of the dependent variable, RA and how it was measured. The chapter then discussed the results from the data analysis for each of the independent variables: FL, FTP and FRT. Following this was a discussion of the results from the data analysis for each demographic variable i.e. gender, age, marital status, education and income. The next section of the chapter discussed the bivariate relationship between FL, FRT, FTP and the dependent variable.

A bivariate analysis was used to determine the relationship between the dependent and independent variables where positive correlations were evident amongst the three independent variables and the dependent variable. The last section of the analysis focused on the multiple regression model to determine if the independent variables were predictors of the dependent variable (RA) in a combined model for the full sample and then for the subsamples of banking and non-banking employees. A detailed discussion of these findings contained in Chapter 5 . 


\section{CHAPTER 5}

\section{DISCUSSION OF FINDINGS}

\subsection{INTRODUCTION}

The objective of this study was to explore the link between FL, FRT, FTP and perceived RA, comparing employees in the financial industry in Lesotho to those working for a non-financial institution. The majority of research done in this field focuses on areas such as America, Australia and Europe, but this study focuses on Lesotho, providing an African context to retirement saving.

Chapter 4 of this study provided the description of the independent variables and analysed the relationship between all the independent variables and the dependent variable. Chapter 5 discusses and interprets the results analysed in Chapter 4 . It discusses the bivariate and multivariate relationships of all of the variables and compares the findings to prior studies. The discussion will also compare the full sample and each of the subsamples, banking and non-banking employees, and provide a summary of the chapter.

\subsection{PERCEIVED RETIREMENT ADEQUACY}

The first objective of the study was to assess whether employees in Lesotho perceive themselves to be adequately prepared for retirement. Perceived RA was measured on a seven-point scale and the descriptive results from Chapter 4 found a mean score of 3.74 and a standard deviation of 1.475 for perceived RA, indicating generally low levels of perceived $R A$, as this score falls between "neutral" and "disagree to some extent" with respect to perceptions of retirement adequacy. Furthermore, only $41 \%$ of respondents in this study reported scores of above 4 , indicating that they were generally confident about their retirement preparations. This study also found that employees working in the banking sector reported higher scores for perceptions of RA than non-banking employees. However, the difference between banking and non-banking employees' perceptions of RA was not statistically significant. 
Perceived RA has been a dependent variable in several studies. Studies by Van Dalen et al. (2010), Malroutu and Xiao (1995), and Segel-Karpas and Werner (2014) associated retirement confidence with a number of psychological and socio-economic predictors. When comparing scores related to perceptions of RA to the current study's scores, Van Dalen et al. (2010), Chou et al. (2015), and Malroutu and Xiao (1995) reported RA mean scores of 3.8, 2.81 and 3.9 respectively. Van Dalen et al. (2010) assessed workers using an identical survey distribute to Dutch and American workers in 2007, while Malroutu and Xiao (1995) collected data in 1989 from personal interviews with a large number of randomly selected households in the US. These scores were, however, measured on fivepoint scales, and therefore cannot be directly compared to a seven-point scale. However it does appear that these studies showed individuals had relatively higher retirement adequacy scores compared to the current Lesotho sample. . Van Dalen et al. (2010) found that half of their sample, both from the Netherlands and America, were confident about their retirement. Results from the data analysis in chapter 4 of this study found that $41 \%$ of the sample had average scores above 4 and were confident about their retirement. Therefore, the RA scores and percentage of those who believe they are adequately preparing for retirement for this study was lower than that found in prior studies. The expectation is that the level of retirement confidence in the USA and other European countries will be higher than in Africa because of well- developed retirement infrastructure, policies and various financial education initiatives. . The next section discusses the findings related to the independent variables in the study, from both a bivariate and multivariate perspective, and compares these findings to previous studies in order to address the second and third research objectives.

\subsection{RELATIONSHIP BETWEEN FINANCIAL LITERACY AND PERCEIVED RETIREMENT ADEQUACY}

Researchers such as Segel-Karpas and Werner (2014) argue that people who perceive themselves to have higher levels of $\mathrm{FL}$ also have higher levels of retirement savings. As there are potential differences between objective and subjective FL, 
these were considered as separate variables in the present study, and the discussion below first considers subjective FL, and then objective FL.

To determine the relationship between subjective $\mathrm{FL}$ and perceived RA, the relationship is tested using the following hypothesis:

$H_{0}$ : There is no relationship between subjective $F L$ and $R A$.

$\mathrm{H}_{\mathrm{a}}$ : There is a positive relationship between subjective assessed FL and RA.

When considering the results of the bivariate analysis, this study found that there was a positive correlation between subjectively assessed FL and perceived RA for the full sample. Looking at the results for each of the subsamples, banking and nonbanking, there was a positive relationship between subjectively assessed FL and perceived RA, indicating that those with higher levels of subjectively assessed FL also demonstrated high levels of perceived RA.

In the multivariate context, this study found that subjectively assessed FL was a predictor of RA for the full sample. Similarly, subjectively assessed FL was found to be a predictor of RA for the non-banking sample. However, the results showed that subjectively assessed financial knowledge was not a predictor of perceived RA for the banking subsample.

These findings are generally consistent with prior studies by Robb and Woodyard (2011), Babiarz and Robb (2013), Scheresberg (2013), Lusardi and Mitchell (2011), and Bucher-Koenen and Lusardi (2011) who found a positive relationship between respondents' subjectively assessed FL and various good financial behaviours, such as saving for retirement. In particular the study confirms the findings of Van Dalen et al. (2010) that subjective financial knowledge is positively related with perceived RA. Robb and Woodyard (2011) found that financial knowledge was an important factor in financial decision making and had a significant impact on financial behaviour among a sample of 1488 American participants, but they found that more than half of those who believed they had a fair amount of financial knowledge actually knew very little. Similarly, Scheresberg (2013) found that respondents' subjective financial 
knowledge assessments did not mirror the objective FL measures. Many respondents gave themselves high scores, yet they did not demonstrate a high level of $\mathrm{FL}$.

This study also tested the relationship between objectively assessed FL and perceived RA where basic and advanced FL were tested. To determine the relationship between objectively assessed financial knowledge and perceived RA, the relationship was tested using the following hypothesis:

$\mathrm{H}_{0}$ : There is no relationship between RA and objectively assessed FL.

$\mathrm{H}_{\mathrm{a}}$ : There is a positive relationship between RA and objectively assessed FL.

From a bivariate perspective, this study found a statistically significant positive relationship between objectively assessed FL and RA. The same was found for each of the subsamples. Therefore those who showed higher levels of objectively assessed financial knowledge had higher levels of perceived RA. In a multivariate context, similar results were found. Results from this study found objectively assessed financial knowledge to be a predictor of perceived RA for the full sample. For those in the non-banking subsample, objectively assessed financial knowledge was a predictor of perceived RA, but for those in the banking subsample it was not a significant predictor of perceived RA.

The results above are generally consistent with prior studies done by Clark and d'Ambrosio (2002); Lusardi and Mitchell (2007), Scheresberg (2013), and BucherKoenen and Lusardi (2011) who also found a positive relationship between financial knowledge and various positive financial behaviours. In a multivariate context, the findings of this study appear to be consistent with research done by Babiarz and Robb (2013) who found that objective measures of financial knowledge were significant determinants of the propensity to save. The next section looks at the relationship between FTP and perceived RA. 


\subsection{THE RELATIONSHIP BETWEEN FUTURE TIME PERSPECTIVE AND PERCEIVED RETIREMENT ADEQUACY}

Hershey and Mowen (2000) and Jacobs-Lawson and Hershey (2005) are of the view that individuals that are future orientated are more likely to plan and save for retirement. To determine the relationship between FTP and perceived RA, the relationship was tested using the following hypothesis:

$\mathrm{H}_{0}$ : There is no relationship between FTP and RA.

$\mathrm{H}_{\mathrm{a}}$ : There is a positive relationship between FTP and RA.

From a bivariate perspective, this study found that there was a statistically significant positive relationship between FTP and RA for the full sample. A positive relationship was also found for each of the subsamples, where banking and nonbanking employees' FTP score was related to higher retirement savings. This study also conducted a multivariate analysis, where all the variables were entered into a regression model. This study found FTP to be predictor of RA for the full sample and non-banking sample. However, the same was not found for the banking employee sample where FTP was not a significant predictor of perceived RA. It can there be concluded that for the full sample and the non-banking subsample that there is a positive relationship between FTP and perceived RA where higher levels of FTP were associated with higher levels of perceived RA.

These findings are generally consistent with studies done by Jacobs-Lawson and Hershey (2005), Chou et al. (2015), and Van Dalen et al. (2010) who found future time orientation to be positively associated with RA. Furthermore, Chou et al. (2015) and Dalen et al. (2010) found FTP to be a predictor of RA in a multivariate context. Jacobs-Lawson et al. (2008) also associated FTP with time spent planning for retirement, where the study revealed that FTP was positively related to time spent planning for retirement. These findings therefore associate higher levels of FTP with higher levels of perceived RA. 


\subsection{THE RELATIONSHIP BETWEEN FINANCIAL RISK TOLERANCE AND RETIREMENT ADEQUACY}

Researchers such as Yao et al. (2004) are of the view that FRT influences a wide range of household decisions. The consequence of this is that many households with low levels of risk tolerance struggle with achieving adequate retirement savings and other financial goals. To determine the relationship between FRT and perceived RA, the following hypothesis was tested:

$\mathrm{H}_{0}$ : There is no relationship between FRT and RA.

$\mathrm{H}_{\mathrm{a}}$ : There is a relationship between FRT and RA.

From a bivariate perspective, this study found that there was a statistically significant positive relationship between FRT and RA for the full sample and for the nonbanking subsample. The results for the banking subsample found that the relationship between FRT and perceived RA was not statistically significant. In a multivariate context, results did not point to FRT being a predictor of RA both for the full sample and each of the subsamples. This finding is contrary to what JacobsLawson and Hershey (2005) and Joo and Pauwels (2002) found, as their studies indicated that higher FRT was associated with higher RA scores. However in the Joo and Pauwels (2002) study this finding only related to women, whereas there was no statistically significant relationship between these variables for men. Findings from Jacobs-Lawson and Hershey (2005) indicated that FTP and risk tolerance interacted with one another to influence retirement saving, and therefore in the current study this interaction might explain these contradictory findings, however, investigation of this interaction is beyond the scope of the current study, but presents an area for future research.

\subsection{DEMOGRAPHIC VARIABLES AND PERCEIVED RETIREMENT ADEQUACY}

Malroutu and Xiao (1995), and Jacob-Lawson and Hershey (2008) argue that demographic variables are predictors of retirement saving and perceived RA. The findings related to each of the variables included in the current study are discussed in more detail below. 
The relationship between gender and RA was tested by the following hypothesis:

$\mathrm{H}_{0}$ : The mean RA score of males is not different from females.

$\mathrm{H}_{\mathrm{a}}$ : The mean RA score of males is higher than for females.

From a bivariate analysis perspective, this study found that the difference between perceived RA for males and females was not significantly different. Therefore there is no statistically significant difference between the RA scores for men and women for the full sample and both subsamples. In a multivariate context, gender was also found not to be a predictor of perceived RA for either the full sample or the subsamples.

Fisher (2010) and Segel-Karpas and Werner (2014) found differences between females and males: women were less likely to save in the short term than their male counterparts. Similar findings were presented by Malroutu and Xiao (1995), where results of the study indicated that females were less likely to perceive themselves as having adequate retirement income. Malroutu and Xiao (1995) attributed this to women not having a choice about whether and where to work and to the breaks in their employment. Furthermore, women might struggle to find employment, endure layoffs or struggle with negotiating benefits. The findings of this study differ from existing literature and highlight the view presented by Noone et al. (2010) who argue that research has focused on the role of men with regard to retirement saving, ignoring the increasing presence of women in the workplace. Therefore, the findings of the present study provide some insight into the perception of RA of women in the workplace.

The relationship between age and RA was tested with the following hypothesis:

$\mathrm{H}_{0}$ : There is no relationship between age and RA.

$\mathrm{H}_{\mathrm{a}}$ : There is a positive relationship between age and RA.

In a bivariate context, this study found that there was no statistically significant relationship between the perceived RA scores and age for the full sample and both subsamples. In a multivariate context, this study found age to be a predictor of RA 
for the banking employees. The results suggested that being older is associated with a higher level of perceived RA. The same results were not found for the full sample and non-banking employees.

Van Rooij et al. (2012) and Jacob-Lawson et al. (2008) found a strong correlation between age and retirement saving. In their study, Segel-Karpas and Werner (2014) also found age to be a significant predictor of perceived RA, which is consistent with the findings of this study only for the subsample of banking employees.

In a similar manner, the relationship between marital status and RA was tested using the following hypothesis:

$\mathrm{H}_{0}$ : The mean RA score of married individuals is not different from unmarried individuals.

$\mathrm{H}_{\mathrm{a}}$ : The mean RA score of married individuals is higher than for unmarried individuals.

This study found no statistically significant difference between the perceived RA scores for single people versus married people for the full sample and both subsamples. The multivariate analysis also found that marital status was not a predictor for RA for any of the samples. The findings of the current study therefore contrast with Montalto's (2000) study which found that households with married couples were more likely to hold retirement assets than households of unmarried individuals. Segel-Karpas and Werner (2014) found that being married was negatively associated with perceived financial preparedness for retirement.

The relationship between education and RA was tested using the hypothesis below:

$\mathrm{H}_{0}$ : The mean RA score of those with lower levels of education is not different from those with postgraduate qualifications.

$\mathrm{H}_{\mathrm{a}}$ : The mean RA score of those with lower levels of education is lower than those with postgraduate qualifications

Results from the bivariate analysis in this study found that those with lower levels of education reported lower perceived RA than those with postgraduate qualifications 
for the full sample and banking subsample. In contrast, for the non-banking subsample, those with lower levels of education did not have statistically significant different perceived RA scores than those with postgraduate qualifications._Therefore, there is a statistically significant difference between the perceived RA for those with a higher level of education than those with a lower education level for the full sample and banking employees subsample and no statistically significant difference for the non-banking subsample. For the full sample and the banking employees subsample, those with higher education levels reported higher levels of perceived RA than those with lower education levels. However, in a multivariate context, the level of education was not found to be a predictor of RA for the full sample or either of the subsamples.

Jacob-Lawson (2008) revealed that educational level had a statistically significant relationship with perceived RA. Those with lower levels of education had lower mean scores than those with higher levels of education which supports the bivariate findings in this study with respect to the full sample and banking subsample. In the multivariate context, Kim et al. (2005) and Segel-Karpas and Werner (2014) found that education was not a predictor of retirement confidence. Therefore, this study's findings in a multivariate context were consistent with those from prior studies.

The relationship between income and RA was tested using the following hypothesis:

$\mathrm{H}_{0}$ : The mean RA score for those with an income below M10 000 does not differ from that of those with an income of M10 000 or more.

$\mathrm{H}_{\mathrm{a}}$ : The mean RA score for those with an income below M10 000 is lower than that of those with an income of M10 000 or more.

The hypothesis was tested for household income. For household income levels, this study found that there was a statistically significant difference between the perceived RA scores of those with higher household income, compared to those with lower household income for the full sample and the banking employees subsample. In both cases, those with higher household income reported higher levels of perceived RA than those with lower household income. In contrast, for the non-banking employee subsample, there was no statistically significant difference. 
A multiple regression analysis was conducted to determine the predictors of RA. In this analysis, only household, and not individual income, was tested in the model as discussed in Chapter 4. In the multivariate analysis, household income was found to be a predictor of perceived RA for the banking employee sample but not for the full sample or the non-banking sample. The results in this study with respect to banking employees support the findings of previous researchers Malroutu and Xiao (1995) who found that income had a significant relationship with adequacy of retirement income and Jacobs-Lawson et al. (2008) who also found that higher levels of income were related to higher levels of perceived RA.

\subsection{SUMMARY AND CONCLUSION}

This chapter discussed the findings where, on average, respondents in this study were not confident about their retirement. This study concluded that for the full sample in a multivariate model, three independent variables were predictors of RA: higher levels of objective FL, subjective FL and FTP were associated with higher levels of perceived RA.

The multivariate model for the banking employees subsample found that higher levels of FTP, higher household income and higher age were predictors of perceived RA. The non-banking sample presented similar findings to the full sample where objective FL, subjective FL and FTP were positive predictors of perceived RA. These findings indicated that higher levels of objective and subjective FL and of FTP were associated with higher levels of perceived RA. 


\section{CHAPTER 6}

\section{CONCLUSION}

\subsection{SUMMARY OF FINDINGS}

This study set out to achieve three objectives. The first objective was to determine whether employees in Lesotho perceived themselves to be adequately prepared for retirement. The second objective was to explore the link between FL, FRT, FTP and perceived RA. The last objective was to determine whether there were differences in the predictors of RA when comparing those employed in financial institutions to those in non-financial institutions. The study adopted a survey questionnaire with questions developed by Lusardi and Mitchell (2007, 2009, 2011), Van Rooij et al. (2012), and Jacobs-Lawson and Hershey (2005) to measure variables such as FL, FTP and FRT and determine relationships between the dependent and independent variables from a bivariate and multivariate perspective.

In addressing the first objective, this study considered the overall perceptions of RA among a sample of employees in Lesotho. This study found that the full sample and the non-banking sample of employees in Lesotho had low confidence levels about retirement and their perceived RA scores were lower than those observed in other studies carried out in a variety of countries.

The second objective was to explore the link between FL, FRT, FTP and perceived RA, and in terms of the third research objective, determine whether there were differences in the predictors for those working in the financial sector compared to those outside of this sector. From a bivariate perspective, this study found a statistically significant positive relationship between both subjectively assessed financial knowledge and objectively assessed financial knowledge, and perceived RA for the full sample and each of the subsamples. Those who reported higher levels of subjectively and objectively assessed financial knowledge had higher levels of perceived RA. In a multivariate context, both subjectively assessed and objectively assessed financial knowledge were statistically 
significant predictors of perceived RA for the full sample and the non-banking sample, but not for the banking sample.

With respect to FTP from a bivariate perspective, this study found a statistically significant positive relationship between FTP and RA for the full sample and both the subsamples. Those who reported higher levels of FTP had higher levels of perceived RA. In the multivariate model, results showed that FTP was a statistically significant predictor of perceived RA for the full sample and both the subsamples.

The third bivariate relationship was between FRT and perceived RA. From a bivariate perspective, this study found that there was a statistically significant positive relationship between FRT and RA for the full sample and the non-banking subsample, but not for the banking employee subsample. In the multivariate model, FRT was not a statistically significant predictor for any of the models.

This study also looked at the relationship between various demographic variables and perceived RA. From a bivariate analysis perspective, this study found that perceived RA scores for males and females were not significantly different and neither were there statistically significant differences in the scores of married and single respondents. Nor was there a statistically significant relationship between age and perceived RA.

Another demographic variable tested to determine the relationship with perceived RA, was education. Results from the bivariate analysis reported that there was a relationship between education and perceived $R A$, where the first-degree category reported significantly lower RA scores for the full sample and the banking subsample than those with postgraduate qualifications. The last relationship was between the perceived household income and RA. This study found that there was a statistically significant difference between the perceived RA scores of those with higher household income and those with lower household income for the full sample and the banking employees subsample. 
In the multivariate models for the full sample and the non-banking subsample, none of the demographic variables were statistically significant predictors of perceived RA. However, in the banking subsample both age and household income were found to be significant predictors with those who were older, and those with higher incomes both being more likely to report higher levels of perceived RA.

In conclusion, with respect to research objectives two and three, in a multivariate context, this study concluded that for the full sample, three independent variables were predictors of perceived RA: higher levels of objective and subjective $\mathrm{FL}$ and FTP were associated with higher levels of perceived RA. In the multivariate model, FTP, household income and age were found to be predictors for banking employees: higher levels of FTP, higher household income and being older were all associated with higher levels of perceived RA.

Lastly, the non-banking sample presented similar findings to those found for the full sample; where objective $\mathrm{FL}$, subjective FL and FTP were positive predictors of perceived RA. These findings indicated that higher levels of objective and subjective FL, as well as a higher level of FTP were associated with higher levels of perceived RA.

\subsection{CONCLUSIONS}

This study offers new insights for financial planners, educators and policy makers about the profile of individuals who are confident about retirement savings, and how this contrasts with those who are not confident so that they are perhaps able to tailor advice and policies to particular sub groups of the population. Furthermore, this research lays the foundation for future research in the field of retirement saving in Lesotho and other African countries, where results indicated and confirmed that there psychological factors related to employees' perceptions regarding their preparedness for retirement.

This study found that statistically significant relationships exist between perceived RA and subjectively and objectively assessed financial knowledge, FRT and FTP from a bivariate perspective. The psychological factors that play a role in complex financial decisions therefore cannot be ignored by industry role players as these factors are shown to be associated with perceived RA. 
This study set out to determine whether there were differences in the predictors of RA when comparing those employed in the financial institutions with those from nonfinancial institutions. The assumption was that employees working in the banking industry might be more financially literate and as a consequence be better prepared for retirement than those working in the non-banking industry.

This study found that banking employee' RA scores, FTP, FRT, and objectively measured FL scores were not statistically significantly different from non-banking employees. This study therefore confirmed that the difference between those working in financial institutions and those working in non-financial institutions was not as significant as expected; other than the fact that those in the banking sector subjectively assessed themselves as having higher levels of financial knowledge compared to non-banking employees.

In a multivariate context, this study however confirmed differences between employees working in financial institutions and those working in non-financial institutions with respect to the predictors of perceived RA. The conclusion reached by this study was that the perceived RA of employees working in the banking industry in Lesotho was predicted by FTP, their household income and their age. A difference was noted for employees working in the non-banking industry where the perceived RA was predicted by subjectively and objectively assessed financial knowledge and FTP. These findings therefore confirmed that there were differences in the predictors of RA when comparing those employed in financial institutions to those from non-financial institutions; where those employees in the banking industry who reported higher levels of FTP, higher household income and were older, reported higher levels of retirement confidence. Similarly, this study concluded that those non-banking employees who reported higher levels of subjectively and objectively assessed financial knowledge and FTP had higher levels of retirement confidence. The findings and conclusions in this study were exploratory in nature and cannot be generalised to the broader working population of Lesotho. 


\subsection{SUMMARY OF CONTRIBUTIONS}

This study introduced an African context, focusing on Lesotho in particular to get a clearer understanding of how confident individuals are about their retirement preparation because of the Lesotho's very limited retirement system. This study also introduced a comparison between employees working in different industries in Lesotho to better understand what factors are associated with whether individuals perceive themselves to be adequately prepared for retirement, as this may differ from countries where retirement systems are more advanced and where public pension plans are in place to provide an additional safety net during retirement. This study lays the foundation for future research as very little research has been done that focused on the African continent. This study also contributes to the existing literature where the findings are in accordance with previous literature in this field also confirming that financial knowledge, FTP and household income are predictors of RA.

\subsection{SUGGESTIONS FOR FURTHER RESEARCH}

The first suggestion for future research is to collect data from a more representative sample of employees in Lesotho. This might reveal new evidence that could contribute to a better understanding of the relationships between the various predictors in a broader Lesotho context. The second suggestion for future research is to study perceptions of RA and retirement confidence of employees in other African countries. Currently, most literature focuses on other continents such as America, Asia and Europe. This will not only present an opportunity for the development of the literature in this field, but will also provide industry role players in Lesotho and across Africa to enhance their product offering. The dynamics in Africa are different from other continents and the findings could provide a better understanding of the different factors influencing employees' saving decisions. The third suggestion for future research is to consider actual RA and compare it to people's perceptions of RA to determine whether there are differences. 


\section{LIST OF REFERENCES}

Agarwal, S., Amromin, G., Ben-David, I., \& Chomsisengphet, S. (2015). Financial literacy and financial planning: Evidence from India. Journal of Housing Economics, 27, 4-21.

Andrew, J. (2004). The conversion of member's rights in South African retirement funds from defined benefits to defined contributions and the statutory apportionment of the resulting actuarial surplus. Actuarial Society of South Africa, 4, 1-62.

Antolin, P. (2009). Private pensions and the financial crisis: How to ensure adequate retirement income from dc pension plans. Financial Market Trends, 2, 1-21.

Babiarz, P., \& Robb, C. A. (2013). Financial literacy and emergency saving. Journal of Family and Economic Issues, 35, 40-50.

Baholo, S. (1994). Income tax (superannuation and life assurance) regulations. https://www.lesotholii.org/ls/legislation/s//1994/24

Banks, J., Blundell, R., Disney, R., \& Emmerson, C. (2002). Retirement, pensions and the adequacy of saving: A guide to the debate. Fiscal Studies, 29, 1-40.

Barretta, G. F., \& Kecmanovic, M. (2013). Changes in subjective well-being with retirement: Assessing savings adequacy. Applied Economics, 45(35), 48834893.

Becker, G. S. (1962). Irrational behavior and economic theory. Journal of Political Economy, 70(1), 1-13.

Benartzi, S., \& Thaler, R. H. (2007). Heuristics and biases in retirement savings behavior. The Journal of Economic Perspectives, 21(3), 81-104.

Bender, K. A. (2011). An analysis of well-being in retirement: The role of pensions, health and 'voluntariness' of retirement. The Journal of Socio-Economics, 41, 424-433.

Bernheim, B. D., \& Garrett, D. M. (2003). The effects of financial education in the workplace: Evidence from a survey of households. Journal of Public Economics, 87, 1487-1519.

Bhattacherjee, A. (2012). Social science research: Principles, methods, and practices. USF Tampa Bay Open Access Textbooks Collection. Book 3. 
Binswanger, J., \& Carman, K. G. (2012). How real people make long term decisions: The case of retirement preparation. Journal of Economic Behavior \& Organisation, 81, 39-60.

Binswanger, J., \& Schunk, D. (2012). What is an adequate standard of living during retirement? Pension Economics and Finance, 11(02), 203-222.

Bodie, Z. (1989). Pensions as retirement income insurance. (NBER Working Paper No. 2917). Cambridge, MA: National Bureau of Economic Research.

Bodie, Z., Marcus, A. J., \& Merton, R. C. (1988). Defined benefit versus defined contribution pension plans: What are the real trade-offs? Pensions in the U.S. Economy (p139-162). Chicago, University of Chicago Press.

Brady, P. J. (2010). Measuring retirement resource adequacy. Pension Economics and Finance, 9(02), 235-262.

Browning, M., \& Crossley, T. F. (2001). The life-cycle model of consumption and saving. The Journal of Economic Perspectives, 15(3), 3-22.

Bucher-Koenen, T., \& Lusardi, A. (2011). Financial literacy and retirement planning in Germany. Journal of Pension Economics and Finance, 10(04), 565-584.

Butler, M.B.J., \& van Zyl, C.J. (2012). Retirement adequacy goals for South African households. South African Actuarial Journal, 12(1), 31-64.

Calasanti, T. M. (1996). Gender and life satisfaction in retirement: An assessment of the male model. Journal of Gerontology, 51B(1), 18-29.

Caldwell, J. G. (2010). Sample survey design for evaluation (the design of analytical surveys). Retrieved from http://www.foundationwebsite.org/SampleSurveyDesignForEvaluation.pdf

CBL. (2008). Introduction of government pension fund and its implication on inflation, savings and investment in Lesotho.http://www.centralbank.org.Is/publications/MonthlyEconomicReviews/ 2008/Econ_Rev_Sept_2008.pdf

Choi, J. J., Laibson, D., Madrian, B. C., \& Metrick, A. (2002). Defined contribution pensions: Plan rules, participant choices, and the path of least resistance. Tax Policy and the Economy, 16, 69-113.

Chou, K.-L., Yu, K.-M., Chan, W.-S., Wu, A. M., Zhu, A. Y. F., \& Lou, V. W. Q. (2015). Perceived retirement savings adequacy in Hong Kong: An 
interdisciplinary financial planning model. Ageing and Society, 35(08), 15651586.

Clark, R. L., \& d'Ambrosio, M. B. (2002). Financial education and retirement savings. Paper presented at the Retirement Implications of Demographic and Family Change Symposium, San Francisco.

Collins, J. M., \& O'Rourke, C. M. (2010). financial education and counselling - Still holding promise. The Journal of Consumer Affairs, 44(3), 483-498.

Coppock, M., Forte, D., Ncube, B., Ooka, E., Richards, K., \& Vyas, A. (2009). Lesotho. Retrieved from http://s3.amazonaws.com/zanran_storage/fic.wharton.upenn.edu/ContentPag es/22334018.pdf

Dalen, H. P. V., Henkens, K., \& Hershey, D. A. (2010). Perceptions and expectations of pension savings adequacy: A comparative study of Dutch and American workers. Ageing and Society, 30(05), 731-754.

De Clercq, B. \& Venter, J. (2009). Factors influencing a prospective chartered accountant's level of financial literacy: An exploratory study. Meditari Accountancy Research, 17, 47-60.

DiCenzo, J. (2007). Behavioral finance and retirement plan contributions: How participants behave, and prescriptive solutions. Employee Benefit Research Institute 301, 1-19.

Duflo, E., \& Saez, E. (2003). Implications of information and social interactions for retirement saving decisions. Pension Research Council, 13, 1-28.

Fernandes, D., Lynch, J. G., \& Netemeyer, R. G. (2014). Financial literacy, financial education, and downstream financial behaviors. Management Sciences, 60(8), 1861-1883.

Field, A. (2009). Discovering Statistics Using IBM SPSS Statistics: Sage Publications.

Fisher, P. J. (2010). Gender differences in personal saving behaviors. Journal of Financial Counselling and Planning, 21(1), 14-22.

Grable, J. (2000). Financial risk tolerance and additional factors that affect risk taking in everyday money matters. Journal of Business and Psychology, 14(4), 626630. 
Gustman, A. I., \& Steinmeier, T. L. (2005). Imperfect knowledge of social security and pensions. Industrial Relations, 44(2), 373-395.

Haveman, R., Holden, K., Romanov, A., \& Wolfe, B. (2007). Assessing the maintenance of savings sufficiency over the first decade of retirement. International Tax Public Finance, 14, 481-502.

Hershey, D. A. (2004). Psychological influences on the retirement investor. CSA: Certified Senior Advisor, 22, 31-39.

Hershey, D. A., Jacobs-Lawson, J. M., McArdle, J. J., \& Hamagami, F. (2007). Psychological foundations of financial planning for retirement. Journal of Adult Development, 14, 26-36.

Hershey, D. A., \& Mowen, J. C. (2000). Psychological determinants of financial preparedness for retirement. The Gerontological Society of America, 40(6), 687-697.

Ippolito, R. A., \& Thompson, J. W. (2000). The survival rate of defined benefit plans 1987-1995. Industrial Relations, 39(2), 228-244.

Jacobs-Lawson, J. M., \& Hershey, D. A. (2005). Influence of future time perspective, financial knowledge, and financial risk tolerance on retirement saving behaviors. Financial Services Review 14, 331-344.

Jacobs-Lawson, J. M., \& Hershey, D. A. (2008). Perceptions of financial stability in retirement: Do Americans really know what to expect? Advances in Psychology Research, 22, 123-136.

Jacobs-Lawson, J. M., Hershey, D. A., \& Neukam, K. A. (2008). Gender differences in factors that influence time spent planning for retirement. Journal of Women \& Aging, 16(3-4), 55-69.

Joo, S.-H., \& Pauwels, V. W. (2002). Factors affecting workers' retirement confidence: A gender perspective. Association for Financial Counselling and Planning Education, 13(2), 1-11.

Keller, G., \& Warrack, B. (2003). Statistics for management and economics ( $6^{\text {th }}$ ed.). Calfonia, United States of America: Curt Hinrichs.

Kim, J., Kwon, J., \& Anderson, E. A. (2005). Factors related to retirement confidence: Retirement preparation and workplace financial education. Association for Financial Counselling and Planning Education, 16(2), 77-89. 
Knoef, M., J., Alessie.,Caminda, K., Goudswaard,K., \& Kalwiij, A. (2015). Retirement preparation and workplace financial education. Association for Financial Counseling and Planning Education, 16(2), 77-89.

Laibson, D. I., Repetto, A., \& Tobacman, J. (1998). Self-control and saving for retirement. Brookings Papers on Economic Activity, 1(1), 91-172.

Leedy, P. D., \& Ormrod, J. E. (2013). Practical research: Planning and design (10th ed.). New York, NY United States of America: Pearson Education.

Li, J., Montalto, C. P., \& Geistfeld, L. V. (1996). Determinants of financial adequacy for retirement. Financial Counselling and Planning Education, 7, 39-44.

Income Tax Public Ruling: Terminal Benefits, 3,18,32,95,99 and 156 1-16 (2012).

Lusardi, A. (2005). Saving and the effectiveness of financial education. In O. S. Mitchell \& S. P. Utkus (Eds.), Pension design and structure: New lessons from behavioral finance (157-184). New York, NY: Oxford University Press Inc.

Lusardi, A., \& Mitchell, O. S. (2005). Financial literacy and planning: Implications for retirement wellbeing (Working Paper 2005-108). Ann Arbro, MI: University of . Michigan Press, Michigan Retirement Research Center.

Lusardi, A., \& Mitchell, O. S. (2007). Financial literacy and retirement planning: New evidence from the Rand American Life Pane (Working Paper 2007-157). Ann Arbo, MI: University of Michigan Press, Michigan Retirement Research Center.

Lusardi, A., \& Mitchell, O. S. (2009). How ordinary consumers make complex economic decisions: Financial literacy and retirement readiness.(NBER working paper 15350), 91

Lusardi, A., \& Mitchell, O. S. (2011). Financial literacy around the world: An overview. Journal Of Pension Economics and Finance, 10, 497-508.

MacFarland, D. M., Marconi, C. D., \& Utkus, S. P. (2003). "Money attitudes" and retirement plan design: One size does not fit all. In O. S. Mitchell \& S. P. Utkus (Eds.), Pension design and structure: New lessons from behavioral finance (97-120). New York, NY: Oxford University Press Inc.

Madrian, B. C., \& Shea, D. F. (2000). The power of suggestion: Inertia in 401(k) Participation and Saving Behavior. (NBER Working Paper No. 7682). Cambrige, MA: National Bureau of Economic Research. 
Malroutu, Y. L., \& Xiao, J. J. (1995). Perceived adequacy of retirement income. Financial Counseling and Planning Education, 6, 17-24.

Metropolitan. (2015, June). Time is a valuable tool for long-term investors. Metrolive: Employee Benefits Newsletter, 7, 2-14.

Mhango, M. (2013). Constitutional challenges in the implementation of a compulsory pension fund: The case of Lesotho. Paper presented at the IRF Conference at the University of the Witwatersrand, Johannesburg, South Africa.

Mitchell, O. S., \& Utkus, S. P. (2004). Lessons from behavioral finance for retirement plan design. New York, NY : Oxford University Press Inc.

Montalto, C. P. (2000). Retirement savings of American households: Asset levels and adequacy. Report to the Consumer Federation of America and Direct Advace.com. Consumer and Textiles Services Department, College of Human Ecology, Ohio State University.

Mullock, K., \& Turcotte, J. (2012). Financial literacy and retirement saving. (Working Paper 2012-01). Retrieved from http://www.fin.gc.ca/pub/pdfs/wp2012-01e.pdf

Munnell, A. H., Webb, A., \& Golub-Sass, F. (2007). Is there really a retirement savings crisis? An NRRI Analysis (7-11). Center For Retirement Research, Boston College.

National Treasury, Republic of South Africa. 2004.Retirement fund reform: A discussion paper.Retrieved from http://www.treasury.gov.za/public\%20comments/Retirement\%20Fund\%20Ref orm\%20A\%20Discussion\%20Paper.pdf

Noone, J., Alpass, F., \& Stephens, C. (2010). Do men and women differ in their retirement planning? Testing a theoretical model of gendered pathways to retirement preparation. Research on Aging, 32(6), 715-738.

Ntalianis, M., \& Wise, V. (2011). The role of financial education in retirement planning. Australasian Accounting Business and Finance 5(2), 23-37.

Phua, V. C., \& McNally, J. W. (2008). Men planning for retirement - Changing meanings of preretirement planning. Journal of Applied Gerontology, 27(5), 588-608.

Poterba, J., Rauh, J., Venti, S., \& Wise, D. (2007). Defined contribution plans, defined benefit plans, and the accumulation of retirement wealth. Journal of Public Economics, 91, 2062-2086. 
Power, M. L., Hobbs, J. M., \& Ober, A. (2011). An empirical analysis of the effect of financial education on graduating business students' perceptions of their retirement planning familiarity, motivation and preparedness. Risk Management and Insurance Review, 14(1), 89-105.

Private Pensions Bill, 2015. Government of Lesotho.

Reno, V. P., \& Lavery, J. (2007). Social security and retirement income adequacy. National Academy of Social Insurance, 25, 1-12.

Reyers, M., van Schalkwyk, C. H., \& Gouws, D. G. (2014). The rationality of retirement preservation decision: A conceptual model. Journal of Economic Behavioral Studies, 6(5), 418-431.

Reyers, M., van Schalkwyk, C. H., \& Gouws, D. G. (2015). Rational and behavioural predictors of pre-retirement cash-outs. Journal of Economic Psychology, 47, 23-33.

Robb, C. A., \& Woodyard, A. S. (2011). Financial knowledge and best practice behavior. Financial Counselling and Planning Education, 22(1), 60-70.

Scheresberg, C. d. B. (2013). Financial literacy and financial behavior among young adults: Evidence and implications. Advancing Education in Quantitative Literacy, 6(2), 1-24.

Segel-Karpas, D., \& Werner, P. (2014). Perceived financial retirement preparedness and its correlates: A national study in Israel. The International Journal of Aging and Human Development, 79(4), 279-301.

Seith-lyengar, S., Jiang, W., \& Huberman, G. (2004). How much choice is too much? Contributions to $401(\mathrm{k})$ retirement plans. Pension Research and structure: New Lessons from behavioral finance, 83,84-87 Council.

Sekaran, U., \& Bougie, R. (2013). Research methods for business: A skill-building approach (6th ed.). West Susses, United Kingdom: Wiley.

Selnow, G. W. (2004). Motivating retirement planning: Problems and solutions. In O. S. Mitchell \& S. P. Utkus (Eds.), Pension design and structure: New lessons from behavioral finance. New York, NY: Oxford University Press Inc.

Shambare, R., \& Rugimbana, R. (2012). Financial literacy among the educated: An exploratory study of selected university students in South Africa. Thunderbird International Business Review, 54(4), 581-590. 
Skinner, J. (2007). Are you sure you're saving enough for retirement? (NBER, 12981). Cambridge, MA: National Bureau of Economic Research.

Stewart, F., \& Yermo, J. (2009). Pensions in Africa. (OECD Working Paper on Insurance and Private Pensios No. 30), OECD Publishing.

Stoller, M. A., \& Stoller, E. P. (2003). Perceived income adequacy among elderly retirees. The Journal of Applied Gerontology, 22, 230-251.

Sulaiman, E. K. (2012). An empirical analysis of financial risk tolerance and demographic features of individual investors. Procedia Economics and Finance, 2, 109-111.

Thahane, H. T. T. (2008). The race for jobs, better life, high and sustainable growth must be won. Budget Speech to Parliament for the 2008/2009 Fiscal Year, Maseru, Lesotho, February 13, 2008.

Van Rooij, M. C. J., Lusardi, A., \& Alessie, R. J. M. (2012). Financial literacy, retirement planning and household wealth. The Economic Journal, 122, 449478.

Van Rooij, M., Lusardi, A., \& Alessie, R. J. M. (2011). Financial literacy and stock market participation. Journal of Financial Economics, 101(2), 449-472.

Van de Venter, G., Michayluk, D., \& Davey, G. (2012). A longitudinal study of financial risk tolerance. Journal of Economic Psychology, 33, 794-800.

Wade, A. (2015). The Lesotho Review: An overview of the Kingdom of Lesotho's economy. Retrieved from http.www.lesothoreview.com/financial-servicesinvestment.php

Yao, R., Hanna, S. D., \& Lindamood, S. (2004). Changes in financial risk tolerance, 1983-2001. Financial Services Review, 13(4), 249-266.

Yu, T.-Y., Huang, H.-C., Chen, C.-L., \& Lin, Q.-T. (2012). Generating effective defined contribution plan using simulation optimization approach. Expert Systems with Applications, 39(3), 2684-2689. 
Before continuing with this questionnaire, please place a cross in the box alongside to indicate that you have read and understand the information provided in the above letter and you give your consent to participate in the study on a voluntary basis.

Section A:

1. What is your current age in years?

\section{What is your current job title?}

3. What is your gender?

a) Male

b) Female

4. What is the highest level of qualification you have completed?

a) Some secondary school education

b) ${ }^{3}$ Form E/Matric

c) Higher Diploma

d) First Degree (e.g. BCom, BA, BAdmin)

e) Honours Degree

f) Master's Degree

g) Doctorate Degree

5. What is your monthly individual after tax income?

a) Less than $M 10,000$ per month

b) $M$ 10,001- $M 20,000$ per month

c) M 20,001 - M 30,000 per month

d) $M$ 30,001 - M 40,000 per month

e) M 40,0001 - M50,000 per month

f) $M$ 50,001- M 60,000 per month

g) More than $\mathrm{M} 60,001$ per month

6. What is your monthly household after tax income?

a) Less than $M 10,000$ per month

\footnotetext{
${ }^{3}$ Form $E$ is an equivalent of Grade 12/Matric
} 
b) $M$ 10,001- $M 20,000$ per month

c) M20,001- M 30,000 per month

d) M30,001 - M 40,000 per month

e) M 40,000-M50,000 per month

f) M50,001 - M 60,000 per month

g) More than M60,001 per month

7. What is your marital status

a) Single

b) Married

c) Widowed

d) Divorced/ Separated

8. What is your ethnicity?

a) Black African

b) White

c) Indian

d) Coloured

e) Other

9. On a scale from 1 to 7 , where 1 means very low and 7 means very high, how would you rate your level of financial knowledge?

\begin{tabular}{|l|l|l|l|l|l|l|}
\hline 1 & 2 & 3 & 4 & 5 & 6 & 7 \\
\hline
\end{tabular}

\section{SECTION B:}

Questions 10 to 20 are multiple choice questions with four options. Please $\underline{\text { do }}$ not use a calculator. If you do not know the answer to a particular question, please do not guess and rather select the "Do not know" option.

10. Suppose you had M100 in a savings account and the interest rate was 2 per cent per year. After 5 years, how much do you think you would have in the account if you left the money to grow?

\begin{tabular}{|c|c|c|c|}
\hline A & B & C & d \\
More than M102 & Exactly M102 & Less than M102 & Do not know \\
\hline
\end{tabular}


11. Suppose you had M100 in a savings account and the interest rate is 20 per cent per year and you never withdraw money or interest payments. After 5 years, how much would you have on this account in total?

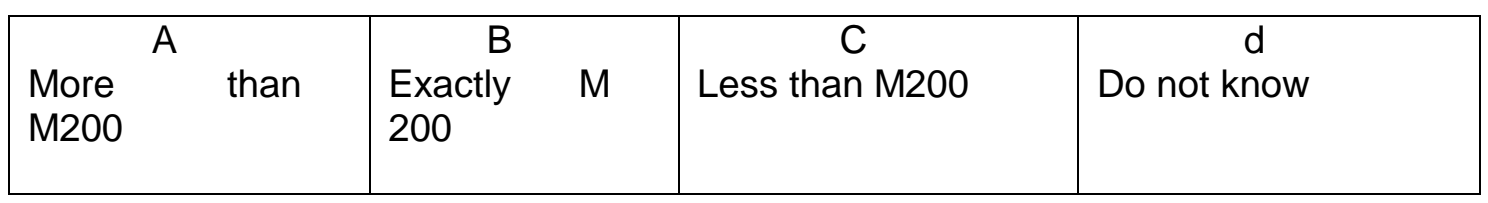

12. Imagine that the interest rate on your savings account was 1 per cent and inflation was 2 per cent per year. After 1 year, how much would you be able to buy with the money in this account?

\begin{tabular}{|c|c|c|c|}
\hline A & B & C & $d$ \\
More than today & Exactly the same & Less than today & Do not know \\
\hline
\end{tabular}

13. Assume a friend inherits $M 10,000$ today and his sibling inherits $M 10,0003$ years from now. Who is richer because of the inheritance?

\begin{tabular}{|c|c|c|c|}
\hline $\begin{array}{c}\text { A } \\
\text { My friend }\end{array}$ & B & C & $d$ \\
& His sibling & They equally rich & Do not know \\
\hline
\end{tabular}

14. Suppose that in the year 2017, your income has doubled and prices of all goods have doubled too. In 2017 , how much will you be able to buy with your income?

\begin{tabular}{|c|c|c|c|}
\hline $\begin{array}{c}\text { A } \\
\text { More than today }\end{array}$ & B & $\begin{array}{c}\text { C } \\
\text { Exactly the same }\end{array}$ & $\begin{array}{c}d \\
\text { Less than today }\end{array}$ \\
\end{tabular}

15. Which of the following statements describes the main function of the stock market?

\begin{tabular}{|c|c|c|c|}
\hline $\begin{array}{l}\quad \text { a } \\
\text { Stock } \\
\text { market } \\
\text { helps } \\
\text { predict } \\
\text { stock/share } \\
\text { earnings }\end{array}$ & $\begin{array}{c}\mathrm{b} \\
\text { The stock } \\
\text { market results } \\
\text { in an increase in } \\
\text { the prices of } \\
\text { stocks/shares }\end{array}$ & \begin{tabular}{l}
\multicolumn{1}{c}{ c } \\
The stock market \\
brings people \\
who want to buy \\
stocks/shares \\
together with \\
those who want \\
to sell \\
stocks/shares
\end{tabular} & $\begin{array}{c}\mathrm{d} \\
\text { None of } \\
\text { the above }\end{array}$ \\
\hline
\end{tabular}

16. Which of the following statements is correct?

\begin{tabular}{|c|c|c|c|}
\hline $\begin{array}{c}\text { A } \\
\text { Once one } \\
\text { invests in a } \\
\text { mutual } \\
\text { fund/unit }\end{array}$ & $\begin{array}{c}\text { B } \\
\text { Mutual fund/unit } \\
\text { trusts can invest } \\
\text { in several }\end{array}$ & $\begin{array}{c}\text { C } \\
\text { Mutual fund/ unit } \\
\text { trusts pay a } \\
\text { guaranteed rate of }\end{array}$ & $\begin{array}{c}\text { d } \\
\text { None of } \\
\text { the above }\end{array}$ \\
\hline
\end{tabular}




\begin{tabular}{|c|c|c|}
\hline $\begin{array}{l}\text { trust, one } \\
\text { cannot } \\
\text { withdraw } \\
\text { the money } \\
\text { in the first } \\
\text { year }\end{array}$ & $\begin{array}{l}\text { assets, for } \\
\text { example invest } \\
\text { in both shares } \\
\text { and bonds }\end{array}$ & $\begin{array}{l}\text { return which } \\
\text { depends on their } \\
\text { past performance }\end{array}$ \\
\hline
\end{tabular}

17. If the interest rates fall, what should happen to bond prices?

\begin{tabular}{|c|c|c|c|}
\hline $\begin{array}{c}\text { A } \\
\text { Rise }\end{array}$ & $\begin{array}{c}\text { B } \\
\text { Fall }\end{array}$ & $\begin{array}{c}\text { c } \\
\text { Stay the } \\
\text { same }\end{array}$ & $\begin{array}{c}\text { None of the } \\
\text { above }\end{array}$ \\
\hline
\end{tabular}

18. Considering a long time period (for example 10 or 20 years), which asset normally gives the highest return?

\begin{tabular}{|c|c|c|c|}
\hline $\begin{array}{c}\text { A } \\
\text { Savings } \\
\text { accounts }\end{array}$ & $\begin{array}{c}\text { B } \\
\text { Bonds }\end{array}$ & C & $\mathrm{d}$ \\
Stocks/Shares & Don't know \\
\hline
\end{tabular}

19. Normally, which asset displays the highest fluctuations over time?

\begin{tabular}{|c|c|c|c|}
\hline $\begin{array}{c}\text { A } \\
\text { Savings } \\
\text { accounts }\end{array}$ & B & C & d \\
\end{tabular}

20. When an investor spreads his money among different assets, does the risk of losing money:

\begin{tabular}{|c|c|c|c|}
\hline $\begin{array}{c}\text { A } \\
\text { Increase }\end{array}$ & $\begin{array}{c}\text { B } \\
\text { Decrease }\end{array}$ & $\begin{array}{c}\text { c } \\
\text { Stay the } \\
\text { same }\end{array}$ & $\begin{array}{c}d \\
\text { Don't know }\end{array}$ \\
\hline
\end{tabular}

21. True or false? Buying a company stock/share usually provides a safer return than a stock mutual fund/share unit trust?

\begin{tabular}{|c|c|c|}
\hline a & b & C \\
True & False & Don't know \\
\hline
\end{tabular}

22. True or false? Stocks/shares are normally riskier than bonds

\begin{tabular}{|c|c|c|}
\hline a & b & C \\
True & False & Don't know \\
\hline
\end{tabular}

\section{SECTION C}

The questions in this section require you to rate your response on a scale where $1=$ strongly disagree and $7=$ strongly agree. Please select the response that is most appropriate to you. 
23. I have made meaningful contributions to a voluntary retirement savings plan.

\begin{tabular}{|l|l|l|l|l|l|l|}
\hline 1 & 2 & 3 & 4 & 5 & 6 & 7 \\
\hline
\end{tabular}

24. Relative to my peers, I have saved a great deal for retirement.

\begin{tabular}{|l|l|l|l|l|l|l|}
\hline 1 & 2 & 3 & 4 & 5 & 6 & 7 \\
\hline
\end{tabular}

25. I have accumulated substantial savings for retirement.

\begin{tabular}{|l|l|l|l|l|l|l|}
\hline 1 & 2 & 3 & 4 & 5 & 6 & 7 \\
\hline
\end{tabular}

26. I have made a conscious effort to save for retirement.

\begin{tabular}{|l|l|l|l|l|l|l|}
\hline 1 & 2 & 3 & 4 & 5 & 6 & 7 \\
\hline
\end{tabular}

27. Based on how I plan to live my life in retirement, I have saved accordingly

\begin{tabular}{|l|l|l|l|l|l|l|}
\hline 1 & 2 & 3 & 4 & 5 & 6 & 7 \\
\hline
\end{tabular}

28. I follow the advice to save for a rainy day

\begin{tabular}{|l|l|l|l|l|l|l|}
\hline 1 & 2 & 3 & 4 & 5 & 6 & 7 \\
\hline
\end{tabular}

29. I enjoy thinking about how I will live years from now in the future.

\begin{tabular}{|l|l|l|l|l|l|l|}
\hline 1 & 2 & 3 & 4 & 5 & 6 & 7 \\
\hline
\end{tabular}

30. The distant future is too uncertain to plan for.

\begin{tabular}{|l|l|l|l|l|l|l|}
\hline 1 & 2 & 3 & 4 & 5 & 6 & 7 \\
\hline
\end{tabular}

31. The future seems very vague and uncertain to me.

\begin{tabular}{|l|l|l|l|l|l|l|}
\hline 1 & 2 & 3 & 4 & 5 & 6 & 7 \\
\hline
\end{tabular}

32. I pretty much live on a day to day basis.

\begin{tabular}{|l|l|l|l|l|l|l|}
\hline 1 & 2 & 3 & 4 & 5 & 6 & 7 \\
\hline
\end{tabular}

33. I enjoy living for the moment and not knowing what tomorrow will bring.

\begin{tabular}{|l|l|l|l|l|l|l|}
\hline 1 & 2 & 3 & 4 & 5 & 6 & 7 \\
\hline
\end{tabular}

34. I am willing to risk financial losses.

\begin{tabular}{|l|l|l|l|l|l|l|}
\hline 1 & 2 & 3 & 4 & 5 & 6 & 7 \\
\hline
\end{tabular}

35. I prefer investments that have higher returns even though they are risker

\begin{tabular}{|l|l|l|l|l|l|l|}
\hline 1 & 2 & 3 & 4 & 5 & 6 & 7 \\
\hline
\end{tabular}

36. The overall growth potential of a retirement investment is more important than the level of risk of the investment. 


\begin{tabular}{|l|l|l|l|l|l|l|}
\hline 1 & 2 & 3 & 4 & 5 & 6 & 7 \\
\hline
\end{tabular}

37. I am very willing to make risky investments to ensure financial stability in retirement.

\begin{tabular}{|l|l|l|l|l|l|l|}
\hline 1 & 2 & 3 & 4 & 5 & 6 & 7 \\
\hline
\end{tabular}

38. As a rule I would never choose the safest investment when planning for retirement

\begin{tabular}{|l|l|l|l|l|l|l|}
\hline 1 & 2 & 3 & 4 & 5 & 6 & 7 \\
\hline
\end{tabular}

